University of Louisville

ThinkIR: The University of Louisville's Institutional Repository

Electronic Theses and Dissertations

$12-2005$

\title{
Comorbidity of Attention Deficit Hyperactivity Disorder and gender with internalizing and externalizing symptoms.
}

Anna Louise Peterson

University of Louisville

Follow this and additional works at: https://ir.library.louisville.edu/etd

\section{Recommended Citation}

Peterson, Anna Louise, "Comorbidity of Attention Deficit Hyperactivity Disorder and gender with internalizing and externalizing symptoms." (2005). Electronic Theses and Dissertations. Paper 1121. https://doi.org/10.18297/etd/1121

This Doctoral Dissertation is brought to you for free and open access by ThinkIR: The University of Louisville's Institutional Repository. It has been accepted for inclusion in Electronic Theses and Dissertations by an authorized administrator of ThinkIR: The University of Louisville's Institutional Repository. This title appears here courtesy of the author, who has retained all other copyrights. For more information, please contact thinkir@louisville.edu. 
COMORBIDITY OF ATTENTION DEFICIT HYPERACTIVITY DISORDER

AND GENDER WITH INTERNALIZING AND EXTERNALIZING SYMPTOMS

\author{
By \\ Anna Louise Peterson \\ B.A., University of Louisville, 1990 \\ M.Ed., University of Louisville, 1992 \\ A Dissertation \\ Submitted to the Faculty of the \\ Graduate School of the University of Louisville \\ In Partial Fulfillment of the Requirements \\ For the Degree of
}

\author{
Doctor of Philosophy \\ Department of Educational and Counseling Psychology \\ University of Louisville \\ Louisville, Kentucky
}

December 2005 
COMORBIDITY OF ATTENTION DEFICIT HYPERACTIVITY DISORDER

AND GENDER WITH INTERNALIZING AND EXTERNALIZING SYMPTOMS

By

Anna Louise Peterson

B.A., University of Louisville, 1990

M.Ed., University of Louisville, 1992

A Dissertation Approved on

December 1, 2005

by the following Dissertation Committee:

Dissertation Director 


\title{
DEDICATION
}

This dissertation is dedicated to the memory of

\author{
Robert L. Montgomery \\ and
}

Joyce A. Smith

two of the most influential people in my life 
ABSTRACT

COMORBIDITY OF ATTENTION DEFICIT HYPERACTIVITY DISORDER AND GENDER WITH INTERNALIZING AND EXTERNALIZING SYMPTOMS

\author{
Anna L. Peterson
}

December 1, 2005

This study examined the association between internalizing and externalizing symptoms, gender, and the diagnosis of Attention-Deficit/Hyperactivity Disorder. Participants included 104 males and 74 females, aged 6 to 16 from a diagnostic clinic. Parents and teachers completed the Attention Deficit Disorders Evaluation Scale, Second Edition (ADDES-2) to determine whether they met the criteria for AttentionDeficit/Hyperactivity Disorder and the Behavior Assessment System for Children (BASC) in order to measure internalizing and externalizing symptoms.

Regression analyses indicated partial support for association between inattention and internalizing symptoms, with higher ratings of inattention found for both anxiety and depression as rated by parents and higher ratings of inattention for depression as rated by school. Although not predicted, a positive association was also found between home and school rated hyperactivity and depression. As hypothesized, higher ratings of 
hyperactivity in the home environment were predictive of all three externalizing behaviors as rated by parents, including measures of aggression, hyperactivity, and conduct problems, but only teacher ratings of hyperactivity. In addition, hyperactivity in the school environment was predictive of all teacher ratings of aggression, hyperactivity, and conduct problems and only aggression as rated by parents. All parent and teacher ratings of externalizing behaviors showed significantly higher scores for males. On measures of internalizing symptoms, no significant relationships were found with gender and parent and teacher ratings of inattention and hyperactivity, other than in the area of teacher ratings of somatization. These results have important implications in terms of identification, treatment, and long-term outcomes of affected individuals. 


\section{ACKNOWLEDGEMENTS}

I would sincerely like to acknowledge all of the special people in my life who helped make the achievement of this goal possible. I am especially grateful for the mentorship of my dissertation chair, Kathleen Kirby, who provided guidance, support, and leadership throughout this project. I have long admired her commitment, compassion, dedication, leadership ability, and expertise. This project would have never been completed without her assistance. In addition, I would like to acknowledge the support and input I received from my dissertation committee members: Joe Petrosko, whom I hold in the highest regard, both as a person and as a statistician; Tom Simmons, who offered exceptional wisdom, skill, and guidance, particularly during the challenging stages of this project; Daya Sandhu, who offered a calming and insightful presence throughout; and Patrick Hardesty, who diligently offered suggestions and provided input. Special thanks also go to Samuel Stringfield, whose leadership, professionalism, and support was greatly appreciated in the final stage of this process.

I am also grateful for the unending and unconditional support of my closest family and friends. Mostly, I would like to acknowledge my husband, Bob. I can't begin to imagine how I would have ever made it through the many challenges of these last five years without him by my side. Thank you so much for providing me the strength, patience, love, and encouragement to help me realize this goal. My children, Kaitlin, 
Kyle, and Janie, were also a constant source of influence and inspiration throughout this project. I truly appreciate all of their sacrifices and support throughout my education. I also owe a debt of gratitude to my sisters, Janie Klausing and Carolyn Wallace. They have provided never-ending support, encouragement, motivation, and strength throughout my education, especially during the difficult times. Finally, I would like to thank the many other people who have provided unending influence, support, motivation, and guidance: Jeffrey Hicks, Nicole and Chad Clark, Debbie and Mark Barnes, Steve Klausing, Kenny and Elizabeth Montgomery, Jerry and Christine Montgomery, Janice Montgomery, Robert Montgomery, Debbie Lockerby, Billy Wallace, Kim Smith, Tamme Roberts, Julie Hideg, Russell Galbraith, Chris Peterson, Mindy and Kevin Peterson, Debbie and Eddie Peterson, Alicia Wheatley, Barbara Kinney, Amy Greenamyer, Jessica Bryant, Rose Wade, Melissa Gaddie, Amy and Mike Burch, Lisa and Dan Iceman, Beverly Moore, and Scott Berry. I am truly grateful for all of your continued contributions and emotional support. 


\section{TABLE OF CONTENTS}

PAGE

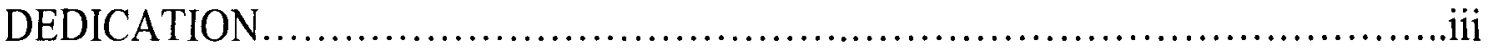

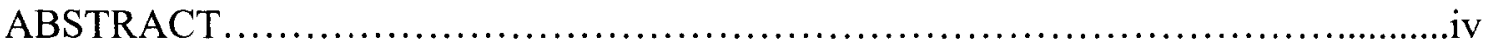

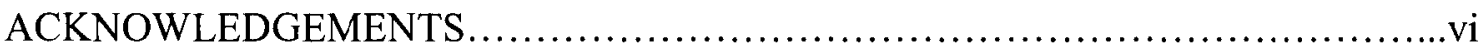

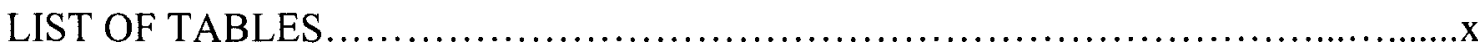

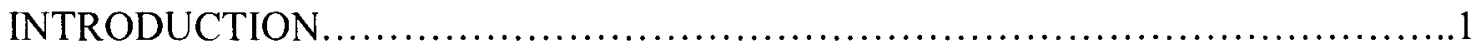

Statement of the Problem................................................2

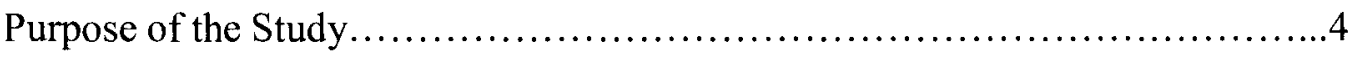

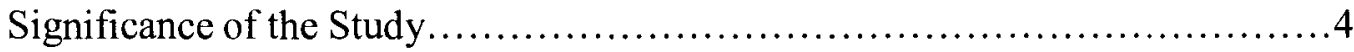

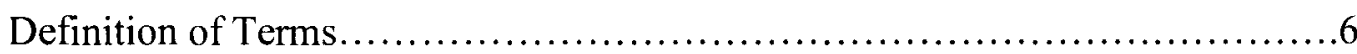

Research Questions..................................................

Research Hypotheses.................................................

REVIEW OF THE LITERATURE........................................ 9

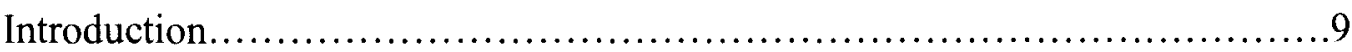

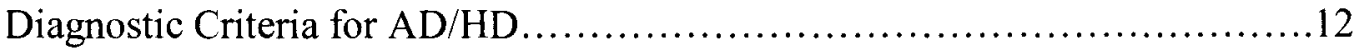

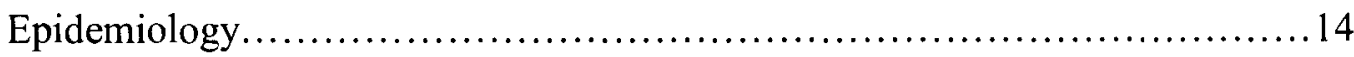

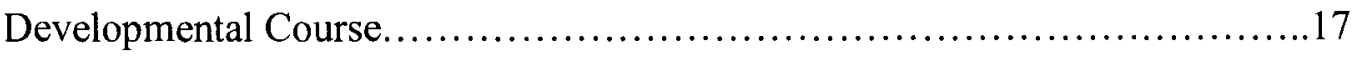

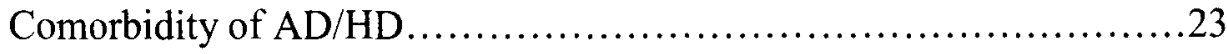

Referral Bias.................................................... 45

Etiology................................................... 52 


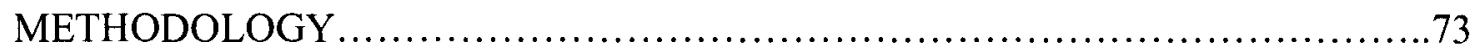

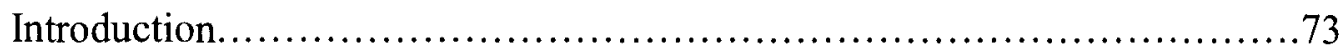

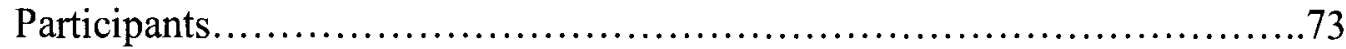

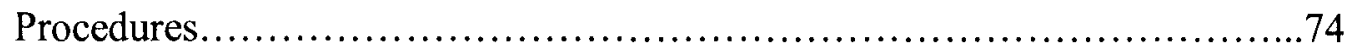

Instrumentation........................................................... 74

Data Analysis....................................................... 79

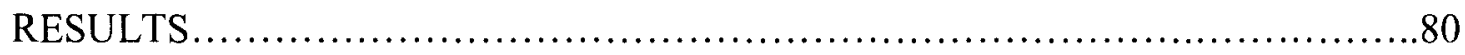

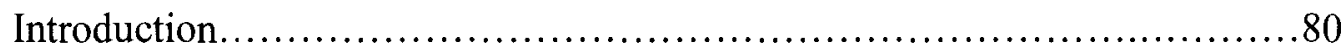

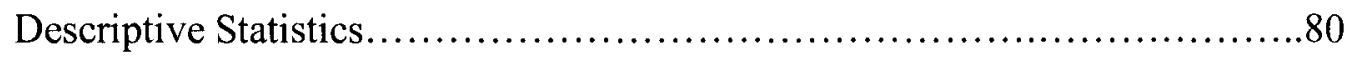

Regression Analysis.................................................95

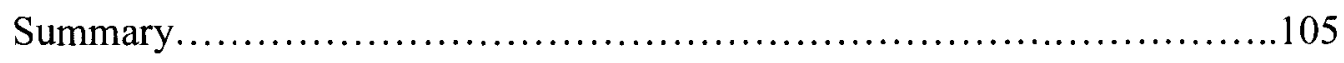

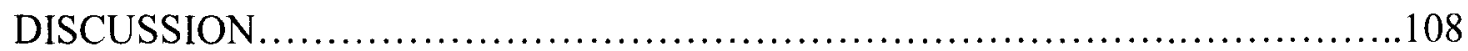

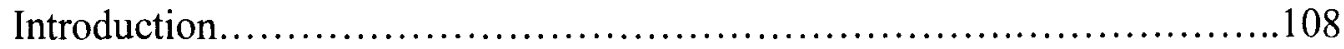

Limitations........................................................... 113

Future Recommendations........................................... 114

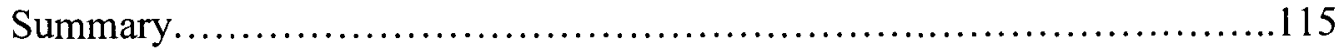

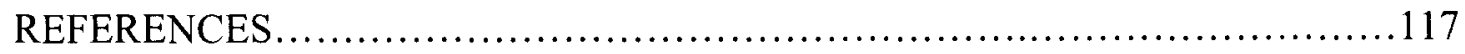

APPENDIX A: Human Studies Approval...............................................142

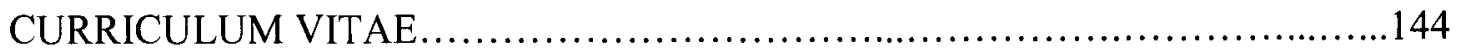




\section{LIST OF TABLES}

TABLE

1. Gender and Ethnicity of Sample Subjects.......................... 80

2. Means and Standard Deviation for ADDES-2 and BASC Scales........81

3. Correlations Among Parent Anxiety Ratings and Five

Predictor Variables.................................................. 83

4. Correlations Among Teacher Anxiety Ratings and Five

Predictor Variables.

5. Correlations Among Parent Depression Ratings and Five

Predictor Variables

6. Correlations Among Teacher Depression Ratings and Five

Predictor Variables............................................ 86

7. Correlations Among Parent Somatization Ratings and Five

Predictor Variables

8. Correlations Among Teacher Somatization Ratings and Five

Predictor Variables................................................. 88

9. Correlations Among Parent Aggression Ratings and Five

Predictor Variables

10. Correlations Among Teacher Aggression Ratings and Five

Predictor Variables 
11. Correlations Among Parent Hyperactivity Ratings and Five

Predictor Variables.

12. Correlations Among Teacher Hyperactivity Ratings and Five

Predictor Variables

13. Correlations Among Parent Conduct Problems Ratings and Five

Predictor Variables

14. Correlations Among Teacher Conduct Problems Ratings and Five

Predictor Variables

15. Regression Analysis for ADDES-2 and Gender Predicting Parent

Anxiety Ratings and Teacher Anxiety Ratings

16. Regression Analysis for ADDES-2 and Gender Predicting Parent

Depression Ratings and Teacher Depression Ratings

17. Regression Analysis for ADDES-2 and Gender Predicting Parent

Somatization Ratings and Teacher Somatization Ratings 98

18. Regression Analysis for ADDES-2 and Gender Predicting Parent Aggression Ratings and Teacher Aggression Ratings 100

19. Regression Analysis for ADDES-2 and Gender Predicting Parent

Hyperactivity Ratings and Teacher Hyperactivity Ratings.

20. Regression Analysis for ADDES-2 and Gender Predicting Parent

Conduct Problems Ratings and Teacher Conduct Problems

Ratings 103

21. Overall Summary of Regression Results 106 


\section{CHAPTER 1}

\section{INTRODUCTION}

\section{$\underline{\text { Context }}$}

Attention-Deficit/Hyperactivity Disorder (AD/HD) is one of the most prevalent psychiatric disorders of childhood and adolescence, estimated to affect $3-5 \%$ of schoolage children (NIH, 2000). According to Brown (2000), AD/HD is one of the most frequent reasons for referral in both school and community agencies, with common sources of referrals for $\mathrm{AD} / \mathrm{HD}$ youth including family physicians, pediatricians, pediatric neurologists, and child psychiatrists (Biederman, Newcorn, \& Sprich, 1991). Generally, $\mathrm{AD} / \mathrm{HD}$ is an unremitting disorder, with up to $50 \%$ or more of $\mathrm{AD} / \mathrm{HD}$ children reporting symptoms that persist into adulthood (Mannuzza, Klein, Bessler, Malloy, \& Lapadula, 1993; Mannuzza, Klein, Bessler, Malloy, \& Lapadula, 1998).

The core behavioral symptoms of $\mathrm{AD} / \mathrm{HD}$ are inattention, hyperactivity, and impulsivity (American Psychiatric Association, 1994). Identification and treatment of $\mathrm{AD} / \mathrm{HD}$ is generally initiated in childhood and is characterized by an onset of some symptoms by age 7 (APA, 1994). Manifestations of the disorder are varied in terms of presentation, developmental course, and comorbidity, with typical characteristics including academic underachievement, special education services, learning disabilities, and impaired neuropsychological performance (Faraone and Biederman, 1994; Nolan, Volpe, Gadow, \& Sprafkin, 1999). 


\section{Statement of the Problem}

Studies conclusively report that $\mathrm{AD} / \mathrm{HD}$ is a chronic disorder that has a negative impact on virtually every aspect of daily social, emotional, academic, and work functioning (Barkley, 1998; NIH, 2000). As a result, $\mathrm{AD} / \mathrm{HD}$ patients are increasingly utilizing available mental health services, social services, and special education services (Szatmari, Offord, \& Boyle, 1989). Recent data indicate that AD/HD children make up $30 \%$ to $50 \%$ of referrals to child mental health practitioners (Barkley, 1998; MTA, 1999). Based on the examination of medical and pharmaceutical data for more than 100,000 beneficiaries of a large Fortune 100 company, AD/HD-related difficulties also result in a significant burden in terms of medical costs and work loss for patients and family members (Swenson, et al., 2003). According to the National Institutes of Health, these individuals utilize a disproportionate amount of resources, including health care, criminal justice, schools, and social service agencies. For example, AD/HD-related national public school expenditures exceeded an estimated three billion dollars in 1995 (NIH, 2000).

When compared with peers without the disorder, individuals with $\mathrm{AD} / \mathrm{HD}$ are at greater risk for a variety of comorbid psychiatric disorders, including oppositional defiant disorder, conduct disorder, depression, and anxiety disorder. In addition, affected persons are also at greater risks of physical injury, use of tobacco, and substance abuse (Barkley, 1998). Unfortunately, $\mathrm{AD} / \mathrm{HD}$ research literature has only recently begun to address comorbidity issues, particularly with respect to gender differences (Costin, Vance, Barnett, O'Shea, \& Luk, 2002). Without recognition of the impact of comorbid symptomatology and $\mathrm{AD} / \mathrm{HD}$, there are repercussions in terms of high morbidity, greater 
rates of disability, and a poor long-term prognosis for affected individuals (Faraone and Biederman, 1994).

Historically, a diagnosis of AD/HD occurs far more often in males than females, even though the female to male ratio is considered to be closer to equal among the inattentive subtype of $\mathrm{AD} / \mathrm{HD}$ (Lahey, et al., 1994). One possible explanation for this trend is that $\mathrm{AD} / \mathrm{HD}$ does indeed occur less often in girls. Another explanation is that the behaviors used to define the criteria of $\mathrm{AD} / \mathrm{HD}$ in the DSM-IV were identified from a sample composed primarily of males (Lahey, et al., 1994), resulting in a greater likelihood of an $\mathrm{AD} / \mathrm{HD}$ diagnosis in males. Alternatively, it has also been suggested that this disorder manifests differently in males and females, and more males are referred for diagnosis and treatment of the disorder due to a bias in referral criteria.

The current literature provides incomplete and inconsistent information regarding gender-specific manifestations of AD/HD. Generally, those studies that do address gender differences are epidemiological in nature (Barkley, 1989; Berry, Shaywitz, \& Shaywitz, 1985; Faraone, Biederman, Keenan, \& Tsuang, 1991; James \& Taylor, 1990; McGee, Williams, \& Silva, 1987). Moreover, most of the prior AD/HD research literature either excludes girls altogether or doesn't include enough girls to warrant separate data analyses.

The limited information on females with $\mathrm{AD} / \mathrm{HD}$, gender differences, and comorbidity issues has resulted in problems with the identification and treatment of affected individuals, particularly with females. Potentially serious public health implications include long-term social, academic, and emotional difficulties (Arnold, 1996; McGee \& Feehan, 1991; Rucklidge \& Tannock, 2001) and a detrimental impact on 
society in terms of the financial costs, familial stress, academic/vocational problems, and self esteem.

\section{Purpose of the Study}

The present investigation is an examination of the association of $\mathrm{AD} / \mathrm{HD}$ and gender with internalizing and externalizing symptoms. In recent years, gender differences in $\mathrm{AD} / \mathrm{HD}$ have begun to be investigated more thoroughly, but with inconsistent findings. Some researchers have concluded that there are differences between boys and girls, whereas others have not found significant differences. There have also been conflicting findings in terms of concomitant difficulties that commonly occur with males and females with $\mathrm{AD} / \mathrm{HD}$. The purpose of this study was to examine the relationship between $\mathrm{AD} / \mathrm{HD}$ and gender with rates of comorbid internalizing and externalizing behaviors according to ratings by both parents and teachers.

\section{Significance of the Study}

Given the relative frequency of $\mathrm{AD} / \mathrm{HD}$, the evidence of long-term disability and the number of families with affected children that seek treatment in various settings, it is apparent that $\mathrm{AD} / \mathrm{HD}$ is of considerable public health importance. If a relationship is found between $\mathrm{AD} / \mathrm{HD}$ and comorbid internalizing and externalizing symptomatology, this will have important clinical implications for both identification and treatment. According to Gershon (2002, p. 143), "identification of gender-related differences in the antecedents and manifestations of attentional deficits has both theoretical and clinical significance." 
The results of the current study will lead to a better understanding of $\mathrm{AD} / \mathrm{HD}$ symptomatology and contribute to the literature regarding those children who are overlooked and undertreated, particularly females. It has been purported that because boys demonstrate a higher level of disruptive behaviors, they are more likely to be referred for treatment. If females do indeed have a different presentation in terms of internalizing and externalizing behaviors, this could provide a possible explanation for the incidence of lower number of referrals. Thus, additional research such as this could potentially alleviate and/or eliminate some of the unnecessary burdens to affected individuals, their families, and society.

It remains to be determined whether previous research findings on children diagnosed with $\mathrm{AD} / \mathrm{HD}$ are related to $\mathrm{AD} / \mathrm{HD}$ itself, the existence of comorbid disorders, or the combination of both. Differences in comorbidity and levels of severity could indicate the need to implement early and aggressive $\mathrm{AD} / \mathrm{HD}$ treatment so that risks and consequences associated with comorbid psychopathology could be moderated (Connor, et al., 2003). Subsequently, this research may have important clinical implications by providing evidence for the existence of distinct syndromes as has been suggested by some researchers (Jensen, et al., 2001). According to these researchers, it may be found that properties attributed to $\mathrm{AD} / \mathrm{HD}$ may in fact be due to one or more comorbid conditions, such as internalizing or externalizing problems, rather than to the current diagnostic subtypes of $\mathrm{AD} / \mathrm{HD}$ alone. Hence, the examination of coexisting patterns of $\mathrm{AD} / \mathrm{HD}$ could lead to the identification of meaningful subtypes of $\mathrm{AD} / \mathrm{HD}$ that have relevance to etiology, treatment, and prognosis. 


\section{Definition of Terms}

Several terms are used throughout this research that must be defined in order for the reader to understand their meanings in the context of this study. Definitions of these terms are consistent with those reported in the manual for the Behavior Assessment System for Children (BASC; Reynolds \& Kamphaus, 1992).

"Aggression" refers to the tendency to act in a physically or verbally hostile manner that is threatening to others.

"Anxiety" refers to feelings of nervousness, worry, and fear.

"Attention Problems" refer to the tendency to be easily distracted and unable to concentrate for an extended period of time.

"Conduct Problems" refer to the tendency to engage in rule-breaking behaviors.

"Depression" refers to feelings of unhappiness, sadness, and stress that may result in an inability to carry out everyday activities.

"Externalizing behaviors" refer to those behaviors that are manifested by external or "acting out" behaviors. In this study, measures of externalizing symptoms included ratings of aggression, hyperactivity, and conduct problems.

"Hyperactivity" refers to the tendency to be overly active, rush through work or activities, and act without thinking.

"Internalizing behaviors" refer to those behaviors that are manifested by internal reactions and states. In this study, measures of internalizing symptoms included ratings of anxiety, depression, and somatization.

"Somatization" refers to the tendency to be overly sensitive or complain about relatively minor physical problems or discomforts. 


\section{$\underline{\text { Research Questions }}$}

The present study was designed to explore the following research questions:

1: Are gender and Attention Deficit Disorder Evaluation Scale (ADDES-2) home and school ratings of inattention and hyperactivity significantly associated with parent ratings of internalizing disorders, as measured by the Anxiety, Depression, and Somatization subscales on the Behavior Assessment System for Children (BASC)?

2: Are gender and ADDES-2 home and school ratings of inattention and hyperactivity significantly associated with teacher ratings of internalizing disorders, as measured by the Anxiety, Depression, and Somatization subscales on the BASC?

3: Are gender and ADDES-2 home and school ratings of inattention and hyperactivity significantly associated with parent ratings of externalizing disorders, as measured by the Aggression, Hyperactivity, and Conduct Problems subscales on the BASC?

4: Are gender and ADDES-2 home and school ratings of inattention and hyperactivity significantly associated with teacher ratings of externalizing disorders, as measured by the Aggression, Hyperactivity, and Conduct Problems subscales on the BASC?

\section{Research Hypotheses}

Based on the above research questions, the following relationships were hypothesized: 
Hypothesis 1: ADDES-2 ratings of inattention in the home environment will be a significant predictor of ratings by parents and teachers of internalizing problems, as measured by the Anxiety, Depression, and Somatization subscales on the Behavior Assessment System for Children (BASC).

Hypothesis 2: ADDES-2 ratings of inattention in the school environment will be a significant predictor of ratings by parents and teachers of internalizing problems, as measured by the Anxiety, Depression, and Somatization subscales on the Behavior Assessment System for Children (BASC).

Hypothesis 3: ADDES-2 ratings of hyperactivity in the home environment will be a significant predictor of ratings by parents and teachers of externalizing problems, as measured by the Aggression, Hyperactivity, and Conduct Problems subscales on the BASC.

Hypothesis 4: ADDES-2 ratings of hyperactivity in the school environment will be a significant predictor of ratings by parents and teachers of externalizing problems, as measured by the Aggression, Hyperactivity, and Conduct Problems subscales on the BASC.

Hypothesis 5: Male gender will be a significant predictor variable of externalizing behaviors, as measured by the Aggression, Hyperactivity, and Conduct Problems subscales on the BASC.

Hypothesis 6: Female gender will be a significant predictor variable of internalizing behaviors, as measured by the Anxiety, Depression, and Somatization subscales on the BASC. 


\section{CHAPTER 2}

\section{REVIEW OF LITERATURE}

\section{Introduction}

The coexistence of internalizing and externalizing conditions differentially affects the functioning of children and adolescents with AD/HD (Jensen, et al., 1997; Melnick and Hinshaw, 2000). Cantwell (1996) contends that comorbidity strongly affects diagnosis due to varying backgrounds, etiologies, and treatment response of these persons. Differences in referral rates could be related to varying symptom presentations of the different subtypes of AD/HD (Gaub \& Carlson, 1997a; Milich, Balentine, \& Lynam, 2001), with AD/HD boys and girls who meet criteria for the inattentive subtype being more difficult to recognize. Many children with inattentive subtype of $\mathrm{AD} / \mathrm{HD}$ often do not display major behavior problems, which results in these children either being not treated at all or treated by primary care physicians rather than by mental health professionals. In addition to the primary $\mathrm{AD} / \mathrm{HD}$ symptoms of inattention and hyperactivity/impulsivity, there are often co-occurring behavioral and/or emotional problems and disorders that should be addressed. Overall, children with AD/HD and a comorbid condition are likely to have more severe symptoms and social dysfunction (Kuhne, et al., 1997). Comorbidity increases the severity of the disorder and functional impairment increases with each additional diagnosis (Abikoff \& Klein, 1992; Biederman, et al., 1996; Kovacs \& Devlin, 1998). Kazdin (1995) argues that progress in treatment 
may be less favorable where comorbid conditions exist. Correspondingly, in a sample of 300 clinically referred subjects with a male to female ratio of 5:1, Connor, et al. (2003) showed that higher levels of comorbid internalizing and externalizing problems are associated with increased severity of $\mathrm{AD} / \mathrm{HD}$ symptomatology.

Numerous studies have found no gender differences in the frequency, presentation, or severity of AD/HD symptoms (Berry, et al., 1985; Brown, Madan-Swain, \& Baldwin, 1991; Horn, Wagner, \& Ialongo, 1989; James \& Taylor, 1990; Kashani, Chapel, Ellis, \& Shekim, 1979; Silverthorn, Frick, Kuper, \& Ott, 1996). For example, Reid, et al. (2000) evaluated a sample of 3322 male and female students aged 5 to 18 and found no significant differences in $\mathrm{AD} / \mathrm{HD}$ symptomatology among males and females. Befera and Barkley (1985) compared normal and hyperactive boys and girls on motherchild interactions, family psychiatric history, and scores on a personality measure and found no differences between boys and girls. In a later study, Breen and Barkley (1988) also showed that boys and girls with $\mathrm{AD} / \mathrm{HD}$ are similarly impaired and create comparable amounts of stress on their caretakers.

Based on parent report, Breen and Altepeter (1990) similarly concluded that few gender differences exist between boys and girls with $\mathrm{AD} / \mathrm{HD}(\mathrm{F}=4.38, \mathrm{p}<.01)$. Gaub and Carlson (1997b) completed a meta-analysis and critical review of gender differences in AD/HD. Their analysis of 18 studies conducted between 1979 and 1992 suggested only minimal gender differences. Moreover, upon further investigation, many of the differences they did obtain were attributed to the referral source.

According to Reid, et al. (2000), some studies that have used behavior ratings (Breen, 1989; Breen \& Altepeter, 1990; Horn, et al., 1989; James \& Taylor, 1990; 
Silverthorn, et al., 1996) have failed to find statistically significant gender-related differences primarily because sample sizes in previous studies were small, ranging from 39 (Breen, 1989) to 80 (Silverthorn, et al., 1996). As a result, these studies may have lacked the statistical power needed to find gender differences. Likewise, many of these research investigations studied only a small number of females with $\mathrm{AD} / \mathrm{HD}$, which seriously limited the generalizability and robustness of their findings. Another issue with prior research is the lack of randomization in the selection process of participants, with most studies choosing subjects drawn from clinically referred groups. Similarly, many of the previous studies did not use normal controls to evaluate variables.

The following review includes an examination of these conclusions drawn from past research regarding associations between $\mathrm{AD} / \mathrm{HD}$ and gender with internalizing and externalizing symptomatology. Differences in the presentation of the disorder will be explored and an extensive review of the comorbidity literature will be conducted. The conflicting findings summarized make it difficult to draw conclusions regarding differences between boys and girls with $\mathrm{AD} / \mathrm{HD}$, but will provide insight into the need for the current investigation.

Of notable importance, the current review includes a description of nosological changes in the naming and diagnosis of the disorder along with information regarding epidemiology and etiological explanations for the differing rates of the disorder in males and females. In addition, the most common treatment options and assessment guidelines are discussed. 


\section{Diagnostic Criteria for $\mathrm{AD} / \mathrm{HD}$}

The nosology of $\mathrm{AD} / \mathrm{HD}$ has undergone a number of changes, with several modifications regarding the terminology and diagnostic criteria for $\mathrm{AD} / \mathrm{HD}$ being presented in the last few decades. Over the years, the terminology used to describe this disorder was changed from brain damage to minimal brain dysfunction (MBD) to hyperactivity. The disorder first became known in the Diagnostic and Statistical Manual of Mental Disorders, $2^{\text {nd }}$ edition (American Psychiatric Association, 1967; DSM-II) as Hyperkinetic Reaction of Childhood.

The DSM-III (American Psychiatric Association, 1980) changed the name to Attention Deficit Disorder (ADD) and added two subtypes: ADD with hyperactivity and ADD without hyperactivity. Consequently, new diagnostic criteria for the disorder were also presented.

Published in 1987, the DSM-III-R (American Psychiatric Association, 1987) replaced these categories with a single, unidimensional category labeled Attention Deficit-Hyperactivity Disorder (AD/HD). In so doing, the DSM-III-R no longer recognized Attention-Deficit Disorder without Hyperactivity, which was now referred to as Undifferentiated Attention-Deficit Disorder.

In the current psychiatric diagnostic system, DSM-IV, ADD was changed to AD/HD (Attention Deficit-Hyperactivity Disorder) and three different subtypes were identified. This current classification system recognizes three empirically derived subtypes of $\mathrm{AD} / \mathrm{HD}$ (Lahey, et al., 1994). When only attention problems are present, the diagnosis is Predominantly Inattentive Type. In order to meet criteria for $\mathrm{AD} / \mathrm{HD}$ Predominantly Inattentive Type, a person must have 6 of the 9 inattention behaviors 
listed. $\mathrm{AD} / \mathrm{HD}$ Predominantly Hyperactive-Impulsive Type is the subtype used to describe a person who meets 6 of 9 hyperactive-impulsive behaviors. When both inattentive and hyperactive-impulsive symptoms are present and the person meets at least 6 of 9 behaviors in both the inattention and hyperactive-impulsive criteria list, $\mathrm{AD} / \mathrm{HD}$ Combined Type is used.

In addition to the three subtypes, criteria were added requiring the presence of impairment in two or more settings (e.g. home, school, and neighborhood), evidence of symptomatology before the age of 7 , clinically significant impairment in social, academic, or occupational functioning, and the inability to account for symptoms by any other disorder.

Overall, research has been favorable regarding the predominately inattentive types being a separate clinical entity, although there are unresolved issues, such as referral age, comorbid disabilities and differences in prevalence among males and females (Morgan, et al., 1996). For the most part, however, Predominantly Hyperactive-Impulsive and Combined subtypes have been more thoroughly researched both in terms of their core symptoms and associated characteristics, and in terms of diagnostic and treatment issues (Barkley, 1998).

Additional evidence supporting the current distinction between three subtypes of $\mathrm{AD} / \mathrm{HD}$ is mounting (Gaub \& Carlson, 1997a; Gomez, Harvey, Quick, Scharer, \& Harris, 1999; Lahey, et al., 1994; Morgan, et al., 1996; Sherman, Iacono, \& McGue, 1997;

Neuman, et al., 1999; Pillow, Pelham, Hoza, Molina, \& Stultz, 1998). For example, Hudziak, et al. (1998) performed latent class and factor analysis on a population of 1549 pairs of adolescent female twins and determined that the DSM-IV subtypes of inattention, 
hyperactivity/impulsivity, and combined are continuous and separate dimensions that approximately correspond to the three DSM-IV subtypes. Other evidence supporting the current use of diagnostic subtypes is the fact that there are significant differences between them in terms of such variables as family history of psychopathology, academic achievement, comorbid disorders, social functioning, and neuropsychological deficits (Milich, Balentine, \& Lynam, 2001). This is particularly apparent with the Predominantly Hyperactive-Impulsive Type and the Predominantly Inattentive Type.

Some researchers contend that the combination of $\mathrm{AD} / \mathrm{HD}$ and antisocial disorders indicates a distinct subtype of $\mathrm{AD} / \mathrm{HD}$ in addition to the current subtypes (Biederman, Newcorn, et al., 1991; Faraone, et al., 1991; Faraone, Biederman, Chen, et al., 1994). Other research contends that the different subtypes may actually represent distinct disorders due to differences in symptom presentation and comorbid difficulties (Barkley, DuPaul, \& McMurray, 1990). According to Jensen (2003), "we must carefully examine for possibly unique diagnostic groups defined by comorbidity, and further refine our categories as evidence proceeds. Even when cases appear similar in terms of current behavioral phenomena, we must remember that it is likely that any single form of psychopathology (whether "pure" or comorbid) may arise through quite different routes (p. 299)."

\section{Epidemiology}

According to the DSM-IV-TR, $3.7 \%$ of children have AD/HD. Lifetime prevalence rates of $4.0 \%$ inattention, $2.2 \%$ hyperactive/impulsive subtype, and $3.7 \%$ combined were found in a sample of 1629 pairs of adolescent female twins (Hudziak, et 
al., 1998). According to many researchers, $\mathrm{AD} / \mathrm{HD}$ is more prevalent in boys than in girls (Arcia and Conners, 1998; Gomez, et al., 1999; Nolan, et al., 1999). Overall, prevalence rates range from $2 \%$ to $10 \%$ of school-age children, with rates that are two to nine times greater among boys than girls (American Academy of Child and Adolescent Psychiatry, 1997, 2002; American Academy of Pediatrics, 2000; Barkley, 1998; Scahill \& SchwabStone, 2000).

Even though there are documented differences in prevalence, between 1991-1992 and 1997-1998, the diagnosis of AD/HD among school-aged girls in the United States tripled, whereas the proportion of boys doubled (Robison, Skaer, Sclar, \& Galin, 2002). Some research contends that gender differences are generally less obvious for the inattentive type of AD/HD (American Psychiatric Association, 2000; Lahey, et al., 1994), whereas some have found higher rates of inattention in males (Hartung, et al., 2002) and others have found a greater prevalence of the inattentive subtype with females (Biederman, et al., 2002; Weiss, Worling, \& Wasdell, 2003). In addition, in those with adult $\mathrm{AD} / \mathrm{HD}$, limited data suggest that the disorder is equally prevalent in men and women (Weiss \& Murray, 2003).

These recorded prevalence rates for $\mathrm{AD} / \mathrm{HD}$ may vary considerably due to the changing diagnostic criteria over time and the varying diagnostic procedures. DSM-III-R or $\mathrm{DSM}-\mathrm{III} \mathrm{AD} / \mathrm{HD}$ is three to six times more prevalent in boys than girls (Faraone, et al., 1991). Barkley (1998) contends that prevalence data are inconsistent as a result of the different instruments and assessment procedures used to diagnose the disorder. The younger the child is, the more likely it is that he or she will be diagnosed as having the 
hyperactive/impulsive AD/HD versus the inattentive or combined types (Barkley, 1998; Weiss, et al., 2003).

Another explanation for the differing prevalence rates involves the use of referred samples to estimate occurrence. Clinically-based male-to-female incidence rates for children range from 2:1 to 9:1 (American Psychiatric Association, 1994; Arnold, 1996), whereas community-based ratios range from 2:1 to 4:1 (APA, 1994; Gaub and Carlson, 1997b; Lahey, et al., 1994; Szatmari, Offord, et al., 1989; Szatmari, 1992; Taylor, Heptinstall, Sonuga-Barke, \& Sandberg., 1998). Interestingly, the male to female ratio of older adolescents is 1:1 (Cohen, et al., 1993). In community-based samples, the ratio of boys to girls is also closer to $1: 1$, whereas in clinic-based samples, it is about $6: 1$ because of the disruptive and noncompliant aspects of their behavior (Barkley, 1998). Within $\mathrm{AD} / \mathrm{HD}$ subtypes, the combined type is more prevalent in clinical samples, whereas the inattentive type is more prevalent in community samples (Milich, Balentine, \& Lynam, 2001). These authors also noted that the combined group was more likely to be male.

These discrepancies between clinic and community rates of $\mathrm{AD} / \mathrm{HD}$ in boys and girls suggest that clinical settings treat far fewer $\mathrm{AD} / \mathrm{HD}$ females than males (Arnold, 1996; Gomez, et al., 1999). Subsequently, studies of community samples suggest that even though a large number of females and males should meet criteria for $\mathrm{AD} / \mathrm{HD}$, females are rarely identified in clinical studies. Thus, "girls with AD/HD may be underidentified and undertreated, which has substantial mental health and educational implications" (Biederman, et al., 1999, p. 966). As a result, girls who are underidentified are at increased risk for long-term emotional, social, and academic problems (McGee \& Feehan, 1991). 


\section{Developmental Course}

Several longitudinal studies have provided compelling evidence that $\mathrm{AD} / \mathrm{HD}$ often persists into adolescence and adulthood. Previous research has shown that childhood $\mathrm{AD} / \mathrm{HD}$ is associated with numerous negative outcomes during adolescence, resulting in impaired adult productivity and well-being (Mannuzza, et al., 1993; Mannuzza, et al., 1998). Faraone, Biederman, \& Monuteaux (2002) assessed 811 AD/HD boys and girls and 132 control subjects between the ages of 6 and 17 and demonstrated that symptom presentations of $\mathrm{AD} / \mathrm{HD}$ in children and adolescents did not differ. These findings indicated similarities in comorbidity with internalizing and externalizing disorders in addition to consistencies in level of impairment in terms of cognitive, academic, interpersonal, and family functioning. Faraone, Biederman, Spencer, et al.. (2000) estimated that $10 \%$ to $60 \%$ of young adults with $\mathrm{AD} / \mathrm{HD}$ had the disorder as children and up to $5 \%$ of adults have $\mathrm{AD} / \mathrm{HD}$ symptomatology. Overall, follow-up studies indicate that $30-50 \%$ of $\mathrm{AD} / \mathrm{HD}$ children continue to show symptoms in adulthood (Barkley, DuPaul, \& McMurray, 1990).

In a sample of 7231 children in grades 1 to 4, August, Braswell, \& Thuras (1998) evaluated the developmental course of $\mathrm{AD} / \mathrm{HD}$ symptoms. At each of three longitudinal assessment points, they found that $38 \%$ of children, for whom follow-up data were available, showed full persistence of AD/HD. An additional 31\% of the sample was defined as moderately persistent. In total, $69 \%$ of the subjects met diagnostic criteria for $\mathrm{AD} / \mathrm{HD} 3$ or 4 years after their initial diagnosis. No significant gender differences in rates of persistence were observed. However, the ratio of boys to girls in the overall sample was $4: 1$, which limits the strength of this determination. 
These rates of persistence can be compared with those obtained from clinicreferred samples. Hart, Lahey, Loeber, Applegate, \& Frick (1995) applied similar persistence criteria with prepubescent children diagnosed at baseline with $\mathrm{AD} / \mathrm{HD}$ and reported that $71 \%$ of their sample showed persistent $\mathrm{AD} / \mathrm{HD}, 21 \%$ showed moderately persistent $\mathrm{AD} / \mathrm{HD}$, while $9 \%$ no longer met criteria for $\mathrm{AD} / \mathrm{HD}$ diagnosis. This is consistent with findings that persistence rates for $\mathrm{AD} / \mathrm{HD}$ can be high in communitybased samples, with little gender difference found in rates of prevalence.

Hart, et al. (1995) demonstrated different patterns of decline for inattention and hyperactivity/impulsivity symptom groups, as defined by endorsements on structured diagnostic interviews, with only the hyperactivity set demonstrating symptom reduction that was developmental in nature. Similarly, other researchers have demonstrated that over the developmental course of this disorder, there is a progressive decline in overt physical hyperactivity symptoms with age, whereas inattentive symptoms show greater persistence (Nolan, et al., 1999; Hart, et al., 1995).

Some studies report that early age of onset is associated with more severe symptomatology and psychopathology (Rucklidge \& Tannock, 2001). Hart, et al. (1995) observed that subjects who continue to meet diagnostic criteria for $\mathrm{AD} / \mathrm{HD}$ over time were those who had been younger, more disruptive (hyperactive/impulsivity symptoms), and more likely to have a comorbid conduct disorder at the point of initial diagnosis. Generally, the younger the child, the more likely they will be diagnosed as predominantly hyperactive/impulsive (American Psychiatric Association, 2000; Barkley, 1998), even though some researchers have shown that most children that show symptoms of hyperactivity/impulsivity also exhibit attention problems as defined by DSM-IV criteria 
(Nolan, et al., 1999). Factors such as comorbidity for other disorders and severity at point of initial diagnosis were associated with persistence of the AD/HD diagnosis (August, et al., 1998).

In a longitudinal study of 142 adolescents with childhood $\mathrm{AD} / \mathrm{HD}$ compared with 100 adolescents without $\mathrm{AD} / \mathrm{HD}$, it was concluded that compared to adolescents without a childhood diagnosis of $\mathrm{AD} / \mathrm{HD}$, those with a childhood diagnosis were at increased risk for use of alcohol, cigarettes, and other drugs (Molina \& Pelham, 2003). It was found that inattentive symptoms along with comorbid conduct disorder more strongly predicted adolescent substance use than hyperactive impulsive or childhood antisocial behavior. This finding suggests that effective treatment of inattentive symptoms, and preventing the development of serious conduct problems, may be especially important in reducing substance use problems during adolescence.

The longer $\mathrm{AD} / \mathrm{HD}$ goes untreated, the more likely it is to result in severely compromised academic performance as well as to the development of other difficulties. In an examination of the epidemiology of disruptive behavior disorders, the authors stated that disruptive behavior disorders are more common in males, with rates of ADD and $\mathrm{AD} / \mathrm{HD}$ declining with age for boys, whereas among girls, the rate tends to remain more consistent (Bauermeister, Canino, \& Bird, 1994). Accordingly, children with comorbid conduct problems are more likely to have problems with $\mathrm{AD} / \mathrm{HD}$ and other psychiatric disorders later in life (August, et al., 1998; Dalsgaard, Mortensen, Frydenberg, \& Thomsen, 2002; Fischer, Barkley, Smallfish, \& Fletcher, 2002; Hart, et al., 1995; Waschbusch, 2002). Waschbusch (2002) showed that coexisting AD/HD and conduct problems occur at a rate greater than expected by chance in boys and girls, the 
comorbid condition results in more adverse outcomes than controls than either condition alone, and provides support for the validity of the additive nature of these two disorders. In a nationally representative sample of 1238 males and 1241 females with $\mathrm{AD} / \mathrm{HD}$, researchers investigated whether attention problems and conduct problems differentially affected levels of disturbance at 3-year and 6-year follow-ups. Results indicated that those high on attention problems were more likely to have received special education services and a combination of attention problems and conduct problems was predictive of the most serious and varied difficulty over the next 6 years (more school behavior problems, mental health service use, substance abuse, and suicidal behavior). In addition, girls with attention and conduct problems were more likely to become pregnant and had higher school drop-out rates as compared to girls with attention problems alone. For boys, there were no differences in drop-out rates between the two groups (MacDonald \& Achenbach, 1999). Overall, participants with attention problems only fared better with regard to developmental outcomes than those with combined attention and conduct problems. These results indicate the importance of treating comorbid difficulties.

Similarly, additional studies report that symptom severity is associated with comorbidity (Biederman, Newcorn, et al., 1991; Gabel, Schmitz, \& Fulker, 1996). In a study of 135 adolescent and families, rates of $\mathrm{AD} / \mathrm{HD}$ and $\mathrm{CD}$ were higher among male adolescent substance abusers than female substance abusers (Latimer, Stone, Voight, Winters, and August, 2002).. The female substance abusers exhibited an elevated rate of major depression compared with substance abusing males (Latimer, et al., 2002). An early age of onset was associated with a higher rate of severe externalizing symptoms and a later age of onset was associated with a higher rate of more severe internalizing 
symptoms. The severity of inattention/hyperactive $\mathrm{AD} / \mathrm{HD}$ symptoms were strongly associated with aggressive, delinquent, and anxious/depressive psychopathology across both parent and teacher reports. These results are consistent with previous research findings that psychopathology covaries with symptom severity in children with $A D / H D$ (Biederman, Newcorn, et al., 1991; Gabel, et al., 1996; Kuhne, Schachar, \& Tannock, 1997). Moreover, it provides support to previous findings suggesting that $\mathrm{AD} / \mathrm{HD}$ symptom severity is strongly associated with the presence of both internalizing and externalizing comorbid psychopathology in referred children across both home and school environments, and an increase in the number of diagnoses a client receives is proportional to an increase in the utilization of mental health services (Bird, Gould, \& Stagheeza, 1993).

Boys seem more likely to develop externalizing problems like delinquency. Other externalizing problems, such as substance use, have been shown to increase at more similar rates for boys and girls (Lewinsohn, Hops, Roberts, Seeley, \& Andrews, 1993). Other researchers have shown a greater likelihood of substance use disorders in female AD/HD clients (Biederman, et al., 2002; Disney, Elkins, McGue, \& Iacono, 1999). Even though the prevalence of emotional and behavioral problems is consistently higher in boys than girls in early and middle childhood, this is not the case during adolescence (Hops, Sherman, \& Biglan, 1990; Petersen, Sarigiani, \& Kennedy, 1991). A number of investigators have reported significantly higher level of internalizing problems among adolescent girls than boys (Allgood-Merten, Lewinsohn, \& Hops, 1990, Ge, Conger, Lorenz, Shanahan, \& Elder, 1995; Lewinsohn, et al., 1993; Nolen-Hoeksema \& Girgus, 1994; Petersen, et al., 1991). In a study by Scaramella, Conger, \& Simons (1999), sought 
to explore differences in growth rates of internalizing and externalizing problems in a community sample of 151 boys and 168 girls. Consistent with previous research, gender differences in the mean levels of externalizing and internalizing problems emerged. Both adolescent boys and girls experienced increased level of externalizing problems from $8^{\text {th }}$ to $12^{\text {th }}$ grades. However, the growth rate of externalizing problems was significantly greater for girls than boys across this period of development, with girls externalizing behavior scores in $12^{\text {th }}$ grade being approximately four to five greater than their scores in 8th grade as compared to three to three and a half for boys. In addition, these researchers found that changes in externalizing behaviors over time significantly increased between girls and a comparable sample of boys, with overall levels of externalizing problems being greater for boys than girls.

Due to mounting evidence regarding the developmental pathways of disruptive behaviors, such as $\mathrm{AD} / \mathrm{HD}$, and the likelihood of comorbidity, early and accurate identification of $\mathrm{AD} / \mathrm{HD}$ problems may be crucial in preventing more severe disruptive behaviors later in life (Burns \& Walsh, 2002; Gresham, MacMillan, Bocian, Ward, \& Forness, 1998; Waschbusch, 2002). The development of significant behavioral problems in children with $\mathrm{AD} / \mathrm{HD}$, such as $\mathrm{CD}$ and $\mathrm{ODD}$, is often predictive of negative long-term outcomes (Burns \& Walsh, 2002; Gresham, et al., 1998). In a study of 268 adults, Biederman, et al. (1995) concluded that both $\mathrm{AD} / \mathrm{HD}$ alone and $\mathrm{AD} / \mathrm{HD}$ with cooccurring mood, anxiety, and antisocial disorders significantly increases the risk for psychoactive substance use disorders. Serious behavior problems should be assessed independently of $\mathrm{AD} / \mathrm{HD}$ symptomatology since they are associated with different longterm risks. 
Children with comorbid conditions show greater impairment than children with a single diagnosis which may increase the likelihood of referral. According to Connor, et al. (2003), the age of onset in $\mathrm{AD} / \mathrm{HD}$ is really the age of problems first being noticed by parents. Aggressive AD/HD children might get noticed by parents earlier in development than non aggressive $\mathrm{AD} / \mathrm{HD}$ children. These authors concluded that since there is such a strong relationship between $\mathrm{AD} / \mathrm{HD}$ symptom severity and comorbid psychopathology, early intervention and clinical efforts to decrease $\mathrm{AD} / \mathrm{HD}$ severity may reduce the development of additional internalizing and externalizing symptoms in referred children. "It is important for clinicians to be aware of variables that are correlated with increased comorbid psychopathology in children with $\mathrm{AD} / \mathrm{HD}$. Such variables can become targets for clinical interventions that may reduce the overall severity of disease burden in referred youths with $\mathrm{AD} / \mathrm{HD}$. In addition, the identification of variable associated with increased comorbid psychopathology in $\mathrm{AD} / \mathrm{HD}$ may stimulate further research efforts, facilitating a greater understanding of comorbidity in $\mathrm{AD} / \mathrm{HD}$ (Connor, et al., 2003, p. 199).

\section{Comorbidity of $\mathrm{AD} / \mathrm{HD}$}

\section{Introduction}

Data from both clinic and community investigations suggest that comorbidity of disorders is the norm in child and adolescent psychiatry (Barkley, 1998; Caron \& Rutter, 1991; Biederman, Newcorn, et al., 1991) and there is compelling evidence of the frequent coexistence of $\mathrm{AD} / \mathrm{HD}$ and conduct, mood, and anxiety disorders throughout the life span

(Biederman, Munir, \& Knee, 1987; Biederman, Newcorn, et al., 1991; Faraone, et al., 
1991; Jensen, Martin, \& Cantwell, 1997; Mannuzza, et al., 1993; Milberger, et al., 1995). About $44 \%$ of children with $\mathrm{AD} / \mathrm{HD}$ have one comorbid disorder, almost a third have two comorbid disorders, and approximately one tenth have three comorbid disorders (Szatmari, Offord, et al., 1989). Too often, co-occurring difficulties tend to be considered a result of primary $\mathrm{AD} / \mathrm{HD}$ symptoms and are not specifically addressed. As a result, there is a need for additional studies that explore the incidence of comorbidity, particularly with children. According to a review of research related to comorbidity of child and adolescent psychopathology, Jensen (2003) reported that the majority of studies, excluding epidemiological studies, have not included children with comorbid disorders.

Comorbid conditions among $\mathrm{AD} / \mathrm{HD}$ patients may include oppositional defiant disorder (American Academy of Child and Adolescent Psychiatry, 1997, 2002); conduct disorder (American Academy of Child and Adolescent Psychiatry, 1997, 2002; Faraone, Biederman, Jetton, \& Tsuang., 1997); anxiety disorders (American Academy of Child and Adolescent Psychiatry, 1997, 2002); depression (American Academy of Child and Adolescent Psychiatry, 1997); and mood disorders (American Academy of Child and Adolescent Psychiatry, 1997; American Academy of Pediatrics, 2000). Many studies comparing children with $\mathrm{AD} / \mathrm{HD}$ and those with $\mathrm{AD} / \mathrm{HD}$ and a comorbid disorder have found differences in functioning on a variety of laboratory, dimensional, and family measures (August, Realmuto, MacDonald, Nugent, \& Crosby, 1996; Biederman, Newcorn, et al., 1991; Eiraldi, Power, \& Nezu, 1997; Hazell, 1997; Kuhne, et al., 1997; Pliszka, 1992). Some of these differences include levels of academic problems, family problems, and impaired social relationships. 
Regarding sex-related differences in presentation of $\mathrm{AD} / \mathrm{HD}$ symptomatology and comorbidity, numerous studies have concluded that $\mathrm{AD} / \mathrm{HD}$ in girls is the same disorder as it is in boys (Biederman, et al., 1999; Castellanos, et al., 2000; Gaub and Carlson, 1997b; Sharp, et al., 1999). Biederman, et al. (1994) studied the clinical, cognitive, and functional characteristics of 128 referred adults with $\mathrm{AD} / \mathrm{HD}$ of both genders. The pattern of psychopathological, cognitive, and psychosocial findings among $\mathrm{AD} / \mathrm{HD}$ women was similar to that of AD/HD men. Biederman, et al. (1999) conducted a large and comprehensive study consisting of 140 girls diagnosed with AD/HD and 122 girls with similar ages and backgrounds as a comparison group. Fifty-nine percent had combined types, $27 \%$ had the Predominantly Inattentive type, and only 7 percent had the Predominantly Hyperactive/Impulsive type. Compared to non-AD/HD girls, girls with $\mathrm{AD} / \mathrm{HD}$ were more likely to be diagnosed with comorbid conduct disorder, oppositional defiant disorder, mood disorders, anxiety disorders, and substance use disorders. In addition, they were also more likely to have lower IQ and achievement scores, and demonstrated more impairment on measures of social, school, and family functioning. Overall, $45 \%$ of the $\mathrm{AD} / \mathrm{HD}$ girls were diagnosed with at least one other condition and the authors concluded that girls with $\mathrm{AD} / \mathrm{HD}$ exhibited the same core symptoms and high levels of comorbid disorders as do boys. Similarly, Sharp, et al. (1999), in a sample of 42 girls and 56 boys with AD/HD, combined type, found similar comorbidity with oppositional defiant disorder, conduct disorder, major depression, anxiety disorders, enuresis, and reading disorders. It is important to note the limitations of this investigation, which included the lack of control for cohort effects and the use of a self-report checklist rather than a structured interview. These finding support other studies that have not found 
sex differences in the number and severity of $\mathrm{AD} / \mathrm{HD}$ symptoms (Berry, et al., 1985; Brown, et al., 1991; Horn, et al., 1989; James \& Taylor, 1990; Kashani, et al., 1979).

The incidence of comorbidity of $\mathrm{AD} / \mathrm{HD}$ with other childhood mental disorders is found in both clinic and community samples, but, generally, children with $A D / H D$ who are clinic-referred for treatment are significantly more likely to have a comorbid condition (Woodward, Taylor, \& Dowdney, 1997). Some of the observed comorbidity patterns may be attributable to the diagnostic systems we currently use. Other patterns of comorbidity probably represent distinct subtypes of syndromes, or even phenomenologically separate disorders (Barkley, et al., 1990; Hazell, 1997). Hypotheses proposed by Biederman, et al. (1991) to account for patterns of comorbidity include: each comorbid disorder represents a distinct and separate clinical entity; the comorbid disorders share common vulnerabilities; the comorbid pattern may represent distinct subtypes within a heterogeneous disorder; one disorder may represent an early developmental expression of another; and the development of one condition may increase the risk of another. According to these authors, from the research standpoint, subgroups of patients with $\mathrm{AD} / \mathrm{HD}$ and comorbid disorders may represent more homogeneous subgroups of patients with $\mathrm{AD} / \mathrm{HD}$. From the clinical standpoint, subgroups of $\mathrm{AD} / \mathrm{HD}$ patients and those with comorbid disorders may respond differently to specific remedial approaches. From the public health standpoint, such subgroups may be at high risk for the development of severe psychopathology (Biederman, Newcorn, et al., 1991; Scahill, et al., 1999).

Subgroups of participants with $\mathrm{AD} / \mathrm{HD}$ and varying co-occurring disorders may have differing risk factors, clinical courses, and pharmacological responses and proper 
assessment may lead to more effective preventive and treatment strategies (Biederman, Newcorn, et al., 1991). Consequently, better targeted treatments that are tailored to the comorbid conditions have been recommended in order to maximize treatment outcomes (Abikoff \& Klein, 1992; Kazdin \& Weisz, 1998; August, et al., 1996).

\section{$\underline{\mathrm{AD} / \mathrm{HD} \text { and Externalizing Problems }}$}

According to DSM-IV TR (APA, 2000), there are three primary types of disruptive behavior disorders: Attention-Deficit/Hyperactivity Disorder (AD/HD), Conduct Disorder (CD), and Oppositional Defiant Disorder (ODD). Symptoms of these disruptive or externalizing disorders include aggressive, impulsive, hyperactive, defiant, disruptive, and noncompliant behaviors. In a community sample of 7231 schoolchildren screened for the presence of comorbidity patterns of disruptive behavior, externalizing behaviors were present in $25 \%$ of those with $\mathrm{AD} / \mathrm{HD}$ when combination of one coexisting diagnosis was considered. However, when two or more comorbid diagnoses were considered, rates increased to $44 \%$ with comorbid externalizing disorders (August, et al., 1996).

The primary focus of this investigation was the diagnosis of AttentionDeficit/Hyperactivity Disorder (AD/HD), which was discussed in detail in a previous section. The second of the disruptive disorders, Conduct Disorder, is defined as a persistent pattern of behavior in which the rights of others and/or age-appropriate societal norms or rules are violated (APA, 2004). Children with CD often cause property loss or damage, cause or threaten physical harm to others, exhibit deceitfulness, steal, and seriously violate rules. The third, Oppositional Defiant Disorder, is defined as a persistent pattern of negativistic, defiant, disobedient, and hostile behavior towards authority 
figures that persists for at least 6 months (APA, 2004). Children with ODD often lose their temper, argue with adults, actively defy and refuse to comply with rules and other demands, deliberately annoy others, routinely blame others for their mistakes and misbehavior, are easily annoyed by others, and are spiteful or vindictive.

In girls, the incidence of both conduct disorder and ODD found in a study by Biederman, et al. (1999) was half of previous reports in boys (Biederman, Newcorn, et al., 1991). These results are in accordance with most previous reports of both clinical and nonclinical samples of AD/HD girls (Faraone, et al., 1991; Horn, et al., 1989). It has been found that approximately half of clinic-referred children with $\mathrm{AD} / \mathrm{HD}$ also have $\mathrm{CD}$ or ODD (APA, 2000; Biederman, Newcorn, et al., 1991; Faraone, et al., 1991). Barkley (1998) specified that about one quarter of children diagnosed with $\mathrm{AD} / \mathrm{HD}$ also meet the criteria for conduct disorder and about one third meet the criteria for oppositional defiant disorder. According to an extensive review of $\mathrm{AD} / \mathrm{HD}$ research literature over a 15 -year span, rates of comorbidity with CD or ODD were shown to range from $43 \%$ to as high as 93\% (Jensen, et al., 1997).

Szatmari, Boyle, and Offord (1989) found that boys exhibiting AD/HD were 14 times more likely than boys without $\mathrm{AD} / \mathrm{HD}$ to experience $\mathrm{CD}$, whereas girls exhibiting $\mathrm{AD} / \mathrm{HD}$ were 40 times more likely than girls without $\mathrm{AD} / \mathrm{HD}$ to experience $\mathrm{CD}$. Likewise, in a study of $128 \mathrm{AD} / \mathrm{HD}$ adults of both genders, rates of $\mathrm{CD}$ were higher in $\mathrm{AD} / \mathrm{HD}$ women as compared to normal control females (Biederman, et al., 1994).

In an examination of archival data of 149 children under age 9 who were referred to an outpatient clinic, no gender differences were found for a diagnosis of $\mathrm{AD} / \mathrm{HD}$ or ODD (Lumley, McNeil, Herschell, \& Bahl, 2002). In contrast, according to the DSM-IV- 
TR, male-to-female ratios of the prevalence of $\mathrm{AD} / \mathrm{HD}$ range from 2:1 to 9:1 (APA, 2000). Additional researchers have estimated that more young males exhibit ODD symptomatology than young females (Goldstein, 1996; Kashani, et al., 1979), but rates are more equivalent after puberty (APA, 2000). Generally, with regard to CD, more males are diagnosed with the disorder throughout the life cycle (APA, 2000; Faraone, et al., 1991; Faraone, et al., 1997; Goldstein, 1996; Kashani, et al., 1979; Szatmari, Boyle, et al., 1989). Other researchers and clinicians have confirmed that these disorders are far more prevalent in young boys than in young girls. Overall, the prevalence rates of conduct disorder and ODD for girls are about half that for boys (Barkley, 1998; Biederman, Newcorn, et al., 1991).

Furthermore, in the first quantitative summary on gender differences in $\mathrm{AD} / \mathrm{HD}$, Gaub and Carlson (1997b) concluded that co-occurring disruptive behavior disorders were more common in AD/HD boys than in AD/HD girls $(\mathrm{d}=.138, \mathrm{p}<.05)$. These researchers found that in comparison to $\mathrm{AD} / \mathrm{HD}$ boys, $\mathrm{AD} / \mathrm{HD}$ girls had lower incidences of conduct disorder, lower ratings on hyperactivity, and lower ratings of externalizing behaviors. No gender differences were found with regard to impulsivity. However, in an investigation of these findings, it was revealed that some of these differences were a result of the influences of moderator variables such as referral source and/or the diagnostic system used by the investigators. Consequently, they found that children who were assessed from clinical samples showed greater impairment than those from community samples. Limitations of their meta-analysis include the use of stringent inclusion guidelines that resulted in the analysis of only a small number of studies, the inclusion of only one unpublished study, which may have resulted in the exclusion of 
negative findings in unpublished research, failure to address comorbidity and developmental variables, possible rater biases, and all of the studies in the meta-analysis were conducted prior to the $\mathrm{DSM}-\mathrm{IV}$ change in the criteria for diagnosing $\mathrm{AD} / \mathrm{HD}$. In a replication of the work of Gaub and Carlson (1997b), Gershon (2002) conducted a metaanalytical review of different manifestations of $\mathrm{AD} / \mathrm{HD}$ in males and females. They analyzed 38 studies, 13 of which were included in the prior review. Overall, the findings were consistent with that of Gaub and Carlson (1997b), indicating that compared to $\mathrm{AD} / \mathrm{HD}$ boys, $\mathrm{AD} / \mathrm{HD}$ girls had lower incidences of hyperactivity $(\mathrm{d}=.29, \mathrm{p}<.05)$, inattention $(\mathrm{d}=.23, \mathrm{P}<.05)$, impulsivity $(\mathrm{d}=.22, \mathrm{p}<.05)$, and externalizing problems $(\mathrm{d}$ $=.21, \mathrm{p}<.05)$. Similar results were also obtained in a study of younger children (Hartung, et al., 2002).

Although some researchers (Rucklidge \& Tannock, 2001) have found no group differences in levels of externalizing problems with males and females, the majority of research studies on disruptive behavior disorders indicate that boys display more externalizing behaviors, including AD/HD, than girls (Arcia and Conners, 1998; Arnold, 1996; Bird, et al., 1993; Heptinstall \& Taylor, 1996; Leadbeater, Kupermine, Blatt, \& Hertzog, 1999), with boys exceeding girls in these rates of externalizing problems throughout childhood and adolescence (Lewinsohn, et al., 1993; Zahn-Waxler, 1993). For instance, studies using rating scales and structured diagnostic interviews have shown that females have fewer externalizing problems, including conduct disorder, delinquency, and aggression (Bauermeister, 1992; deHaas \& Young, 1984; Eme, 1992; McDermott, 1996), present with less disruptive behavior in classroom settings (deHaas, 1986), are at a lower risk for comorbid conduct disorder and oppositional defiant disorder (Biederman, et al, 2002), display significantly less gross motor activity (James \& Taylor, 1990), and have significantly lower rates of hyperactivity, aggression, conduct problems, impulsivity, 
inattention, distractibility, and oppositional defiance as compared to boys (Barkley, 1989; Bauermeister, 1992; Befera and Barkley, 1985; Berry, et al., 1985; deHaas, 1986; deHaas \& Young, 1984; Gaub \& Carlson, 1997b; Newcorn, et al., 2001).

In a sample of $32 \mathrm{AD} / \mathrm{HD}$ girls and $102 \mathrm{AD} / \mathrm{HD}$ boys that were compared with a control group consisting of 62 boys and 32 girls, it was found that disruptive behaviors were more common in boys than girls (Berry, et al., 1985). Likewise, in an examination of archival data of 149 children under age 9 who were referred to an outpatient clinic, it was concluded that girls had significantly lower scores on measures of externalizing behaviors and were less likely to be diagnosed with CD (Lumley, et al., 2002). Carlson, Tamm, \& Gaub (1997) examined gender differences in a sample of 1562 boys and 1422 girls with disruptive behavior disorders, including $\mathrm{AD} / \mathrm{HD}, \mathrm{CD}$, and ODD. They found that girls exhibited more appropriate behavior, lower attention problems, poorer social functioning, and lower aggression and externalizing scores.

In contrast, other studies have not demonstrated higher behavioral ratings of $\mathrm{AD} / \mathrm{HD}$ males when compared to AD/HD females (Horn, et al., 1989; James \& Taylor, 1990) and a number of researchers have not found gender differences in parent or teacher ratings of psychopathology or in observation of behavior in a clinical setting (Arnold, 1996; Breen, 1988; Breen \& Barkley, 1988; Horn, et al., 1989). One example is a study by Breen (1989), which found that boys and girls with AD/HD performed similarly on measures of behavioral functioning.

Other researchers have found that girls exhibited more behavior problems than did boys (Berry, et al., 1985). Biederman, et al. (1999) conducted a large and comprehensive study consisting of 140 girls diagnosed with $\mathrm{AD} / \mathrm{HD}$ and 122 girls with similar ages and backgrounds as a comparison group. Among the few differences found were that girls were less likely to be diagnosed with a comorbid behavior disorder than boys, but were more likely to have conduct problems and problems with substance use. Other researchers also found $\mathrm{AD} / \mathrm{HD}$ girls to be referred for conduct problems more often 
than AD/HD boys (Pelham, Walker, Sturges, \& Hoza, 1989). In addition to higher rates of conduct problems, Rucklidge and Tannock (2001) found that, according to parent and teacher ratings, compared to female controls and $\mathrm{AD} / \mathrm{HD}$ males, $\mathrm{AD} / \mathrm{HD}$ girls demonstrated more $\mathrm{AD} / \mathrm{HD}$ symptomatology, higher rates of inattention and hyperactivity, oppositional behaviors, greater distress, anxiety, depression, and social difficulties.

Some research indicates that when girls do have behavior problems, the problems tend to be more severe than in boys, a situation referred to as a paradoxical gender effect (Eme, 1992; Loeber \& Keenan, 1994). The gender paradox hypothesis predicts that although there will be a lower number of girls with behavioral disorders, girls who meet criteria for one disruptive behavior disorder have a higher probability of meeting criteria for another disorder than do boys and the rate of girls with severe presentations of symptomatology will be higher.

In a recent meta-analysis of comorbid $\mathrm{AD} / \mathrm{HD}$ and conduct problems, Waschbusch (2002) found that even though the overall prevalence rates of disruptive behaviors were highest for boys, girls with conduct problems were more likely to experience severe symptomatology and experience comorbid problems with $\mathrm{AD} / \mathrm{HD}$, which is consistent with the gender paradox hypothesis. In contrast, Lumley, et al. (2002) demonstrated that significantly more males than females met criteria for 2 or 3 disruptive behavior disorder diagnoses which, in turn, contradicts the paradoxical gender effect described by Loeber and Keenan (1994). Possible explanations for these contradictory results could be that Lumley, et al. (2002) studied a clinic-referred sample and the participants where much younger than those in the studies that support the hypothesis.

Abikoff, et al. (2002) found that compared to children with AD/HD alone and those with comorbid anxiety, the children with comorbid disruptive behaviors were more likely to exhibit off-task and aggressive behaviors. Hinshaw (2002) reported that 6-12year-old girls with $\mathrm{AD} / \mathrm{HD}$, Combined Type, who participated in a summer research 
program, were rated significantly higher in relational aggression compared to non$\mathrm{AD} / \mathrm{HD}$ comparison girls. These findings support the hypotheses that the presence of a comorbid disruptive disorder is associated with increased rates of externalizing behaviors and support previous evidence of more severe $\mathrm{AD} / \mathrm{HD}$ presentations and social dysfunction in the presence of comorbid disruptive behavior disorder (Kuhne, et al., 1997; Newcorn, et al., 2001). These increased rates of observed AD/HD behaviors in those children with comorbid disruptive behavior disorder suggest that these behaviors are actually present and not just related to negative halo effects and rater biases (Abikoff, Courtney, Pelham, \& Koplewicz, 1993; Schachar, et al., 1986; Stevens, Quittner, \& Abikoff, 1998).

Some investigators contend that hyperactivity is not a risk factor for later conduct problems (MacDonald \& Achenbach, 1999), while most argue that children of both genders who exhibit difficulties related to hyperactivity and impulsivity have been shown to be more likely to have comorbid conduct problems than are children with primarily inattention problems (APA, 2000; Carlson, Tamm, \& Gaub, 1997; Lahey, Applegate, McBurnett, et al., 1994). Thus, the comorbid conditions of $\mathrm{AD} / \mathrm{HD}$ and $\mathrm{CD}$ are generally associated with more severe symptoms and greater impairment than either condition alone (Caron \& Rutter, 1991). Boys may be referred at a higher rate because of the disruptive consequences of the coexisting behavior problems (Goldstein, 1996; Kashani, et al., 1979) as evidenced by the fact that girls with $\mathrm{AD} / \mathrm{HD}$ are referred less frequently for aggression than are boys with AD/HD (Kashani, et al., 1979). In a study of 403 $\mathrm{AD} / \mathrm{HD}$ boys and $99 \mathrm{AD} / \mathrm{HD}$ girls, ages 7 to 10 , it was investigated whether the classroom behavior of children with $\mathrm{AD} / \mathrm{HD}$ is manifested differently as a function of gender and comorbid externalizing and/or internalizing problems. These researchers found that $\mathrm{AD} / \mathrm{HD}$ boys engaged in more rule-breaking, disruptive, and externalizing behaviors than did girls (Abikoff, et al., 2002). Because comorbidity with disruptive behaviors such as this is associated with behavioral deviance and aggression, particularly 
in males (Ackerman, Dykman, \& Oglesby, 1983; Battle and Lacey, 1972), and because these problems drive clinical referral, the lower rates of these disorders in girls may lead to the underrecognition of $\mathrm{AD} / \mathrm{HD}$ in girls. This, in turn may account for the marked gender differences frequently reported in clinical samples of children with $\mathrm{AD} / \mathrm{HD}$ (Biederman, et al., 1999). These results provide strong argument for examining gender differences in disruptive behavior, particularly with regard to comorbidity, which is seriously lacking in previous research investigations.

\section{$\underline{\mathrm{AD} / \mathrm{HD}}$ and Internalizing Problems}

$\mathrm{AD} / \mathrm{HD}$ is associated with comorbidity with $15 \%$ to $27 \%$ with mood disorders (Biederman, et al., 1987; Bird, et al., 1993) and 25\% to $51 \%$ with anxiety disorders (Biederman, Newcorn, et al., 1991; Bird, et al., 1993). In some cases, rates of major depression and anxiety disorder have been reported in excess of $30 \%$ in clinical and epidemiological samples of children, adolescent, and adult males and females with AD/HD (Biederman, et al., 1993; Biederman, et al., 1994; Biederman, Newcorn, et al., 1991; Jensen, Shervette, Xenakis, \& Richters, 1993). The risk of AD/HD children for developing depression has been found to be consistently greater (Treuting \& Hinshaw, 2001), with estimates as high as 3 times greater than for other children (Biederman, Mick, \& Faraone, 1998). Biederman, et al. (1998) also found that in the 76 participants in their study, the depression was a distinct disorder and not just a result of "demoralization" that was directly associated with the diagnosis of $\mathrm{AD} / \mathrm{HD}$.

Although it has not been shown to co-occur as commonly as comorbid ODD/CD and $\mathrm{AD} / \mathrm{HD}$, the coexistence of anxiety disorder and $\mathrm{AD} / \mathrm{HD}$ has been extensively reported in the research literature (Biederman, et. al., 1991; Jensen, et al., 1993; Perrin \& 
Last, 1996; Russo \& Biedal, 1994). Rates of coexistence of anxiety disorder range from $2-21 \%$ in studies of children referred to anxiety clinics (Russo \& Biedel, 1994), to $50 \%$ in studies of children referred to behavior disorder clinics (Jensen, et al., 1997; Kazdin, 1996), to as much as $50.8 \%$ in a community sample (Bird, et al., 1993). According to one study, internalizing behaviors, such as anxiety and depressive symptoms, were present in $9 \%$ of those with $\mathrm{AD} / \mathrm{HD}$ when combination of one additional diagnosis was considered. However, when two or more comorbid diagnoses were considered, rates increased to 64\% with comorbid internalizing disorders (August, et al., 1996). These internalizing comorbid conditions have been associated with a more complicated course of $\mathrm{AD} / \mathrm{HD}$ (Biederman, et al., 1999).

Overall, depressive and anxiety disorders are more common in women (APA, 1994; Allgood-Merten, et al., 1990; Pinn, 2003; Reeves, Werry, Elkind, \& Zametkin, 1987) and adult women typically suffer from both depression and anxiety at twice the rate of men (Nolen-Hoeksema, \& Girgus, 1994; Pinn, 2003). Although some researchers have found no significant differences in comorbidity rates of $\mathrm{AD} / \mathrm{HD}$ and internalizing behaviors between males and females (Bird, et al., 1993; Hartung, et al., 2002), some have found lower rates of depression in females as compared to males (Biederman, et al, 2002), whereas others contend that $\mathrm{AD} / \mathrm{HD}$ in girls is characterized by a greater prevalence of comorbid internalizing behavior disorders (Berry, et al., 1985). Others have not shown greater internalizing symptomatology with the inattentive subtype (Morgan, et al., 1996). According to a large study that compared clinical correlates of $\mathrm{AD} / \mathrm{HD}$ children with the inattentive and combined subtypes, those children with the inattentive type were older, more likely to be female, and experienced a greater incidence of 
comorbid internalizing disorders (Weiss, et al., 2003). This is consistent with results that show referred children with the inattentive type are more likely to exhibit comorbid internalizing disorders than those that are not referred (Eiraldi, et al., 1997). Gershon (2002), in a replication and extension of quantitative analysis by Gaub and Carlson (1997b), concluded that girls exhibited more internalizing problems than males $(d=-.12$, $\mathrm{p}<.05$ ), suggesting that comorbid conditions such as depression and anxiety may be more problematic for $\mathrm{AD} / \mathrm{HD}$ females than males.

In an investigation of neuropsychological and personality differences between 49 $\mathrm{AD} / \mathrm{HD}$ males and $26 \mathrm{AD} / \mathrm{HD}$ females, it was found that although attentional problems were similar between males and females, female subjects had greater degrees of anxiety and depression (Katz, Goldstein, \& Geckle, 1998). These authors concluded that the higher rates of internalizing symptomatology in females may result in the diagnosis of depression rather than a diagnosis of $\mathrm{AD} / \mathrm{HD}$ or a comorbid diagnosis of $\mathrm{AD} / \mathrm{HD}$ and depression or anxiety.

Among clinic-referred samples, $\mathrm{AD} / \mathrm{HD}$ girls have more depressed/anxious behavior than do $\mathrm{AD} / \mathrm{HD}$ boys (Rucklidge \& Tannock, 2001). Compared to AD/HD boys, $\mathrm{AD} / \mathrm{HD}$ girls are more likely to exhibit anxiety disorders, depression, and low selfesteem and less likely to show severe behavioral problems and conduct disorder (Biederman, Newcorn, et al., 1991). In addition, empirical evidence suggests that internalizing problems such as depression and anxiety increase for girls but not for boys during adolescence (Ge, et al., 1995; Lewinsohn, et al., 1993). In one such study, researchers collected data on 460 middle school students and found that girls showed elevated levels of internalizing symptoms during this stage (Leadbeater, et al., 1999). 
This is consistent with evidence indicating that internalizing symptomatology is more prevalent in older girls when compared to younger girls, and highlights the importance of assessing for comorbid mood disorders across time, particularly in older females (Kato, Nichols, Kerivan, \& Huffman, 2001).

Moreover, recent reviews have suggested that girls' greater socialization for selfregulation and sensitivity to interpersonal concerns increases their vulnerability to internalizing problems compared with boys (Leadbeater, et al., 1999; Zahn-Waxler, 1993). Rucklidge and Tannock (2001) compared the psychiatric, psychological, and cognitive functioning of 13-16-year-old adolescent males $(n=35)$ and females $(n=24)$ with non-AD/HD male $(n=20)$ and female adolescent $(n=28)$ comparisons. Compared to non- $\mathrm{AD} / \mathrm{HD}$ girls, they exhibited higher rates of strained relationships with teachers, thoughts of suicide and past episodes of self-harm. Not only were the AD/HD females significantly more impaired than their non-AD/HD counterparts on measures of depression, anxiety, self-esteem, overall symptom distress, and stress, they appeared to also be having more difficulties than adolescent $\mathrm{AD} / \mathrm{HD}$ boys with higher rates of overall distress, social problems, anxiety, and depression.

Biederman, et al. (1999) found that compared to non-AD/HD girls, girls with $\mathrm{AD} / \mathrm{HD}$ showed a higher incidence of inattentive symptomatology than hyperactive $(\mathrm{t}=$ $7.99, \mathrm{p}<.001)$ and impulsive symptomatology $(\mathrm{t}=5.9, \mathrm{p}=.001)$, and a greater occurrence of mood and anxiety problems rather than disruptive behavior problems. This is consistent with evidence that comorbid anxiety is more likely to be seen in $\mathrm{AD} / \mathrm{HD}$ children who are not particularly hyperactive (Biederman, Newcorn, et al., 1991; Pliszka, 1992). Pliszka (1992) found that children with $\mathrm{AD} / \mathrm{HD}$ and comorbid anxiety disorder, 
though more impaired than controls, were inattentive but less hyperactive-impulsive than children with $\mathrm{AD} / \mathrm{HD}$ alone. The author suggests that the lower rate of impulsive responding among comorbid children may protect them against the development of conduct problems. This is consistent with results from a study of 498 children from the MTA sample with the Combined Type of AD/HD (Newcorn, et al., 2001). In this study, researchers analyzed parent and teacher ratings and CPT performance and found similarly high rates of inattention and lower rates of hyperactivity/impulsivity in anxious $\mathrm{AD} / \mathrm{HD}$ girls than those without. The lower impulsivity found in CPT performance was only found in girls with comorbid anxiety disorder, not boys. Werry, Elkind, \& Reeves (1987) found differences in activity level, but no differences on other measures including the continuous performance task.

Contrarily, March, et al. (2000), who also used the MTA sample, reported no pretreatment differences between $\mathrm{AD} / \mathrm{HD}$ children with and without coexisting anxiety disorder in teacher ratings of inattentiveness, hyperactivity-impulsivity, social skills, or behavior problems. Horn, et al. (1989), in a comparison of clinic-referred boys and girls, found no gender differences with $\mathrm{AD} / \mathrm{HD}$ on measures of inattention, impulsivity, and hyperactivity. Moreover, Livingston, Dykman, \& Ackerman (1990) found greater impulsivity, inattention and aggression among the comorbid group, which included children with depression. They concluded that these problems may have accounted for the greater disability identified in the comorbid subjects.

Some researchers contend that even though comorbidity with mood and anxiety disorders is higher with girls with $\mathrm{AD} / \mathrm{HD}$, rates are consistent with those found in boys (Biederman, et al., 1999; Faraone, et al., 1991; Horn, et al., 1989). In a study of 128 
$\mathrm{AD} / \mathrm{HD}$ adults of both genders, Biederman, et al. (1994) reported that rates of major depression and anxiety disorders were higher in $\mathrm{AD} / \mathrm{HD}$ women as compared to normal control females, but elevated rates of these disorders was similar among male and female adults with $\mathrm{AD} / \mathrm{HD}$. This is consistent with rates reported in pediatric samples of $\mathrm{AD} / \mathrm{HD}$ girls (Berry, et al., 1985). Boys and girls did not differ significantly on parent or teacher ratings of inattention or internalizing behaviors (Arcia \& Conners, 1998). In an attempt to overcome the limitations posed by individual studies, Gaub and Carlson (1997b) conducted a meta-analysis of 18 studies that examined gender differences in $\mathrm{AD} / \mathrm{HD}$ and found no gender differences with depression (Gaub and Carlson, 1997b). In contrast to the other studies that found that girls exhibit greater rates of internalizing symptomatology, Gaub \& Carlson (1997b) found that in comparison to $\mathrm{AD} / \mathrm{HD}$ boys, $\mathrm{AD} / \mathrm{HD}$ girls had lower ratings of internalizing problems $(\mathrm{d}=.099)$.

Hazell (1997) reported that AD/HD and anxiety seem to represent very distinct syndromes. Thus, he contends that the presence of anxiety will result in a different pattern of disabilities and response to treatment than do children with $\mathrm{AD} / \mathrm{HD}$ alone, which indicates a different approach to the management of the $\mathrm{AD} / \mathrm{HD}$. Reeves, et al. (1987) demonstrated that $\mathrm{AD} / \mathrm{HD}$ and anxious children have markedly different symptom profiles on the Revised Behavior Problem Checklist and Conners Teacher Questionnaire, suggesting evidence of discriminant validity. Children with anxiety and $\mathrm{AD} / \mathrm{HD}$ as well as $\mathrm{ODD} / \mathrm{CD}$ tend to exhibit more severe symptomatology such as irritability, mood lability and emotional outbursts, and higher levels of aggression (Kashani, Deuser, \& Reid, 1991; Eiraldi, et al., 1997). This evidence highlights the importance of appropriate diagnosis and treatment of those with coexisting $\mathrm{AD} / \mathrm{HD}$ and internalizing problems. 


\section{Developmental Delays}

$\mathrm{AD} / \mathrm{HD}$ commonly occurs in association with many developmental disorders, such as speech and language delays and learning disabilities (August, et al., 1996). Studies that looked at the gender-related differences in the manifestations of AD/HD have found greater cognitive and language impairment in females (Ackerman, et al., 1983; Berry, et al., 1985; Brown, et al., 1991; James \& Taylor, 1990; Kashani, et al., 1979; Shaywitz \& Shaywitz, 1991). In a study of patients who met criteria for hyperkinetic syndrome, James and Taylor (1990) found an increased rate of language problems among female than males. According to a study by Lumley, et al. (2002), girls had a higher rate of developmental delays, which is consistent with other investigations (Berry, et al., 1985; Brown, et al., 1991). In a comparison of 32 girls with AD/HD and 102 boys with $\mathrm{AD} / \mathrm{HD}$, girls who also had hyperactivity experienced lower ratings of language ability and a higher referral rate for speech problems than did male participants (Berry, et al., 1985). This evidence is consistent with other research that indicates that children with the inattentive subtype are more likely to be female in addition to being more likely to exhibit difficulties with learning disabilities and speech and language difficulties (Weiss, et al., 2003).

\section{$\underline{\mathrm{AD} / \mathrm{HD} \text { and Learning Problems }}$}

Cognitive deficits, particularly impairments in attention and executive functions, are hypothesized to be core impairments of AD/HD. With a population of 77 9-12-yearold boys, McInnes, Humphries, Hogg-Johnson, \& Tannock (2003) showed that listening comprehension and working memory are impaired in children with $\mathrm{AD} / \mathrm{HD}$. In addition, 
a substantial body of literature shows that children with $\mathrm{AD} / \mathrm{HD}$ are at high risk for poor cognitive functioning as measured by grade repetitions, academic underachievement, learning disabilities, placement in special classes, need for tutoring, and impaired performance on neuropsychological measures (Barkley, et al., 1990; Faraone and Biederman, 1994; Pineda, Ardila, \& Rosselli, 1999).

These cognitive difficulties continue through adolescence into adulthood and are associated with chronic underachievement and failure in school. Subsequently, AD/HD children have been found to obtain lower scores on intelligence measures (Werry, et al., 1987). Faraone, et al. (1993), in a study of $140 \mathrm{AD} / \mathrm{HD}$ children, 120 normal controls, and 303 siblings, found that $\mathrm{AD} / \mathrm{HD}$ children were more likely to have had learning disabilities, repeated grades, impairments on ability and achievement measures, special class placement, and receive academic tutoring.

Compared to $\mathrm{AD} / \mathrm{HD}$ boys, $\mathrm{AD} / \mathrm{HD}$ girls are more likely to manifest cognitive impairments (Berry, et al., 1985; Biederman, Newcorn, \& Sprich, 1991; Brown, MadanSwain, and Baldwin, 1991; Faraone, et al, 1991 a; Gaub \& Carlson, 1997b), including poorer performance on Full Scale IQ $(\mathrm{d}=.27, \mathrm{p}<.05)$ and Verbal IQ $(\mathrm{d}=.37, \mathrm{p}<.05)$, and increased levels of inattention $(\mathrm{d}=.23, \mathrm{p}<.05)($ Gershon, 2002). AD/HD in girls was associated with significant impairments in academic achievement, psychosocial functioning, and measure of school failure (Biederman, et al., 1999). Similarly, other studies have shown that girls with $\mathrm{AD} / \mathrm{HD}$ have greater intellectual impairment, poorer ratings on academic performance and have a greater prevalence of comorbid learning problems (Ackerman, et al., 1983; Berry, et al., 1985; Cutting, Koth, Mahone, \& Denckla, 2003; Ernst, Liebenauer, Jons, \& Zametkin, 1994; Gaub \& Carlson, 1997b; 
Rucklidge and Tannock, 2001). Hinshaw (2002) studied 245 6-12 -year-old girls with $\mathrm{AD} / \mathrm{HD}$ and 88 comparison girls without $\mathrm{AD} / \mathrm{HD}, \mathrm{AD} / \mathrm{HD}$ girls were more likely to have experienced academic difficulty and obtained lower scores on measures of cognitive functioning (although in the average range). Seidman, et al., 1997 showed that 43 girls with $\mathrm{AD} / \mathrm{HD}$ were more impaired on estimated IQ than comparison subjects, but they did not differ significantly from controls on executive function tasks. In a study of 128 $\mathrm{AD} / \mathrm{HD}$ adults of both genders, rates of school failure and cognitive impairment were higher in $\mathrm{AD} / \mathrm{HD}$ women as compared to normal control females (Biederman, et al., 1994).

Contrary to studies suggesting that $\mathrm{AD} / \mathrm{HD}$ in girls is associated with greater intellectual impairments than in boys, the magnitude of cognitive impairments in girls with $\mathrm{AD} / \mathrm{HD}$ in other studies was consistent with previously reported cognitive findings in boys with AD/HD (Biederman, et al., 2002; Biederman, et al., 1999). According to McGee, et al. (1987), inattentive symptomatology and cognitive features are the same for boys and girls. Other researchers have found limited or no gender differences between boys and girls with $\mathrm{AD} / \mathrm{HD}$. For example, Breen (1989) found that boys and girls with $\mathrm{AD} / \mathrm{HD}$ performed similarly on measures of achievement. By comparing data collected on teacher-identified hyperactive girls to the results of other studies that have examined hyperactive boys, DeHaas and Young (1984) concluded that boys and girls with AD/HD both have poor concentration and short attention spans.

Similarly, other researchers have found no significant differences between $\mathrm{AD} / \mathrm{HD}$ males and females on measures of neurological and cognitive functioning (Hartung, 2002; Silverthorn, et al., 1996). Consistent with these findings, Arcia \& 
Conners (1998) studied AD/HD children and adults and found that verbal and performance IQ scores were equivalent and neurological performance did not differ significantly with males and females. Likewise, Gershon (2002) found no significant gender differences on measures of academic achievement or neuropsychological functioning. Castellanos, et al., 2000 compared 32 girls aged 6 to 13 years with 20 agematched, normal control girls and confirmed that girls with $\mathrm{AD} / \mathrm{HD}$ exhibit impairments in executive functioning similar to boys. Limitations in this study included small sample size, only girls, and a small number of trials used to measure outcomes. DuPaul and Barkley (1992) found that boys with AD/HD demonstrated more severe problems with attention, and in more settings, than did girls with $\mathrm{AD} / \mathrm{HD}$. However, in a sample of 915 identical and fraternal twins, Gjone, et al. (1996) found no differences between males and females for attention problems.

One explanation for the inconsistent findings regarding sex-related differences could be related to the occurrence of comorbidity of internalizing symptomatology with specific subtypes of AD/HD. Chhabildas, Pennington, \& Willcutt (2001) examined neuropsychological functioning in the three subtypes of $\mathrm{AD} / \mathrm{HD}$ in 1148 eighteen-yearold children with $\mathrm{AD} / \mathrm{HD}$ and 82 comparison children without $\mathrm{AD} / \mathrm{HD}$. The findings demonstrated that only inattentive symptoms were predictive of neuropsychological deficits. Children with the inattentive and combined forms of AD/HD performed worse than comparison children on all measures of neuropsychological functioning and measures of IQ and achievement, while hyperactive-impulsive children had relatively normal neuropsychological profiles. The authors noted that these findings are consistent 
with prior research that contends that the inattentive symptoms are associated with poorer academic functioning.

\section{$\underline{\text { Peer Relationships and } \mathrm{AD} / \mathrm{HD}}$}

Other documented difficulties related to AD/HD include peer relationship problems, which predict a number of subsequent problems. Children with $A D / H D$ have specifically been found to suffer in social relationships through rejection by peers (Hinshaw \& Melnick, 1995). This, in turn, results in higher rates of criminal behavior, depression, anxiety, and substance use for boys (Greene, Biederman, Faraone, Sienna, \& Garcia-Jetton (1997) and depression, anxiety, and higher levels of aggression in girls (Mikami \& Hinshaw, 2003).

Generally, peer difficulties are related to impulsive behavior and difficulties reading social cues that result from attention deficits. For the most part, children with the $\mathrm{AD} / \mathrm{HD}$ combined type display the highest rates of social problems and peer rejection (Milich, et al., 2001).

Evidence suggests that girls with $\mathrm{AD} / \mathrm{HD}$ suffer greater levels of peer rejection than their male counterparts (Arnold, 1996; Berry, et al., 1985; Carlson, Tamm, \& Gaub, 1997). Moreover, girls with the AD/HD, Predominantly Inattentive Type, are more rejected than boys (Berry, et al., 1985). Biederman, et al. (1999) found that girls with $\mathrm{AD} / \mathrm{HD}$ were more impaired on social functioning than non-referred girls. Likewise, Hinshaw (2002) studied 2456 twelve-year-old girls with AD/HD and 88 comparison girls without $\mathrm{AD} / \mathrm{HD}$ and found that girls with $\mathrm{AD} / \mathrm{HD}$ were less well liked by peers. Blachman \& Hinshaw (2002), in one of the few studies that addresses peer relations and 
friendship patterns in females, studied 140 6-12-year-old girls with AD/HD and 88 without. These authors concluded that girls, like boys, have difficulties with peer relationships. However, girls with $\mathrm{AD} / \mathrm{HD}$ were less well liked by peers, developed fewer friendships, were more likely to have no friends, less likely to maintain friendships, and their friendships tended to be less stable and include more negative relationship qualities.

In contrast, Gershon (2002) have found no significant differences on measures of social functioning. Other researchers similarly concluded that there are no gender differences found with regard to social behavior (Gaub and Carlson, 1997b; Greene, et al., 2001).

According to Blachman \& Hinshaw (2002), lack of friendship may play a particularly important role in the development of internalizing difficulties. Bagwell, Newcomb, and Bukowski (1998) found that peer acceptance and friendship provided independent contributions to adult adjustment, with general self-worth and depressive symptomatology uniquely predicted by childhood friendship status. According to these authors, ascertaining the impact that friendship experiences may have on the emotional adjustment of girls with $\mathrm{AD} / \mathrm{HD}$ appears important, given the rates of internalizing difficulties among females and preliminary evidence that friendship process may play a role in the development of such problems.

\section{$\underline{\text { Referral Bias }}$}

According to the Surgeon General's Report on Mental Health (2001), girls are less likely to receive a diagnosis and treatment for $\mathrm{AD} / \mathrm{HD}$ compared to boys. This trend has also been noted by other researchers (Biederman, et al., 1999). Taylor and Keltner 
(2002) delineate several factors to explain the lower rates of referral and diagnosis of females with $\mathrm{AD} / \mathrm{HD}$ that include issues related to the DSM criteria, a later age of onset, and/or different manifestations in females.

Referrals and diagnosis of $\mathrm{AD} / \mathrm{HD}$ are based on the use of diagnostic criteria, such as in the Diagnostic and Statistical Manual of Mental Disorders, 4th edition (DSMIV; American Psychiatric Association, 1994). Other methods are the use of behavior rating scales, diagnostic interviews, and/or clinical judgment, which can vary depending on the diagnostician. Several researchers suggest more noticeable sex differences for teacher ratings, in that teachers have a tendency to rate males higher on $\mathrm{AD} / \mathrm{HD}$ behaviors (Breen \& Altepeter, 1990; McGee \& Feehan, 1991; McGee, et al., 1987; Szatmari, Offord, et al., 1989). In addition, Gershon's (2002) investigation of the different ratings of teachers and parents resulted in other gender differences, including lower rates of hyperactivity according to parent and teachers. In addition, $\mathrm{AD} / \mathrm{HD}$ females showed lower rates of externalizing and inattention problems according to teachers only. The author purported that parent and teacher ratings commonly differ on some of the core symptoms and comorbid conditions, and teachers rate $\mathrm{AD} / \mathrm{HD}$ males as significantly more impaired than $\mathrm{AD} / \mathrm{HD}$ females in comparison to parent ratings (Gershon, 2002). Such differences in ratings may indicate a "halo effect," whereby teachers overly attend to coexisting externalizing problems when rating $\mathrm{AD} / \mathrm{HD}$ symptom severity and downplay inattentive behaviors (Abikoff, et al., 1993; Schachar, et al., 1986; Stevens, et al., 1998). Similarly, it has been found that only females with severe presentation of $\mathrm{AD} / \mathrm{HD}$ symptomatology are referred for clinical intervention (Nolan, et al., 1999). This potential bias might contribute to the underidentification of affected 
females, particularly in the classroom. "Since potential ratings biases exist in the disorder, and the symptoms of $\mathrm{AD} / \mathrm{HD}$ in females tend to be subtler than in males, it is likely that many AD/HD females are unrecognized (Gershon, 2002, p.150)." Due to this evidence suggesting rater biases in the reporting of $\mathrm{AD} / \mathrm{HD}$ symptomatology, McGee \& Feehan (1991) recommend the use of separate cutoff scores or sex-specific norms and diagnostic criteria when diagnosing $\mathrm{AD} / \mathrm{HD}$ in girls, particularly when using teacher ratings.

Another explanation for the differences in referral rates could be related to varying symptom presentations of the different subtypes of $\mathrm{AD} / \mathrm{HD}$ (Gaub \& Carlson, 1997a; Milich, Balentine, \& Lynam, 2001), with AD/HD boys and girls who meet criteria for the inattentive subtype being more difficult to recognize. Many children with inattentive subtype of $\mathrm{AD} / \mathrm{HD}$ often do not display major behavior problems, which results in these children either being not treated at all or treated by primary care physicians rather than by mental health professionals. For example, inattentive children have been shown to have significantly worse intellectual and academic performance (Goldstein, 1987). Likewise, in a sample of 19,542 grade school children from Spain, Germany, and the U.S., it was shown that academic problems were associated more closely with inattention and hyperactivity/impulsivity was more closely associated with problems in both academic and behavioral domains (Wolraich, et al., 2003). Hudziak, et al. (1998) similarly obtained results with adolescent females that indicated that those with primarily inattentive difficulties were more likely to suffer from academic difficulties, yet were least likely to be referred for treatment. In addition, researchers have found that predominantly inattentive children are not only more likely to demonstrate appropriate 
behaviors, but are also more likely to exhibit internalizing behaviors and less likely to exhibit externalizing behaviors (Gaub \& Carlson, 1997a). This is consistent with evidence that $\mathrm{AD} / \mathrm{HD}$ females are more likely to present inattentive behavior than $\mathrm{AD} / \mathrm{HD}$ males, and, as a result, are more likely to be ignored (Biederman, et al., 2002; Gaub \& Carlson, 1997b).

Abikoff, et al. (2002) observed 5027 ten-year-old children diagnosed with $\mathrm{AD} / \mathrm{HD}$, combined type ( 403 boys and 99 girls). Their results indicated that $\mathrm{AD} / \mathrm{HD}$ girls demonstrated significantly lower disruptive, rule-breaking behaviors than boys with $\mathrm{AD} / \mathrm{HD}$. In addition to being less aggressive than boys with $\mathrm{AD} / \mathrm{HD}$, girls with $\mathrm{AD} / \mathrm{HD}$ were no more aggressive or likely to be out of their seat than girls without $\mathrm{AD} / \mathrm{HD}$. As a result, teachers may be less likely to pick up on these girls' difficulties. This could result in being identified much later than boys, or to never being identified at all. These observational findings highlight the need for teachers as well as clinicians to be aware of these gender-related differences and of their potential impact on the underidentification and misdiagnosis of girls with $\mathrm{AD} / \mathrm{HD}$.

Nadeau, Littman, and Quinn (1999) proposed that AD/HD females are more likely to receive referrals as a result of school-related difficulties or learning problems, which are more closely associated with the inattentive subtype, and that the reported gender differences in intellectual functioning might reflect a referral bias. This is consistent with a large chart review that showed individuals with the inattentive subtype, which was shown to more prevalent in females, were two to five times more likely to be referred for speech and language problems (Weiss, et al., 2003). In addition, these children were more likely to have problems with academic achievement. Kashani, et al. 
(1979) compared 28 hyperactive boys with 28 hyperactive girls who were clinic-referred and found that girls were more often referred due to cognitive problems related to learning and/or speech problems, whereas boys identified as hyperactive were more frequently referred for behavior problems than learning problems. This was evident in the sample even though measures of overactivity, attention span, restlessness, and distractibility in boys and girls were equivalent. Nonetheless, even though there were no differences between genders in overall IQ, hyperactive girls showed significantly lower verbal IQ's when compared to hyperactive boys. According to the authors, however, this finding could be accounted for by the higher frequency of referral of girls with learning and/or speech problems.

Additionally, a similar study indicated that girls with AD/HD may be underidentified and that cognitive deficits have a more prominent role in the identification of girls whereas behavioral disturbances increase the likelihood of identification for boys (Berry, et al., 1985). Their results support a varying presentation of $\mathrm{AD} / \mathrm{HD}$ in boys and girls, with boys showing more aggressive presentations and girls showing lower verbal IQ, more severe cognitive and language deficits, and poorer social functioning. Thus, girls who are generally referred are those that either have high levels of hyperactivity or substantial cognitive and/or academic difficulties, with those that are neither inattentive nor demonstrating cognitive or academic impairments being unnoticed.

According to some researchers, boys with hyperactivity were referred 8 months earlier than boys without hyperactivity and girls with hyperactivity were referred 18 months earlier than males and 38 months before girls without hyperactivity (Berry, et al., 
1985). These authors purported that hyperactivity may be less tolerated in girls because it violates cultural expectations of appropriate gender behaviors.

Additional studies suggest that girls are referred for treatment at an earlier age than boys with $\mathrm{AD} / \mathrm{HD}$, despite similarity in symptoms (Berry, et al., 1985; James \& Taylor, 1990; McGee, Williams, \& Feehan, 1992; Silverthorn, et al., 1996). In contrast, Arcia \& Conners (1998) found that girls were referred at approximately the same average age as boys and they found no evidence of a referral bias against girls who were clinicreferred. They showed that those children with more severe presentations of symptoms of hyperactivity or of $\mathrm{CD}$ were referred at younger ages than those with less severe symptomatology. Confidence in these results may be limited, however, due to the very small sample of girls used in this study.

Girls often do not fit stereotypical AD/HD behaviors and, hence, may be overlooked as a result (Taylor \& Keltner, 2002). Accordingly, referral bias could be the result of varying patterns of behavioral symptoms that are exhibited by males and females (Scahill \& Schwab-Stone, 2000). A large amount of empirical evidence supports the conclusion that externalizing behaviors are less prevalent in girls with $\mathrm{AD} / \mathrm{HD}$, showing less rule-breaking, aggression, and other disruptive behavior, but higher rates than normal, comparison girls. For instance, this particular pattern was reported in a meta-analytic review using teacher and parent ratings of nonreferred and clinic-referred AD/HD children, $\mathrm{d}=.168$ (Gaub \& Carlson, 1997b), and in staff ratings and observations in a summer research program for girls with and without $\mathrm{AD} / \mathrm{HD}$ (Hinshaw, 2002). According to Biederman, et al. (1994), the evidence that the presenting symptoms of conduct disorder are observed less frequently among $\mathrm{AD} / \mathrm{HD}$ girls than among $\mathrm{AD} / \mathrm{HD}$ 
boys may explain why girls are less likely to come to the attention of health care providers. According to these authors, this difference may lead to the overrepresentation of males in pediatric samples in comparison with the more even gender representation in self-referred $\mathrm{AD} / \mathrm{HD}$ adults.

Hence, according to some researchers, girls with $\mathrm{AD} / \mathrm{HD}$ are neglected by clinicians and researchers due to their varied manifestation of the disorder (Berry, et al., 1985). These different clinical manifestations could lead to a gender-based referral bias because children with disruptive externalizing behaviors are more likely to be referred than those with nondisruptive internalizing behaviors. This evidence is consistent with the research finding that girls with $\mathrm{AD} / \mathrm{HD}$ tend to have more comorbid internal manifestations of the disorder, whereas boys with $\mathrm{AD} / \mathrm{HD}$ have been noted to express more aggressive overt types of behavior (Breen \& Altepeter, 1990; deHaas, 1986). Those girls who are referred are likely to show more signs of mood and anxiety disorders than are seen in boys with $\mathrm{AD} / \mathrm{HD}$ (Kato, et al., 2001). This may lead some clinicians to diagnose these internalizing disorders and not $\mathrm{AD} / \mathrm{HD}$, particularly with those girls who show predominantly inattentive symptomatology.

In sum, many researchers contend that $\mathrm{AD} / \mathrm{HD}$ girls are an underidentified and underserved group who are at significant risk for long-term academic, social, emotional, and behavioral problems (Berry, et al., 1985.; Hudziak, et al., 1998). Consequently, without a timely diagnosis, secondary emotional problems, relationship difficulties, and feelings of underachievement are inevitable (Solden, 1995). This is even more important given that $\mathrm{AD} / \mathrm{HD}$ females have been shown to have a higher risk of psychiatric admissions in adulthood when compared to AD/HD males (Dalsgaard, et al., 2002). 
Gender differences in diagnosis may be due to differing symptom patterns between boys and girls, because girls are less likely to show hyperactive and aggressive symptoms than are boys (Brown, 2000). Thus, boys may be brought to the attention of teachers and clinicians more often due to frequency and/or severity of disruptive behaviors. These sex differences in externalizing and rule-breaking behavior may play a role in sex-differential identification and referral, consistent with girls being identified later than boys, or in some instances, being missed altogether (Abikoff, et al., 2002; McGee \& Feehan, 1991). In addition, if mood and anxiety disorders are indeed typically co-occurring with $\mathrm{AD} / \mathrm{HD}$ symptomatology in females, clinicians may diagnose girls with these disorders rather than $\mathrm{AD} / \mathrm{HD}$. Hence, since $\mathrm{AD} / \mathrm{HD}$ in girls is as serious a condition and has a comparably damaging impact on children's functioning and adjustment as it does in boys, referral sources need to be aware of these gender-specific behavioral patterns and of their possible influence on the underidentification and underreferral of girls with $\mathrm{AD} / \mathrm{HD}$ (Abikoff, et al., 2001; Biederman, et al., 1999; Biederman, et al., 1994; Nolan, et al., 1999).

\section{Etiology}

$\underline{\text { Genetic }}$

After years of clinical research and accumulation of information regarding $\mathrm{AD} / \mathrm{HD}$ symptomatology, there is no conclusive evidence regarding the cause or causes of this disorder (NIH, 2000). Genetic studies assessing families, twins, and adopted siblings support a substantial genetic predisposition for $\mathrm{AD} / \mathrm{HD}$, with the relatives of $\mathrm{AD} / \mathrm{HD}$ children being at an increased risk for $\mathrm{AD} / \mathrm{HD}$ and other psychiatric disorders 
(Biederman, et al., 1992; Sherman, Iacono, et al., 1997). Approximately one fourth to one third of biological parents of children with $\mathrm{AD} / \mathrm{HD}$ are affected by $\mathrm{AD} / \mathrm{HD}$ themselves, suggesting a significant genetic component (Barkley, 1998). Twin studies have found that monozygotic twins of $\mathrm{AD} / \mathrm{HD}$ children are at greater risk for $\mathrm{AD} / \mathrm{HD}$ than dizygotic twins (Goodman \& Stevenson, 1989; Sherman, McGue, \& Iacono, 1997; Lopez, 1965). Also, the adoptive relatives of $\mathrm{AD} / \mathrm{HD}$ children are less likely to have $\mathrm{AD} / \mathrm{HD}$ than are the biological relatives of AD/HD children (Cantwell, 1975; Morrison \& Stewart, 1973).

Faraone, et al. (1993) in a study of $140 \mathrm{AD} / \mathrm{HD}$ children, 120 normal controls, and 303 siblings provided further support for a familial basis for AD/HD. Epstein, et al. (2000) also supported prior research on the familial basis of AD/HD. In a study of 579 parents of $\mathrm{AD} / \mathrm{HD}$ children, their results showed significantly greater rates of $\mathrm{AD} / \mathrm{HD}$ symptomatology (i.e. inattention, cognitive impairment, hyperactivity, impulsivity, emotional lability, and restlessness) in parents of $\mathrm{AD} / \mathrm{HD}$ children as compared to those of non-AD/HD children.

Subsequently, in a study of $140 \mathrm{AD} / \mathrm{HD}$ patients and 122 non-AD/HD comparison subjects, rates of $\mathrm{AD} / \mathrm{HD}$ were higher in relatives of $\mathrm{AD} / \mathrm{HD}$ subjects than in non- $\mathrm{AD} / \mathrm{HD}$ subjects. These authors concluded that the familial transmission of $\mathrm{AD} / \mathrm{HD}$ and comorbid disorders is consistent between boys and girls with $\mathrm{AD} / \mathrm{HD}$ (Faraone, Biederman, \& Monuteaux, 2000). This is consistent with other studies which support a genetic basis of AD/HD (Biederman, Faraone, Keenan, Knee, \& Tsuang, 1990; Faraone, Biederman, \& Milberger, 1994; Pauls, 1991). Likewise, many other authors contend that the genetic contributions to $\mathrm{AD} / \mathrm{HD}$ are comparable in males and females (Faraone \& Biederman, 1994; Sharp, et al., 1999). 
Some researchers contend that $\mathrm{AD} / \mathrm{HD}$ etiological factors may not differ between genders since they show similar presentations in the disorder (Biederman, et al., 1994). Other researchers have attempted to develop an etiologic model of $\mathrm{AD} / \mathrm{HD}$ that explains evidence that the disorder is more prevalent among boys compared with girls. Two theoretical models that were developed to explain the preponderance of $\mathrm{AD} / \mathrm{HD}$ in males include the polygenetic multiple-threshold model (PMT) and the constitutional variability model (CV).

The PMT model (Carter, 1969; DeFries, 1989) purports that individual genetic and/or environmental characteristics combine to form a vulnerability to AD/HD. According to this model, in order to meet the diagnosis of $\mathrm{AD} / \mathrm{HD}$, one must meet a certain threshold. Consequently, girls are less likely to have $\mathrm{AD} / \mathrm{HD}$, so they must have a higher threshold, a higher genetic loading for the disorder, and a greater incidence of the disorder in their families. In turn, families of $\mathrm{AD} / \mathrm{HD}$ individual would also have an elevated level of the genes and/or environmental characteristics needed to develop the disorder. A lower prevalence is thus due to a higher threshold, which would predict that females who are diagnosed with $\mathrm{AD} / \mathrm{HD}$ have a more severe form of the disorder. This explains the lower prevalence among girls because, unlike boys, girls will not become ill with fewer pathogenic genes.

According to PMT, increased intellectual impairment in girls with $\mathrm{AD} / \mathrm{HD}$ is due to a relatively higher threshold to insult. This protects some girls from the condition, but those girls that do become affected have more severe presentations of symptoms because insults must be substantial to cross the threshold (DeFries, 1989). 
This etiological research suggests polygenic transmission as a possible genetic model. If the genetic model is the same in males and females and multiple genes are involved in the genetic predispositon, the higher rates of males with the disorder indicate that females with the disorder have a higher threshold for the expression of the phenotype, carrying more genes responsible for hyperactivity. Hyperactivity in females is located at a higher threshold point which suggests that females would be expected to have a greater genetic loading than males for the disorder since more genes would be required for the expression of the phenotype. The sex-related multiple threshold model would predict that females might have a more severe form of the disorder, and therefore a more unfavorable outcome than males, and that the prevalence of hyperactivity, as well as other disorders that may be related to it, should be greater among family members of affected females compared to affected males (Kashani, et al., 1979).

In a literature review by Eme (1992), some support was given for the finding that the sex less frequently afflicted by a disorder is the relatively more severely afflicted. Thus, females diagnosed as having $\mathrm{AD} / \mathrm{HD}$ would need to demonstrate extreme levels of behavior to receive an $\mathrm{AD} / \mathrm{HD}$ diagnosis, which has been found by some researchers (Nolan, et al., 1999). This is consistent with the contention that even though males are more frequently afflicted with neurodevelopmental disorders, when such conditions arise in the female, a more severe form is usually manifest (Gualtieri and Hicks, 1985).

Alternately, the $\mathrm{CV}$ model contends that boys with $\mathrm{AD} / \mathrm{HD}$ are subject to more genetic variability (James \& Taylor, 1990). They might be affected more frequently than girls because their relatively slower development results in a longer period of susceptibility to neurological damage (James \& Taylor, 1990). In this regard, boys are 
notably more susceptible to prenatal, perinatal, and postnatal insults to the developing brain. In contrast to the PMT theory, this would result in a greater prevalence for the disorder in relatives of males than females with the disorder.

There is some support for a multiple threshold explanation of sex differences in hyperactivity. For instance, Kashani, et al. (1979) reported a higher prevalence of psychiatric disorder among the parents of 28 hyperactive girls than among the parents of 28 hyperactive boys. In their investigation, they found psychiatric illness in the parents of $64 \%$ of girls with $\mathrm{AD} / \mathrm{HD}$ compared with only $28 \%$ of boys with $\mathrm{AD} / \mathrm{HD}$.

In contrast, other researchers found that relatives of $\mathrm{AD} / \mathrm{HD}$ girls did not have higher rates of $\mathrm{AD} / \mathrm{HD}$ than relatives of $\mathrm{AD} / \mathrm{HD}$ boys (Faraone, Biederman, \& Monuteaux., 2000; Gjone, Stevenson, \& Sundet, 1996; James \& Taylor, 1990; Rhee, Waldman, Hay, \& Levy, 1999).as found by others (Biederman, Newcorn, \& Sprich, 1991). Additionally, an investigation by Arcia and Conners (1998) failed to provide support for the PMT model. Although gender differences were not found in this study, confidence in these results is limited due to the use of mostly males relative to females in their sample. In an investigation of gender-related differences in hyperactive children, Mannuzza and Gittelman (1984) showed that hyperactive boys tended to have a less favorable outcome than hyperactive girls, but these researchers failed to find a higher prevalence of psychopathology among the parents of girls. The sample used in this analysis, which consisted of 12 hyperactive girls, 24 hyperactive boys, and 24 male controls, however, was too small to significantly support their findings. James and Taylor (1990) showed some support for the CV model, but 
additional studies do not support the conclusions of either model (Bhatia, et al. 1991; Faraone, et al., 1991). For example, in a study of girls with DSM-III attention deficit disorder, Faraone, et al. (1991) documented the same patterns of comorbidity and familiality in girls that had been observed in boys. The results of these studies, which suggest that $\mathrm{AD} / \mathrm{HD}$ is as familial in boys as it is in girls, correspond with the findings from twin studies (Gjone, et al., 1996; Rhee, et al., 1999). Because both hypotheses predict higher rates of $\mathrm{AD} / \mathrm{HD}$ among relatives of girl probands, both are weakened by studies that do not confirm this prediction. In their follow-up study of 12 girls with AD/HD, Mannuzza and Gittelman (1984) found that the parents of boy probands were at a nonsignificantly higher risk for $\mathrm{AD} / \mathrm{HD}(33 \%$ vs. $9 \%)$, conduct disorder ( $5 \%$ vs. $0 \%)$, and antisocial personality (14\% vs. $9 \%$ ) compared with the parents of girls probands. Faraone, et al. (1991) found no differences in the risk for DSM-III-defined ADD between relatives of boy and girl probands with ADD (25\% vs. $20 \%)$. Both types of families also had similarly increased risks for antisocial, affective, and anxiety disorders. The only differences were the higher risk for alcohol dependence among relatives of boys with add and the higher risk for school dysfunction among relatives of girls with ADD. Similarly, Silverthorn, et al. (1996) evaluated both theoretical models to determine whether girls would demonstrate a more severe form of $\mathrm{AD} / \mathrm{HD}$ and found that boys and girls appeared similar.

Overall, most of the evidence suggests that there are no marked sex differences in the correlates of $\mathrm{AD} / \mathrm{HD}$. There do not appear to be different etiological pathways to the disorder in boys and girls nor does it appear to be the case that girls require a "larger dose" of risk factors than boys to have the disorder (McGee \& Feehan, 1991). According 
to Faraone, Biederman, \& Monuteaux (2000), additional research is needed to assess the "familial dose" model because its rejection would point $\mathrm{AD} / \mathrm{HD}$ researchers to nonfamilial environmental events as the cause of the differing prevalence of $\mathrm{AD} / \mathrm{HD}$ between genders.

\section{Neurological}

Current evidence indicates that deficits in behavioral inhibition and sustained attention are central features of $\mathrm{AD} / \mathrm{HD}$ (Consensus Statement on $\mathrm{AD} / \mathrm{HD}, 2002)$. Seidman, et al. (1997) found that neuropsychological performance on tests of executive function was less impaired than that previously documented in boys with $\mathrm{AD} / \mathrm{HD}$. They concluded that gender differences exist in the biological features of $\mathrm{AD} / \mathrm{HD}$ in that girls with $\mathrm{AD} / \mathrm{HD}$ may not have executive deficits, may be less vulnerable to such deficits, or may have a form of executive function deficits that differs from that for boys (Seidman, et al., 1997).

The primary deficits in this disorder have been linked through numerous studies to certain brain regions, including the frontal lobe, basal ganglia, and the cerebellum (NIH, 2000). In a study investigating brain metabolism in female adolescents with $\mathrm{AD} / \mathrm{HD}$, Ernst, et al. (1994) suggested significant brain dysfunction for $\mathrm{AD} / \mathrm{HD}$ girls but not boys due to the existence of lower cerebral glucose metabolism in the brains of females with $\mathrm{AD} / \mathrm{HD}$ as compared to males. These authors concluded that this may reflect the greater severity of the disorder in females.

The cause of $\mathrm{AD} / \mathrm{HD}$ could be related to dysfunction in neural pathways and insufficient amounts of dopamine (Nadeau, Littman, \& Quinn, 1999). A dopamine 
transmitter gene (DAT-1) and a dopamine receptor gene (DRD-4), among others, have been linked to $\mathrm{AD} / \mathrm{HD}$ children and families (Elia, Ambrosini, \& Rapoport, 1999). Another study suggests that sex differences in the prevalence of AD/HD may be a result of sex differences in dopamine receptor density (Andersen \& Teicher, 2000). In male rats, striatal dopamine D2 receptor density increases $144 \%$ during the onset of puberty, whereas the increase in females is only $31 \%$. This evidence suggests that, before and during puberty, boys have an overproduction of dopamine receptors, which may explain hyperactivity and motor dysfunction. This higher level parallels the early developmental appearance of motor symptoms of $\mathrm{AD} / \mathrm{HD}$ and may explain why prevalence rates are 2 to 4 times greater in boys than girls. This receptor density is reduced by $55 \%$ by adulthood (Andersen \& Teicher, 2000), which can explain remitting hyperactivity. Girls, on the other hand, seem protected until puberty, when an increase in estrogen leads to an increase in dopamine receptors, and, subsequently, symptoms of AD/HD.

\section{Environment}

Environmental factors also appear to contribute to the occurrence of $\mathrm{AD} / \mathrm{HD}$, including complications of pregnancy and deliver, diet, and lead exposure. In an investigation of the association of the quality of the family environment with adhd symptomatology in 233 male and female adolescents, no relationship was found (Rey, Walter, Plapp, \& Denshire). Others contend that environmental factors, such as poor parenting or educational practices, do not cause AD/HD but may increase the severity of symptoms (Barkley, 1990). 
Gender differences in levels of internalizing symptomatology may be explained by differing experiences of adolescent boys and girls, including differential treatment by parents (Nadeau \& Quinn, 2002; Nolen-Hoeksema \& Girgus, 1994; Petersen, et al., 1991). Results of a study by Battle and Lacey (1972) found that mothers of overactive boys were critical, disapproving, unaffectionate, and severe in their punishment. These behaviors were not found in the mothers of overactive girls in this study. Psychosocial adversity may also predispose a child to the development of AD/HD (Markowitz, Straughn, \& Patrick., 2003) and may contribute to greater symptom severity (Scahill, et al., 1999).

Another explanation could be that sociocultural or social learning factors play a role. Huselid and Cooper (1994), in a random sample of 2013 adolescents, indicated that gender roles significantly mediate sex differences in internally directed psychological distress or internalizing problems and in externally directed deviant behavior or externalizing problems. Conventional gender role attitudes were positively related to externalizing problems among male adolescents, but were unrelated to pathology among female adolescents. The tendency for men to externalize and women to internalize distress is consistent with cultural gender role norms. This study tests the assumption that internalizing and externalizing problems are alternative manifestations of distress and are consistent with stereotypical norms for males and females. These finding support the contention of others that differential socialization, including gender-specific biases and expectations, of young men and women at least partially explains specific gender-linked vulnerabilities to the experience and/or expression of symptoms (Nadeau \& Quinn, 2002). 


\section{$\underline{\text { Referral Source }}$}

In addition to PMT and CV theories which attempt to account for the differences in prevalence among males and females, it is also possible that the gender differences previously identified are a result of an identification bias. The difference between males and female prevalence among clinical and epidemiologic samples suggest that a substantial number of girls are not being referred. In addition, the proportion of females who seek treatment for $\mathrm{AD} / \mathrm{HD}$ symptomatology rises considerably in adulthood, when self-referral is the norm. One possibility is that girls with milder presentations of symptoms are not referred as often as boys, which would result in relatively greater severity of symptoms among diagnosed $\mathrm{AD} / \mathrm{HD}$ girls, because those with more moderate $\mathrm{AD} / \mathrm{HD}$ would not be referred (Arcia \& Conners, 1998).

Gaub and Carlson (1997b) noted that differences between boys and girls were mainly a function of the referral source, with more similarities being evident when clinical populations are used. They found a tendency for greater severity of inattention among females in a clinically referred sample. However, this pattern was not evident among nonreferred children. Among children with $\mathrm{AD} / \mathrm{HD}$ identified from nonreferred populations, girls with $\mathrm{AD} / \mathrm{HD}$ displayed lower levels of inattention, less internalizing behavior, and less peer aggression than boys with $\mathrm{AD} / \mathrm{HD}$. However, girls and boys with $\mathrm{AD} / \mathrm{HD}$ identified from clinic-referred samples did not differ in level of impairment on these variables. Since girls referred to clinics were as impaired as their male counterparts, the authors concluded that girls with $\mathrm{AD} / \mathrm{HD}$ seen in treatment setting represented the most severely affected of the girls with $\mathrm{AD} / \mathrm{HD}$. Barkley (1989) agrees, contending that 
discrepant findings regarding gender differences are primarily attributable to the population used in the research. This is consistent with other research that indicates that only half of the children with the inattentive type are referred for clinical evaluation and treatment (Gaub \& Carlson, 1997b).

\section{$\underline{\text { Treatment }}$}

\section{Introduction}

In a large and comprehensive examination of current trends in the treatment of AD/HD, Olfson, Gameroff, Marcus, and Jensen (2003) analyzed data from the 1987 National Medical Expenditure Survey and the 1997 Medical Expenditure Panel Survey. They discovered that there was an increase in treatment of $\mathrm{AD} / \mathrm{HD}$ in children ages 3 to 18 from $.9 \%$ in 1987 to $3.4 \%$ in 1997 , with lower rates noted in ethnic and racial groups. According to these authors, these increases may be attributed to several factors. First, in 1991, the U.S. Department of Education enacted regulations that specifically recognized that students with $\mathrm{AD} / \mathrm{HD}$ could be considered disabled and therefore eligible for special education services. This, in turn, may have helped to increase the recognition of $\mathrm{AD} / \mathrm{HD}$ within schools. In addition, the growth of school-based health clinics and the growth in the popularity of easily administered instruments for assessing behavior problems may have promoted recognition and treatment of $\mathrm{AD} / \mathrm{HD}$. Accordingly, inclusion of $\mathrm{AD} / \mathrm{HD}$ as a disabling condition that may make a child eligible for special education services has resulted in the increased screening, assessment, and ultimate diagnosis of the disorder (Kamphaus, Petoskey, \& Rowe, 2000). Moreover, a growing public awareness of AD/HD may have also played a role in the increase in $\mathrm{AD} / \mathrm{HD}$ treatment. This greater awareness 
may have been largely attributable to the growth of $\mathrm{AD} / \mathrm{HD}$ support and advocacy groups. In the 1980's, two large national advocacy organization, Children and Adults with $\mathrm{AD} / \mathrm{HD}$ (CHADD) and the Attention Deficit Disorder Association (ADDA) began holding annual meetings.

Regardless of the negative consequences of this disorder, recent studies have indicated that a large percentage of affected children do not receive the necessary and appropriate services (Hudziak, et al., 1998; Szatmari, Offord, et al., 1989), with some studies indicating that less than half of those with AD/HD receive treatment (Barkley, 2002). In addition, recent trends indicate that children treated for $\mathrm{AD} / \mathrm{HD}$ tended to receive fewer visits but more complex medication regimens, with growth of managed behavioral health being a possible explanation for this recent decline in visits per treatment episode (Olfson, et al., 2003).

Unfortunately, girls may be at particularly increased risk of being undetected and untreated (Cantwell, 1996). For instance, the majority of participants in a study of 1629 adolescent females with severe forms of the three DSM-IV subtypes of AD/HD did not receive treatment (Hudziak, et al., 1998). Likewise, in an exploration of AD/HD risk factors with 1615 elementary school children, it was determined that even though $88 \%$ of the sample were recognized as having $\mathrm{AD} / \mathrm{HD}$ problems, only $39 \%$ had been evaluated, $32 \%$ received an $\mathrm{AD} / \mathrm{HD}$ diagnosis, and $23 \%$ were currently receiving treatment. The rates of boys were 5 times the rate of girls of being assessed, diagnosed, and treated. The authors added that this was evident even though parents equally recognized $\mathrm{AD} / \mathrm{HD}$ difficulties in males and females (Bussing, Zima, Gary, \& Wilson-Garvan, 2003). 
Effective healthcare interventions for $\mathrm{AD} / \mathrm{HD}$ exist, and, if properly treated, core symptomatology can be ameliorated or normalized, reducing the negative impact of the disorder on the individual, their families, and society. The successful management of $\mathrm{AD} / \mathrm{HD}$ begins with an accurate diagnosis. Moreover, the most effective treatment should take into consideration co-occurring disorders and problems.

\section{Assessment and Diagnosis}

Current guidelines for the diagnosis and evaluation of $\mathrm{AD} / \mathrm{HD}$ were suggested by the American Academy of Pediatrics. (2000). These include the use of specific criteria for the diagnosis using DSM-IV criteria, the importance of assessing symptomatology in more than one setting, and investigating the incidence of co-occurring conditions that may be present. In addition, psychological testing is a valuable tool in the assessment of

this disorder. Psychological evaluation or consultation that includes psychological testing is an empirically proven, highly reliable and valid, and descriptive diagnostic procedure for the assessment of a child suspected of having AD/HD (Root \& Resnick, 2003).

Numerous authors have provided guidelines for conducting AD/HD evaluations, both for comorbid psychiatric disorders in general (Achenbach, 1995; American Academy of Child and Adolescent Psychiatry, 1997; Cantwell, 1996; Caron \& Rutter, 1991; Kube, Petersen, \& Palmer, 2002) and for comorbid disruptive behavior problems, specifically (Biederman, Newcorn, \& Sprich, 1991; Jensen, et al., 1997).

\section{$\underline{\text { Pharmacological }}$}

In a summary of the use of medications in treating children with $\mathrm{AD} / \mathrm{HD}$, Kollins, 
Barkley, \& DuPaul (2001) delineated three of the most commonly used approaches: pharmacological, behavioral/psychosocial, and a combination. Although multimodal treatment approaches that integrate drug therapy with psychotherapeutic, environmental, education, and school-based interventions are advocated, pharmacotherapy remains the mainstay treatment for AD/HD (Conners, March, Frances, Wells, \& Ross, 2001; NIH, 2000; Robison, et al., 2002). This is primarily due to the successful outcomes found with the use of pharmacological interventions, particularly psychostimulants (Wolraich, 2003), with some researchers demonstrating approximately $70 \%$ of their $\mathrm{AD} / \mathrm{HD}$ patients being found to be responsive to treatment with stimulant medications, such as methylphenidate, dextroamphetamine, and pemoline, in the short term (Elia, et al., 1999). The current evidence suggests that the younger, more inattentive, less coordinated, more hyperactive, less anxious, and less intellectually delayed a child may be, and the better the parental management and involvement in care of the child, the better the response to stimulant treatment (Kollins, et al., 2001).

Overwhelmingly, psychostimulants are the most widely researched and are used more than any other class of drug to treat AD/HD (Kollins, et al., 2001; Kube, Petersen, \& Palmer, 2002; Markowitz, et al., 2003; NIH, 2000; Wolraich, 2003), particularly methylphenidate. Methylphenidate (Ritalin) is the generic or chemical name for the drug Ritalin. It is the most commonly prescribed stimulant for $\mathrm{AD} / \mathrm{HD}$ and has been demonstrated to be effective for a wide range of problem behaviors. Immediate release MPH has been in clinical use for approximately 50 years and has long been established as the reference standard in the pharmacotherapy of $\mathrm{AD} / \mathrm{HD}$. Conventional sustained-release mph formulations became available in the 1980's to offer the convenience of once-daily 
dosing, while avoiding compliance, confidentiality, and storage security issues. However, sustained release mph was not viewed as an optimal dosage formulation nor was it widely embraced by clinicians. Hence, a new generation once-daily MPH formulation has emerged since 2000 including Concerta, Ritalin LA, Metadate CD, and Focalin (Markowitz, et al., 2003).

Dextroamphetamine, the generic name for the drug Dexedrine, also has been shown to be effective for a range of behavior problems associated with AD/HD. Adderall is the trade name for a generic compound of mixed amphetamine salts. It has become available for use with $\mathrm{AD} / \mathrm{HD}$ relatively recently compared to the other stimulants and has a comparable effectiveness to Ritalin. Pemoline is the generic name for the drug Cylert, and is typically used either when children do not respond to other stimulants or when multiple daily dosing is an issue. Other drugs that are less commonly used to manage symptoms associated with $\mathrm{AD} / \mathrm{HD}$ include tricyclic antidepressants, Selective serotonin-reuptake inhibitors (SSRI's), other antidepressants, and antihypertensive drugs.

The longest systematic study of the use of medication with children who have $\mathrm{AD} / \mathrm{HD}$ noted continued clinical benefits 14 months after initiating treatment (MTA, 1999). Furthermore, other studies have noted that the use of stimulant medication may have long-term protective effects against the development of other kinds of problems such as substance abuse (Biederman, et al., 1999).

Due to a dearth of randomized, controlled medication trials in girls with $\mathrm{AD} / \mathrm{HD}$, it is currently unclear whether response rates to medications for $\mathrm{AD} / \mathrm{HD}$ are similar in males and females. In two small studies, it was found that no differences existed between boys and girls in response to methylphenidate (Barkley, 1989; Pelham, et al., 1989). 
Barkley (1989) found that the effects of methylphenidate on interactions between mother and child were the same on 31 measures during free play and set tasks of hyperactive boys and girls. Pelham, et al. (1989) examined the effects of stimulant medication on prosocial behaviors, classroom behaviors, and academic performance tasks in boys and girls showing $\mathrm{AD} / \mathrm{HD}$ behaviors. Medication effects were comparable for both sexes. Likewise, Sharp, et al. (1999) compared 42 girls with AD/HD, combined type with 56 previously studied boys with $\mathrm{AD} / \mathrm{HD}$ on comorbid diagnosis, behavioral ratings, psychological measures, psychiatric family history, and stimulant drug response. They concluded that girls with $\mathrm{AD} / \mathrm{HD}$ were comparable to boys on all measures and responded equally well to methylphenidate and dextroamphetamine.

The MTA study demonstrated that carefully conducted medication and behavioral treatments are effective for girls with $\mathrm{AD} / \mathrm{HD}$ as well as boys, and making sure that a higher percentage of girls with $\mathrm{AD} / \mathrm{HD}$ receive such treatments is an important public health issue (MTA, 1999).

Behavioral/Psychosocial treatments

A variety of psychosocial treatment interventions for $\mathrm{AD} / \mathrm{HD}$ exist, including behavior modification, clinical behavior training, parent training, social skills training, and cognitive-behavioral treatment. These interventions are generally administered in the home or school and those that use rewards and consequences appear to be the most successful (Markowitz, et al., 2003). This is particular important with $\mathrm{AD} / \mathrm{HD}$ females, in which needed attention to coexisting difficulties are not addressed. This is especially likely when a primary care physician is the sole treatment providers due to the fact that 
they may be less attentive to a child's overall emotional and behavioral functioning in their evaluations, and may tend to rely on medication treatment alone when other interventions may also be needed.

Cognitive-behavioral family-based intervention did not significantly change level of symptomatology with a group of clients with comorbid $\mathrm{AD} / \mathrm{HD}$ and anxiety (Costin, et al., 2002). This is consistent with the majority of evidence that suggests that cognitivebehavioral treatments are not beneficial in managing $\mathrm{AD} / \mathrm{HD}$ symptomatology $(\mathrm{NIH}$, 2000).

The empirical evidence supports a behavioral-psychosocial treatment for $\mathrm{AD} / \mathrm{HD}$ children with mild to moderate symptomatology, for children of preschool age, for children with comorbid internalizing disorders, and for children with social skills deficits (Root \& Resnick, 2003). A mediation-only approach has empirical support for the core symptoms of $\mathrm{AD} / \mathrm{HD}$, but a behavioral-psychosocial or combined approach is more effective for dealing with the various comorbid problems that a large proportion of children with $\mathrm{AD} / \mathrm{HD}$ have, and to enhance treatment compliance (Root \& Resnick, 2003). In addition, a combined behavioral-psychosocial and medication approach is more appropriate for more severe $\mathrm{AD} / \mathrm{HD}$ symptomatology, when there are comorbid externalizing problems when there is serious family discord caused by $\mathrm{AD} / \mathrm{HD}$ symptoms, when a rapid response is needed, and when problems related to mental retardation, reading achievement, or central nervous system are present (Root \& Resnick, 2003). Overall, including an ongoing behavioral-psychosocial treatment component in the treatment of children with $\mathrm{AD} / \mathrm{HD}$ will lead to increased treatment compliance and to the child more quickly developing effective behavioral-psychosocial skills. A combined 
behavioral-psychosocial and medication approach allow significantly lower doses of medication than a mediation-only approach in achieving treatment outcomes, thus minimizing side effects (Root \& Resnick, 2003).

The Multimodal Treatment Study of Children with AttentionDeficit/Hyperactivity Disorder (MTA) was the largest treatment study of AD/HD ever conducted. This investigation was a cooperative treatment study performed by six independent research teams in collaboration with the staff of the Division of Clinical and Treatment Research of the National Institute of Mental Health (NIMH) and the Office of Special Education Programs (OSEP) of the U.S. Department of Education (DOE). In this 14-month, randomized clinical trial, 579 children between the ages of 7 and 10 with $\mathrm{AD} / \mathrm{HD}$ Combined Type were studied. The goal of this study was to compare the effectiveness of carefully conducted medication treatment, intensive behavioral treatment, the combination of mediation and behavioral treatment, and typical treatment for $\mathrm{AD} / \mathrm{HD}$ in the community. The study demonstrated that children receiving medical management or combined treatment had significantly greater improvement in hyperactive-impulsive symptoms than those receiving either behavioral treatment alone or community-based treatment. Symptomatic improvement differences between those receiving only medical treatment and those receiving combined treatment were not statistically significant. Medication was found to be superior to behavioral treatment on core $\mathrm{AD} / \mathrm{HD}$ symptoms such as inattention and hyperactivity, but there were no significant differences in other areas of the client's functioning such as oppositional behavior, peer relations, and academic achievement. However, those subjects with a cooccurring anxiety disorder did as well with behavioral intervention alone as they did with 
medication and combined treatment, which is consistent with other evidence that $\mathrm{AD} / \mathrm{HD}$ with comorbid anxiety is less responsive to psychostimulant medication (Vance \& Luk, 1998). No meaningful differences were found with relation to gender, preexisting medication history, or coexisting behavioral disorders. However, generalizations are limited due to the fact that girls made up only about 20 percent of the sample. In sum, the MTA study clearly demonstrated the benefits of pharmacotherapy in $\mathrm{AD} / \mathrm{HD}$ for a continued period. This project demonstrated that, compared to standard community-based care and a structured behavioral intervention, a carefully managed protocol of stimulant medication or a combination of medication and behavioral intervention leads to the greatest reduction in $\mathrm{AD} / \mathrm{HD}$ symptoms across participants for a continued period of time (MTA, 1999).

Jensen, et al. (2001) compared treatment outcomes for the 4 different groups from the MTA study and found that those AD/HD children with comorbid difficulties showed differences in both symptom presentations and treatment responses. Specifically, children with $\mathrm{AD} / \mathrm{HD}$ and an anxiety disorder were more likely to have academic problems and be diagnosed with a learning disability. In the children with $\mathrm{AD} / \mathrm{HD}$ and an anxiety disorder, behavioral treatment resulted in similar treatment gains as compared to medication. Conversely, in children with $\mathrm{AD} / \mathrm{HD}$ alone or $\mathrm{AD} / \mathrm{HD}$ and $\mathrm{ODD} / \mathrm{CD}$, the best treatment gains were seen with medication alone as compared to combined treatment or behavioral treatment alone.

This is consistent with other evidence that indicates that an intensive behavior therapy program delivered in school and home is not nearly as beneficial as methylphenidate for $\mathrm{AD} / \mathrm{HD}$, nor a combination of methylphenidate and behavioral 
therapy in a sample of 89 children (Klein \& Abikoff, 1997). These authors recommended the use of stimulants as a first line of treatment, and suggest the combined use of behavior therapy particularly when medication results are incomplete. Overall, there is a high level of concurrence between psychologists and psychiatrists in the use of psychostimulants as a first-line treatment, and psychosocial interventions as an adjunctive treatment in cases of those who do not wish to utilize pharmacotherapy methods, when comorbid conditions exist, or in cases when inadequate medication results are obtained (Conners, et al., 2001).

\section{Other Treatments}

Other interventions that have been used to address the problems related to $\mathrm{AD} / \mathrm{HD}$ include neurofeedback, dietary interventions, use of vitamins, herbs, and minerals, biofeedback, and perceptual stimulation. Neurofeedback training involves sessions in which a person watches their brainwaves on a computer screen as they occur. In this way, they can be taught to maintain a pattern of brainwave activity that is associated with an alert, focused, and attentive state. Monastra, Lubar, \& Linden (2001) conducted a study with 101 children and adolescents with $\mathrm{AD} / \mathrm{HD}$. All participants received stimulant medication, behavioral therapy, and school consultation services, with approximately half also received neurofeedback therapy. Those whose treatment also included neurofeedback showed greater improvement according to parent and teacher ratings. Fuchs, Birbaumer, Lutzenberger, Gruzelier, \& Kaiser. (2003) showed significant and comparable reductions in symptomatology when compared with stimulant medication. Results should be used with caution, however, since neither study used random 
assignment, measures of long-term outcome, nor did researchers account for the additional attention this study group received from therapists. Although patients who receive neurofeedback treatment appear to obtain some benefit, there is insufficient data to support its efficacy and regular use. 


\section{CHAPTER 3}

\section{METHODOLOGY}

\section{Introduction}

The purpose of this study was to examine the relationship between males and females with and without $\mathrm{AD} / \mathrm{HD}$ on measures of internalizing and externalizing behaviors. The current research utilized the Attention Deficit Disorder Evaluation Scale Second Edition (ADDES-2) and gender to predict internalizing and externalizing symptoms as measured by the Behavior Assessment System for Children (BASC). Data were archival in nature. All data were entered into the Statistical Package for the Social Sciences, Version 11.0 (SPSS 11.0) and analyzed using multiple regression procedures.

\section{Participants}

Participants for this study included children and youth ages 6 to 16. Females made up $42 \%$ of the sample $(n=74)$, and males made up $58 \%$ of the sample $(n=104)$. The sample was $83 \%$ Caucasian $(n=149), 10 \%$ African American $(n=17), 7 \%$ other $(n=$ 13). The referral sources were varied, and included pediatricians, school, mental health professionals, and self. 


\section{Procedures}

Archival data from children referred to a clinic for psychoeducational assessment was used. Subjects were referred to the clinic by parents, school personnel, and/or mental health practitioners in order to assess behavioral, academic, and emotional disturbances. Assessment batteries were conducted by masters and doctoral level persons under the direct supervision of a licensed psychologist. Each subject was administered the same basic battery of assessment instruments, with additional instruments added at the discretion of the test administrator. Upon completion, all testing information was entered into the Statistical Package for the Social Sciences, Version 11.0 (SPSS 11.0). The data set was composed of cases where the parents or guardian had agreed to allow the use of case material without identifying information for research purposes. Missing data caused some files to be unusable, so these cases were eliminated from the analysis.

\section{$\underline{\text { Instrumentation }}$}

$\underline{\text { BASC }}$

It has been shown that children, particularly those who are 10 and over, can reliably report on their behavior, with reliability of these report increasing incrementally with age (Edwards, Schultz, \& Long, 1995). In addition, children are more reliable in reporting on internalizing symptoms, such as anxiety and mood symptoms, than on externalizing symptoms such as aggressive behavior. Subsequently, the level of agreement on symptoms between teachers and parents is often relatively low and may represent differences other than the presence of core symptoms (Barkley, 1998), even 
though studies provide evidence of the correlation of teacher ratings with a variety of validating measure, including clinician ratings (Schachar, et al., 1986).

Teacher ratings are often viewed as "indicative of functioning in the school environment and are, thus, an important component in the assessment process" (Barkley, 1989). Reid, et al. (2000) concluded in their analysis of gender and ethnic differences in $\mathrm{AD} / \mathrm{HD}$ as assessed by behavior ratings that gender has a significant effect on teacher rating of $\mathrm{AD} / \mathrm{HD}$ symptoms, $\mathrm{F}(18,3310)=12.66, \mathrm{p}<.01$. Abikoff, et al. (1993) reported that halo effects, which inflate behavior rating scale scores, can occur when teachers rate students with oppositional behaviors. Similar findings have been reported by Schachar, et al. (1986) who contend that since males are more likely to demonstrate these types of behaviors, they would be more likely to be subject to halo effects and, thus, have spuriously higher ratings. Similarly, the correspondence of rating scales and direct observation of the child's behavior provides evidence of rating scale validity (Schachar, et al., 1986). In order to avoid drawbacks related to individual raters, it has been suggested by numerous researchers that multiple informants are required to accurately identify the symptoms of $\mathrm{AD} / \mathrm{HD}$, as was done in this study (Sherman, Iacono, et al., 1997). In addition, given the requirement by the DSM-IV AD/HD criteria that evidence of impairment occur in more than one setting, it is particularly important to obtain information from multiple sources, particularly teachers (Kamphaus \& Frick, 1996).

According to Brown (2000), the narrow-band rating scales are useful for documenting the situational pervasiveness of $\mathrm{AD} / \mathrm{HD}$ symptoms and conveniently provide information that may not be quantifiable in other ways. In addition, broad-band 
rating scales, which measure different behavior constructs including depression and anxiety, are useful for identifying comorbid disorders (Brown, 2000).

According to Kollins, et al. (2001), one of the specific instruments used to assess $\mathrm{AD} / \mathrm{HD}$ that is strongly recommended which is available in parent and teacher formats and are among the more widely used and is well standardized is the Behavior Assessment System for Children (BASC; Reynolds \& Kamphaus, 1992). The BASC is an empirically based system that is suitable for children ages 4 through 18. It consists of parent, teacher, and self rating scales along with a structured developmental history and observation form. The system provides measures of both problems and adaptive behaviors.

The BASC includes the Teacher Rating Scales (TRF), Parent Rating Scales (PRS), and a child or Self-Report of Personality (SRP), each available in multiple forms that correspond to the following age levels: preschool ( 4 to 5 ), child (6 to 11$)$, and adolescent (12 to 18). All subjects in the sample received all three versions of this instrument. The items on the teacher (TRS) and parent (PRS) version are rated on a 4point scale ranging from 0 (never) to 4 (almost always), whereas the child version (SRP) utilizes a true-false format. Normative scores for all BASC individual and composite scales are provided in the form of T-scores with a mean of 50 and a standard deviation of 10. In addition, the parent and teacher scales provide scores for over a dozen factors, including attention problems, hyperactivity, conduct problems, anxiety, and depression. Using these factors, the BASC yields T scores in broad internalizing and externalizing domains, which was a combination of the following scale: Externalizing Problems Composite (Aggression + Hyperactivity + Conduct Problems scales); Internalizing Problems Composite (Anxiety + Depression + Somatization). This instrument also 
includes items measuring adaptive behaviors and the items used to measure AD/HD have a high correlation with the DSM-IV diagnostic criteria for different subtypes (Kamphaus \& Frick, 1996).

According to Ostrander, Weinfurt, Yarnold, \& August (1998), the BASC has greater predictive and face validity than the CBCL and is more useful in making diagnostic decisions based on criteria presented in the DSM-IV. In addition, unlike the $\mathrm{CBCL}$, the BASC scales were created to represent content areas relevant to assessment and classification in clinical settings (DSM diagnostic categories). Furthermore, the BASC scales were developed such that each item contributes to only one scale, thus preserving the distinctiveness of the construct (Reynolds \& Kamphaus, 1992).

Reid, et al. (2000) advocate for the use of separate norms males and females to assess $\mathrm{AD} / \mathrm{HD}$ symptomatology with behavior rating scales. In contrast, Silverthorn and colleagues (1996) concluded that separate norms by gender were not warranted based on their finding that girls and boys with $\mathrm{AD} / \mathrm{HD}$ did not differ on measures of severity and that diagnostic cut-scores identified boys and girls with equivalent levels of impairment. They further argued that to use separate norms might artificially reduce the difference in prevalence rates for $\mathrm{AD} / \mathrm{HD}$ for boys and girls. Based on information provided in the manual for the BASC (Reynolds \& Kamphaus, 1992), for the standardization sample, males were rated one third to one half of a standard deviation higher than females on hyperactivity, attention problems, and other subscales. For this reason, the BASC manual includes separate norm tables for males and females, as well as a combined norm table, and recommends that the same-sex norms be used for clinical diagnosis in order to identify those children whose ratings are significant for both their age and gender. 
Referral sources included schools, mental health professionals, and self-referral. Clients were diagnosed by Master's level providers under the supervision of a doctoral level psychologist on the basis of symptoms ratings and of semi-structured clinical interviews. Parent and teachers completed their respective versions of the BASC. Children were also administered intelligence and achievement tests. Parents were interviewed to review symptomatology and to collect a developmental and family history.

\section{$\underline{\text { ADDES-2 }}$}

Many psychologists employ a self-reporting scale to aid in the diagnosis of $\mathrm{AD} / \mathrm{HD}$. The self-report scale that was used in the present research was The Attention Deficit Disorders Evaluation Scale - Second Edition (ADDES-2; McCarney, 1995 a, b). This scale was developed using the diagnostic criteria set forth in the DSM-IV (1994). The ADDES-2 has three versions: Home, School, and Self-Report. The Home (46-item) and School (60-item) versions were administered to all participants in the current study.

The ADDES-2 has been evaluated with large, nationally representative samples of youth, aged 4 to 18 years, for both the home $(n=2415)$ and school $(n=5797)$ versions. It was normed on both $\mathrm{AD} / \mathrm{HD}$ and non- $\mathrm{AD} / \mathrm{HD}$ males and females from all geographic areas of the United States. The ADDES-2 examines the frequency of AD/HD symptoms and yields a total score as well as subscale scores for hyperactivity, impulsivity, and inattention. Raw scores are transformed into standard scores. A standard score below 7 on the Inattentive and/or Hyperactive/Impulsive subscales of both the Home and School version is needed in order to reach statistical significance.

Since few studies are available regarding psychometric properties of this instrument, data regarding reliability and validity is based on the manual. The ADDES-2 manual indicates excellent internal consistency, test-retest, and interrater reliability, with coefficient alphas at the .95 or above level. Evidence of validity is also excellent (McCarney, 1995 a, b). According to a review by Collett, Ohan, and Myers (2003), the 
difference in items on the home and school versions of the ADDES-2 potentially allows more specific assessment across settings and increases ecological validity.

\section{$\underline{\text { Data Analysis }}$}

Multiple regression analysis was conducted to determine the relationship between $\mathrm{AD} / \mathrm{HD}$ and non-AD/HD males and females, as measured by home and school ADDES-2 ratings, on measures of internalizing and externalizing behaviors as rated by parent and teachers. Twelve equations were calculated, with the following subscales on the BASC used as dependent variables: Anxiety, Depression, Somatization, Aggression, Hyperactivity, and Conduct Problems. Five predictor variables were simultaneously entered into the regression equations. These variables included ADDES Home Inattention, ADDES Home Hyperactivity, ADDES School Inattention, ADDES School Hyperactivity, and gender. 


\section{CHAPTER 4}

\section{RESULTS}

\section{Introduction}

This chapter includes demographic information provided by the participants, along with correlations among the five predictor variables and dependent variables. In addition, the results of the statistical analyses used to test each of the research hypotheses are presented. To address the research questions, multiple regression analyses were conducted. A total of twelve equations were calculated, with the following standard scores used as dependent variables: Parent Anxiety, Teacher Anxiety, Parent Depression, Teacher Depression, Parent Somatization, Teacher Somatization, Parent Aggression, Teacher Aggression, Parent Hyperactivity, Teacher Hyperactivity, Parent Conduct Problems, and Teacher Conduct Problems. Variables used as predictor variables included Home Inattention, Home Hyperactivity, School Inattention, School Hyperactivity, and gender. The same procedure was used for each analysis.

\section{Descriptive Statistics}

A total of 178 subjects were selected for inclusion in this study. Demographic information for these subjects is presented in Table 1, which shows frequency distributions for gender and ethnicity of sample subjects. Most subjects (58\%) were male and were Caucasian in ethnicity ( $83 \%)$. Table 2 presents means and standard deviations for all ADDES-2 and BASC variables. 


\section{Table 1}

Gender and Ethnicity of the Sample Subjects $(N=178)$

N $\%$

Gender

$\begin{array}{lll}\text { Male } & 104 & 58\end{array}$

$\begin{array}{lll}\text { Female } & 74 & 42\end{array}$

Ethnicity

$\begin{array}{lll}\text { Caucasian } & 149 & 83\end{array}$

$\begin{array}{lll}\text { African American } & 17 & 10\end{array}$

$\begin{array}{lll}\text { Other } & 7 & 7\end{array}$




\section{Table 2}

Means and Standard Deviations for ADDES-2 and BASC Scale Variables

Variable $\quad \underline{\mathrm{M}} \quad \underline{\mathrm{SD}}$

ADDES Home

8.32

3.66

Inattention

ADDES Home

5.74

3.52

Hyperactivity

ADDES School

6.05

2.98

Inattention

ADDES School

3.55

3.06

Hyperactivity

BASC Parent

52.67

10.97

Anxiety

BASC Teacher

53.93

11.22

Anxiety

BASC Parent

52.96

13.93

Depression

BASC Teacher

49.62

9.21

Depression

BASC Parent

49.60

11.23

Somatization

BASC Teacher

51.29

11.99

Somatization

BASC Parent

50.57

11.63

Aggression

BASC Teacher

49.75

10.03

Aggression 
Table 2 (cont'd)

Means and Standard Deviations for ADDES-2 and BASC Scales

$\underline{\text { Variable }} \quad \underline{M} \quad \underline{\mathrm{SD}}$

$\begin{array}{lll}\text { BASC Parent } & 51.27 & 14.16\end{array}$

Hyperactivity

BASC Teacher

52.60

10.94

Hyperactivity

BASC Parent

52.42

13.34

Conduct Problems

BASC Teacher

49.02

7.75

Conduct Problems

Correlations among BASC variables and the predictor variables, ADDES-2 scales and gender, are provided in Tables 3 through 14. These Pearson correlations revealed significant relationships between many of the variables. The results indicated positive associations among all of the ADDES-2 variables, including Home Inattention, Home Hyperactivity, School Inattention, and School Hyperactivity. A significant positive relationship was also obtained between School Hyperactivity and gender, indicating that males had higher school hyperactivity ratings.

Significant relationships were found between BASC ratings and many of the ADDES scales. In addition, gender was also significantly correlated with BASC ratings. 
The relationships among ADDES scale scores, gender and the BASC ratings were fully explored in the regression analyses that addressed the research questions of this study.

\section{Table 3}

Correlations among Parent Anxiety Ratings and Five Predictor Variables

$$
\underline{\text { Variable }}
$$

$\begin{array}{llllll}1 & 2 & \underline{3} & \underline{4} & \underline{5} & \underline{6}\end{array}$

BASC Parent

Anxiety

ADDES Home

$.40 * * \quad--$

Inattention

ADDES Home

$.31 * * \quad .70^{* *} \quad--$

Hyperactivity

ADDES School

Inattention

ADDES School

Hyperactivity

Gender $(0=\mathrm{F}, 1=\mathrm{M})$

$.02 \quad .36^{* *} \quad .24 * * \quad--$

$\begin{array}{lllll}-.06 & .25 * * & .38^{* *} & .55^{* *} & --\end{array}$

${ }^{*} p<.05, * * p<.01$ 


\section{Table 4}

Correlations among Teacher Anxiety Ratings and Five Predictor Variables

$\begin{array}{llllllll}\text { Variable } & \underline{1} & \underline{2} & \underline{3} & \underline{4} & \underline{5} & \underline{6}\end{array}$

BASC Teacher

Anxiety

ADDES Home

.12

Inattention

ADDES Home

$.14 \quad .70^{* *} \quad--$

Hyperactivity

ADDES School

$.28 * * \quad .36^{* *} \quad .24 * * \quad--$

Inattention

ADDES School

$\begin{array}{lllll}-.18^{*} & .25^{* *} & .38^{* *} & .55^{* *} & --\end{array}$

Hyperactivity

Gender $(0=\mathrm{F}, 1=\mathrm{M})$

$\begin{array}{llllll}-.21 * & -.22 * * & -.19 * & -.22 * * & .05 & --\end{array}$

$* p<.05, * * p<.01$ 


\section{Table 5}

Correlations among Parent Depression Ratings and Five Predictor Variables

$\begin{array}{lllllll}\text { Variable } & \underline{1} & \underline{2} & \underline{3} & \underline{4} & \underline{5} & \underline{6}\end{array}$

BASC Parent

Depression

ADDES Home

$.49^{* *} \quad--$

Inattention

ADDES Home

$.56^{* *} \quad .70^{* *} \quad--$

Hyperactivity

ADDES School

$.05 \quad .36^{* *} \quad .24^{* *} \quad-$

Inattention

ADDES School

Hyperactivity

$\begin{array}{lllll}.15 & .25^{* *} & .38^{* *} & .55^{* *} & --\end{array}$

Gender $(0=F, 1=M)$

$\begin{array}{llllll}-.06 & -.22 * * & -.19^{*} & -.22 * * & .05 & --\end{array}$

${ }^{*} p<.05,{ }^{* *} p<.01$ 


\section{Table 6}

Correlations among Teacher Depression Ratings and Five Predictor Variables

$\begin{array}{llllllll}\text { Variable } & \underline{1} & \underline{2} & \underline{3} & \underline{4} & \underline{5} & \underline{6}\end{array}$

BASC Teacher

Depression

ADDES Home

Inattention

ADDES Home

Hyperactivity

ADDES School

Inattention

ADDES School

Hyperactivity

Gender $(0=\mathrm{F}, 1=\mathrm{M})$
.14

$.20^{*} \quad .70^{* *} \quad--$

$.23 * * \quad .36 * * \quad .24 * *--$

$\begin{array}{lllll}.42 * * & .25^{* *} & .38^{* *} & .55^{* *} & --\end{array}$

$\begin{array}{llllll}.05 & -.22 * * & -.19 * & -.22 * * & .05 & --\end{array}$

$* p<.05, * * p<.01$ 


\section{Table 7}

Correlations among Parent Somatization Ratings and Five Predictor Variables

$\begin{array}{lllllll}\text { Variable } & \underline{1} & \underline{2} & \underline{3} & \underline{4} & \underline{5} & \underline{6}\end{array}$

BASC Parent

Somatization

ADDES Home

$.32 * * \quad--$

Inattention

ADDES Home

$.34 * * \quad .70^{* *} \quad--$

Hyperactivity
ADDES School
$.07 \quad .36^{* *} \quad .24 * * \quad--$

Inattention
ADDES School
$\begin{array}{lllll}.07 & .25^{* *} & .38^{* *} & .55^{* *} & --\end{array}$
Hyperactivity

Gender $(0=F, 1=M)$

$\begin{array}{llllll}-.17^{*} & -.22 * * & -.19 * & -.22 * * & .05 & --\end{array}$

${ }^{*} p<.05,{ }^{* *} p<.01$ 


\section{Table 8}

Correlations among Teacher Somatization Ratings and Five Predictor Variables

Variable

BASC Teacher

Somatization

ADDES Home

Inattention

ADDES Home

Hyperactivity

ADDES School

Inattention

ADDES School

Hyperactivity

Gender $(0=\mathrm{F}, 1=\mathrm{M})$

$* p<.05, * * p<.01$

$.03 \quad--$

$.14 \quad .70 * * \quad-$

$.12 \quad .36^{* *} \quad .24 * * \quad-$

$\begin{array}{lllll}-.11 & .25 * * & .38 * * & .55^{* *} & --\end{array}$

$\begin{array}{llllll}-.20 * & -.22 * * & -.19 * & -.22 * * & .05 & --\end{array}$ 
Table 9

Correlations among Parent Aggression Ratings and Five Predictor Variables

$\underline{\text { Variable }}$

$\begin{array}{llllll}1 & \underline{2} & \underline{3} & \underline{4} & \underline{5} & \underline{6}\end{array}$

BASC Parent

Aggression

ADDES Home

$.46^{* *}--$

Inattention

ADDES Home

$.67 * * \quad .70^{* *} \quad--$

Hyperactivity

ADDES School

Inattention

$.14 \quad .36^{* *} \quad .24^{* *} \quad--$

ADDES School

Hyperactivity

$\begin{array}{lllll}.39 * * & .25 * * & .38 * * & .55^{* *} \quad--\end{array}$

Gender $(0=F, 1=M)$

$\begin{array}{llllll}.03 & -.22 * * & -.19 * & -.22 * * & .05 & --\end{array}$

${ }^{*} p<.05,{ }^{* *} p<.01$ 
Table 10

Correlations among Teacher Aggression Ratings and Five Predictor Variables

$\underline{\text { Variable }}$

$\begin{array}{llllll}1 & \underline{2} & \underline{3} & \underline{4} & \underline{5} & \underline{6}\end{array}$

BASC Teacher

Aggression

ADDES Home

$.06 \quad--$

Inattention

ADDES Home

Hyperactivity

ADDES School

Inattention

ADDES School

Hyperactivity

Gender $(0=\mathrm{F}, 1=\mathrm{M})$

$.21 * \quad .70^{* *} \quad--$

$.27 * * \quad .36 * * \quad .24 * * \quad--$

$\begin{array}{lllll}.71^{* *} & .25^{* *} & .38^{* *} & .55^{* *} & --\end{array}$

$.25 * * \quad-.22 * *$

$-.19 * \quad-.22 * * \quad .05$

$* p<.05, * * p<.01$ 


\section{Table 11}

Correlations among Parent Hyperactivity Ratings and Five Predictor Variables

$\underline{\text { Variable }}$

$\begin{array}{llllll}\underline{1} & \underline{2} & \underline{3} & \underline{4} & \underline{5} & \underline{6}\end{array}$

BASC Parent

Hyperactivity

ADDES Home

Inattention

$.58^{* *}--$

ADDES Home

$.78 * * \quad .70^{* *} \quad--$

Hyperactivity

ADDES School

Inattention

$.16 \quad .36^{* *} \quad .24^{* *} \quad--$

ADDES School

$\begin{array}{lllll}.35^{* *} & .25^{* *} & .38^{* *} & .55^{* *} & --\end{array}$

Hyperactivity

Gender $(0=\mathrm{F}, 1=\mathrm{M})$

$\begin{array}{llllll}-.04 & -.22 * * & -.19 * & -.22 * * & .05 & --\end{array}$

${ }^{*} p<.05,{ }^{* *} p<.01$ 


\section{Table 12}

Correlations among Teacher Hyperactivity Ratings and Five Predictor Variables

$\underline{\text { Variable }}$

$\begin{array}{llllll}1 & \underline{2} & \underline{3} & \underline{4} & \underline{5} & \underline{6}\end{array}$

BASC Teacher

Hyperactivity

ADDES Home

$.20^{*} \quad--$

Inattention

ADDES Home

$.36 * * \quad .70^{* *} \quad--$

Hyperactivity

ADDES School

$.39 * * \quad .36 * * \quad .24 * * \quad--$

Inattention

ADDES School

$\begin{array}{lllll}.81^{* *} & .25^{* *} & .38^{* *} & .55^{* *} & --\end{array}$

Hyperactivity

Gender $(0=F, 1=M)$

$.25 * *-.22 * *$

$\begin{array}{lll}-.19 * & -.22 * * & .05\end{array}$

${ }^{*} p<.05,{ }^{* *} p<.01$ 


\section{Table 13}

Correlations among Parent Conduct Problems Ratings and Five Predictor Variables

$\underline{\text { Variable }}$

$\begin{array}{llllll}1 & \underline{2} & \underline{3} & \underline{4} & \underline{5} & \underline{6}\end{array}$

\section{BASC Parent}

Conduct Problems

ADDES Home

Inattention

ADDES Home

$.55 * * \quad .70 * * \quad--$

Hyperactivity

ADDES School

$.21^{* *} \quad .36^{* *} \quad .24^{* *} \quad--$

Inattention

ADDES School

$\begin{array}{lllll}.36^{* *} & .25^{* *} & .38^{* *} & .55^{* *} & --\end{array}$

Hyperactivity

Gender $(0=\mathrm{F}, 1=\mathrm{M})$

$\begin{array}{llllll}.09 & -.22 * * & -.19 * & -.22 * * & .05 & --\end{array}$

${ }^{*} p<.05,{ }^{* *} p<.01$ 
Table 14

Correlations among Teacher Conduct Problems Ratings and Five Predictor Variables

$\underline{\text { Variable }}$

$\underline{1} \quad \underline{2} \quad \underline{3} \quad \underline{4} \quad \underline{5} \quad \underline{6}$

BASC Teacher

Conduct Problems

ADDES Home

$.15--$

Inattention

ADDES Home

$.22 * * \quad .70 * *$

Hyperactivity

ADDES School

$.34 * * \quad .36 * * \quad .24 * * \quad--$

Inattention

ADDES School

Hyperactivity

$\begin{array}{llllll}.55^{* *} & .25^{* *} & .38^{* *} & .55^{* *} \quad--\end{array}$

Gender $(0=\mathrm{F}, 1=\mathrm{M})$

$\begin{array}{lllll}.20 * & -.22 * * & -.19 * & -.22 * * & .05\end{array}$

${ }^{*} p<.05,{ }^{* *} p<.01$

\section{$\underline{\text { Regression Analyses }}$}

In total, 12 regression equations were calculated. They will be presented in pairs of six. For each BASC dependent variable, results are presented for parent ratings and for teacher ratings.

Parent Anxiety

For the dependent variable Parent Anxiety, the regression equation with five predictors was statistically significant, $F(5,137)=5.74, \mathrm{p}<.01$. The adjusted $\mathrm{R}^{2}$ for the 
equation was . 14 , indicating that the predictors accounted for $14 \%$ of the variance in the dependent variable. For the dependent variable Teacher Anxiety, the regression equation with five predictors was statistically significant, $F(5,135)=3.33, p<.01$. The adjusted $R^{2}$ for the equation was . 08 , indicating that the predictors accounted for $8 \%$ of the variance in the dependent variable.

\section{Table 15}

Regression Analysis for ADDES-2 and Gender Predicting Parent Anxiety Ratings and Teacher Anxiety Ratings

Variable $\quad$ BASC Parent Anxiety

$\underline{B} \quad \underline{\text { SEB }} \quad \underline{B}$

$.98 \quad .33$

$.24 \quad .34$

.08

Hyperactivity

ADDES School

$$
-.28
$$

.37

$-.08$

$.83 \quad .40$

$.22 *$

Inattention

ADDES School

$\begin{array}{lll}-.43 & .36 & -.12\end{array}$

Hyperactivity

Gender

$$
-2.97
$$

\section{BASC Teacher Anxiety}

$\underline{B} \quad \underline{\text { SEB }} \quad \underline{\beta}$

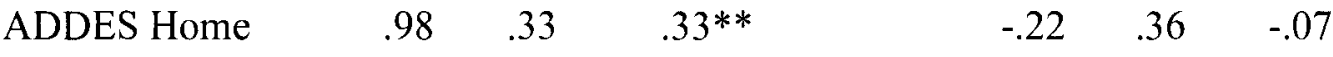

$-2.97 \quad 1.87 \quad-.14$

$* p<.05, * * p<.01$

Note: For BASC Parent Anxiety, $\mathrm{R}^{2}$ adjusted $=.14(\mathrm{~N}=143, p<.01)$

Note: For BASC Teacher Anxiety, $\mathrm{R}^{2}$ adjusted $=.08(\mathrm{~N}=142, p<.01)$ 
Table 15 shows the regression coefficients for the equations. As can be seen in the table, controlling for the other four predictor variables, there was a significant positive association between Home Inattention and Parent Anxiety. This result indicates that the greater the rating of inattention in the home environment, the higher the Parent Anxiety score. Another positive association occurred between School Inattention and Teacher Anxiety, indicating that the greater the rating of inattention at school, the higher the Teacher Anxiety score.

\section{Parent Depression}

For the dependent variable Parent Depression, the regression equation with five predictors was statistically significant, $F(5,139)=15.74, p<.01$. The adjusted $R^{2}$ for the equation was .34 , indicating that the predictors accounted for $34 \%$ of the variance in the dependent variable. For the dependent variable Teacher Depression, the regression equation with five predictors was statistically significant, $F(5,136)=5.82, p<.01$. The adjusted $\mathrm{R}^{2}$ for the equation was .15 , indicating that the predictors accounted for $15 \%$ of the variance in the dependent variable.

Table 16 shows the regression coefficients for the equations. As can be seen in the table, controlling for the other four predictor variables, there was a significant positive association between Home Inattention and Parent Depression. This result indicates that the greater the rating of inattention in the home environment, the higher the Parent Depression score. Another positive association occurred between Home Hyperactivity and Parent Depression, indicating that the greater the rating of hyperactivity at home, the higher the Parent Depression score. In addition, there was a positive association between 
School Hyperactivity and Teacher Depression, indicating that the greater the rating of hyperactivity in the school environment, the higher the Teacher Depression score.

\section{Table 16}

Regression Analysis for ADDES-2 and Gender Predicting Parent Depression Ratings and Teacher Depression Ratings

Variable

$\underline{\text { BASC Parent Depression }}$

$\underline{B} \quad \underline{\text { SEB }}$

$\underline{\beta}$
$\underline{B} \quad \underline{\text { SEB }} \quad \underline{\beta}$

BASC Teacher Depression

$\begin{array}{llllllll}\text { ADDES Home } & 1.05 & .37 & .27^{* *} & & .05 & .28 & .02\end{array}$

Inattention

$\begin{array}{lllllll}\text { ADDES Home } & 1.72 & .39 & .43^{* *} & .13 & .30 & .05\end{array}$

Hyperactivity

$\begin{array}{llllllll}\text { ADDES School } & -.50 & .42 & -.11 & .11 & .05 & .32 & .02\end{array}$

Inattention

$\begin{array}{lllllll}\text { ADDES School } & -.08 & .41 & -.02 & 1.15 & .31 & .38^{* *}\end{array}$

Hyperactivity

$\begin{array}{lllllll}\text { Gender } & 2.52 & 2.11 & .09 & .91 & 1.60 & .05\end{array}$

$* p<.05,{ }^{* *} p<.01$

Note: For BASC Parent Depression, $\mathrm{R}^{2}$ adjusted $=.34(\mathrm{~N}=145, p<.01)$

Note: For BASC Teacher Depression, $\mathrm{R}^{2}$ adjusted $=.15(\mathrm{~N}=142, p<.01)$

Parent Somatization

For the dependent variable Parent Somatization, the regression equation with five predictors was statistically significant, $F(5,139)=3.38, p<.05$. The adjusted $R^{2}$ for the equation was .08 , indicating that the predictors accounted for $8 \%$ of the variance in the 
dependent variable. For the dependent variable Teacher Somatization, the regression equation with five predictors was not statistically significant, $F(5,135)=2.01$. The adjusted $\mathrm{R}^{2}$ for the equation was .04 , indicating that the predictors accounted for $4 \%$ of the variance in the dependent variable. Table 17 shows the regression coefficients for the equations. As can be seen in the table, controlling for the other four predictor variables, there was a significant negative association between gender and Teacher Somatization, indicating that females have higher Teacher Somatization scores.

\section{Table 17}

Regression Analysis for ADDES-2 and Gender Predicting Parent Somatization Ratings and Teacher Somatization Ratings

Variable BASC Parent Somatization

B $\quad \underline{\text { SEB }} \quad \underline{\beta}$

$\begin{array}{lll}.42 & .35 & .14\end{array}$

Inattention

ADDES Home

$.70 \quad .37$

.22

Hyperactivity

$\begin{array}{llll}\text { ADDES School } & -.12 & .40 & -.03\end{array}$

Inattention

ADDES School

$-.11$

.39

$-.03$

Hyperactivity

Gender
$-.63$

.39

$-.19$

BASC Teacher Somatization

$\underline{B} \quad \underline{\text { SEB }} \quad \underline{\beta}$

$\begin{array}{lll}.62 & .41 & .18\end{array}$

$.22 \quad .44$

.06

$\begin{array}{lll}.21 & .42 & .05\end{array}$

$\begin{array}{lll}-4.84 & 2.20 & -.20^{*}\end{array}$

$* p<.05,{ }^{* *} p<.01$

Note: For BASC Parent Somatization, $\mathrm{R}^{2}$ adjusted $=.08(\mathrm{~N}=145, p<.01)$

Note: For BASC Teacher Somatization, $\mathrm{R}^{2}$ adjusted $=.04(\mathrm{~N}=141, p<.01)$ 


\section{Parent Aggression}

For the dependent variable Parent Aggression, the regression equation with five predictors was statistically significant, $F(5,137)=29.05, p<.01$. The adjusted $R^{2}$ for the equation was .50 , indicating that the predictors accounted for $50 \%$ of the variance in the dependent variable. For the dependent variable Teacher Aggression, the regression equation with five predictors was statistically significant, $F(5,135)=34.36, p<.01$. The adjusted $\mathrm{R}^{2}$ for the equation was .54 , indicating that the predictors accounted for $54 \%$ of the variance in the dependent variable. Table 18 shows the regression coefficients for the equations. As can be seen in the table, controlling for the other four predictor variables, there was a significant positive association between Home Hyperactivity and Parent Aggression. This result indicates that the greater the rating of hyperactivity in the home environment, the higher the Parent Aggression score.

Another positive association occurred between School Hyperactivity and Parent Aggression, indicating that the greater the rating of hyperactivity at school, the higher the Parent Aggression score. There was also a positive association between School Hyperactivity and Teacher Aggression, indicating that the greater the rating of hyperactivity in the school environment, the higher the Teacher Aggression score. In addition, there were positive associations between gender and Parent and Teacher Aggression, indicating that males have higher Parent and Teacher Aggression scores. 
Table 18

Regression Analysis for ADDES-2 and Gender Predicting Parent Aggression Ratings and Teacher Aggression Ratings

Variable BASC Parent Aggression $\quad$ BASC Teacher Aggression

$\underline{B} \quad \underline{\text { SEB }} \quad \underline{B} \quad \underline{B} \quad \underline{\text { SEB }} \quad \underline{\beta}$

ADDES Home

$.23 \quad .27$

.07

$-.23 \quad .23 \quad-.08$

Inattention

ADDES Home

$2.09 \quad .29$

$.61^{* *}$

$.12 \quad .24$

.04

Hyperactivity

$\begin{array}{lllllll}\text { ADDES School } & -.31 & .31 & -.08 & -.25 & .25 & -.07 \\ \text { Inattention } & & & & & & \end{array}$

ADDES School

$.72 \quad .30$

$.19^{*}$

$2.45 \quad .25$

$.75^{* *}$

Hyperactivity

Gender

$3.86 \quad 1.55 \quad .16^{*}$

3.68

1.27

$.18^{* *}$

${ }^{*} p<.05,{ }^{* *} p<.01$

Note: For BASC Parent Aggression, $\mathrm{R}^{2}$ adjusted $=.50(\mathrm{~N}=143, p<.01)$

Note: For BASC Teacher Aggression, $\mathrm{R}^{2}$ adjusted $=.54(\mathrm{~N}=141, p<.01)$

\section{Parent Hyperactivity}

For the dependent variable Parent Hyperactivity, the regression equation with five predictors was statistically significant, $F(5,139)=44.67, p<.01$. The adjusted $R^{2}$ for the equation was .60, indicating that the predictors accounted for $60 \%$ of the variance in the dependent variable. For the dependent variable Teacher Hyperactivity, the regression equation with five predictors was statistically significant, $F(5,136)=68.70, p<.01$. The 
adjusted $\mathrm{R}^{2}$ for the equation was .71 , indicating that the predictors accounted for $71 \%$ of the variance in the dependent variable.

Table 19 shows the regression coefficients for the equations. As can be seen in the table, controlling for the other four predictor variables, there was a significant positive association between Home Inattention and Parent Hyperactivity. This result indicates that the greater the rating of inattention in the home environment, the higher the Parent Hyperactivity score. Another positive association occurred between Home Hyperactivity and Parent Hyperactivity, indicating that the greater the rating of hyperactivity at home, the higher the Parent Hyperactivity score. There was also a positive association between School Hyperactivity and Teacher Hyperactivity, indicating that the greater the rating of hyperactivity in the school environment, the higher the Teacher Hyperactivity score. In addition, there were positive associations between gender and Parent and Teacher Hyperactivity, indicating that males have higher Parent and Teacher Hyperactivity scores. 


\section{Table 19}

Regression Analysis for ADDES-2 and Gender Predicting Parent Hyperactivity Ratings and Teacher Hyperactivity Ratings

$\underline{\text { Variable }} \quad \underline{\text { BASC Parent Hyperactivity }}$

B $\quad \underline{\text { SEB }}$

$\underline{\beta}$

BASC Teacher Hyperactivity

$\underline{B} \quad \underline{S E B} \quad \underline{B}$

$\begin{array}{llllllll}\text { ADDES Home } & .60 & .29 & .16^{*} & & -.08 & .20 & -.03\end{array}$

Inattention

$\begin{array}{llllllll}\begin{array}{l}\text { ADDES Home } \\ \text { Hyperactivity }\end{array} & 2.67 & .30 & .67^{* *} & .44 & .21 & .14 *\end{array}$

$\begin{array}{llllllll}\text { ADDES School } & -.23 & .33 & -.05 & .11 & .22 & .03\end{array}$

Inattention

ADDES School

.37

.32

.08

2.62

$.21 \quad .74 * *$

Hyperactivity

Gender

$4.19 \quad 1.63$

$.15^{*}$

$5.38 \quad 1.10$

$.24 * *$

$* p<.05, * * p<.01$

Note: For BASC Parent Hyperactivity, $\mathrm{R}^{2}$ adjusted $=.60(\mathrm{~N}=145, p<.01)$

Note: For BASC Teacher Hyperactivity, $\mathrm{R}^{2}$ adjusted $=.71(\mathrm{~N}=142, p<.01)$

\section{Parent Conduct Problems}

For the dependent variable Parent Conduct Problems, the regression equation with five predictors was statistically significant, $F(5,138)=15.97, p<.01$. The adjusted $R^{2}$ for the equation was .34, indicating that the predictors accounted for $34 \%$ of the variance in the dependent variable. For the dependent variable Teacher Conduct Problems, the regression equation with five predictors was statistically significant, $F(5,133)=13.68, p<$ 
.01 . The adjusted $\mathrm{R}^{2}$ for the equation was .32 , indicating that the predictors accounted for $32 \%$ of the variance in the dependent variable.

Table 20

Regression Analysis for ADDES-2 and Gender Predicting Parent Conduct Problems Ratings and Teacher Conduct Problems Ratings

Variable BASC Parent Conduct Problems $\quad$ BASC Teacher Conduct Problems

$\underline{B} \quad \underline{S E B} \quad \underline{B} \quad \underline{B} \quad \underline{\text { SEB }} \quad \underline{\beta}$

$\begin{array}{llllllll}\text { ADDES Home } & .39 & .35 & .11 & -.02 & .22 & -.01\end{array}$

Inattention

$\begin{array}{lllllll}\text { ADDES Home } & 1.74 & .37 & .46^{* *} & .20 & .23 & .09\end{array}$

Hyperactivity

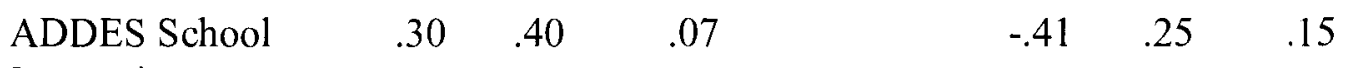

Inattention

$\begin{array}{lllllll}\text { ADDES School } & .48 & .39 & .11 & 1.05 & .24 & .41^{* *} \\ \text { Hyperactivity } & & & & & & \end{array}$

$\begin{array}{lllllll}\text { Gender } & 6.25 & 2.01 & .23^{* *} & 3.47 & 1.24 & .22 * *\end{array}$

${ }^{* p<}<.05, * * p<.01$

Note: For BASC Parent Conduct Problems, $\mathrm{R}^{2}$ adjusted $=.34(\mathrm{~N}=144, p<.01)$

Note: For BASC Teacher Conduct Problems, $\mathrm{R}^{2}$ adjusted $=.32(\mathrm{~N}=139, p<.01)$

Table 20 shows the regression coefficients for the equations. As can be seen in the table, controlling for the other four predictor variables, there was a significant positive association between Home Hyperactivity and Parent Conduct Problems. This result indicates that the greater the rating of hyperactivity in the home environment, the higher the Parent Conduct Problems score. Another positive association occurred between School Hyperactivity and Teacher Conduct Problems, indicating that the greater the 
rating of hyperactivity in the school environment, the higher the Teacher Conduct Problems score. In addition, there were positive associations between gender and Parent and Teacher Conduct Problems, indicating that males have higher Parent and Teacher Conduct Problems scores.

\section{$\underline{\text { Summary }}$}

Several significant results were found after analyzing the available data. A summary of those variables that significantly predicted the dependent variables is presented in Table 21. Hypothesis 1, which stated that ADDES-2 home inattention ratings would be a significant predictor of parent and teacher internalizing problems, as measured by the Anxiety, Depression, and Somatization subscales on the BASC was partially supported. On the anxiety subscale, home inattention scores were a significant predictor for parent ratings, but not for teacher ratings as hypothesized. Likewise, on the depression subscale, home inattention scores were a significant predictor for parent ratings, but not for teacher ratings. On the Somatization subscale, neither parent nor teacher ratings were associated with higher home inattention scores.

Results of this study showed that Hypothesis 2, which stated that ADDES-2 school inattention ratings would be a significant predictor of parent and teacher internalizing problems, as measured by the Anxiety, Depression, and Somatization subscales on the BASC was also partially supported. On the anxiety subscale, school inattention scores were significant predictors for parent and teacher ratings. On the Somatization and Depression subscales, however, school inattention scores were not significant predictors for parent or teacher ratings. 
Hypothesis 3 contended that ADDES-2 home hyperactivity ratings would be a significant predictor of parent and teacher externalizing problems, as measured by the Aggression, Hyperactivity, and Conduct Problems. This hypothesis was supported on all parent ratings of Aggression, Hyperactivity, and Conduct Problems, as well as teacher ratings of Hyperactivity. However, home hyperactivity was not found to be a significant predictor for teacher ratings of Aggression or Conduct Problems.

Hypothesis 4 indicated that ADDES-2 school hyperactivity ratings would be a significant predictor of parent and teacher externalizing problems, as measured by the Aggression, Hyperactivity, and Conduct Problems subscales on the BASC. This hypothesis was also partially supported. School hyperactivity was found to be significant predictor for parent and teacher ratings of Aggression, teacher ratings of Hyperactivity, and teacher ratings of Conduct Problems. Significant associations were not found on parent ratings of Hyperactivity or Conduct Problems.

This study supported Hypothesis 5, which stated that male gender would be a significant predictor of externalizing behaviors, as measured by the Aggression, Hyperactivity, and Conduct Problems subscales on the BASC. This hypothesis was accepted with male gender predicting externalizing behaviors on all parent and teacher rating scales.

Hypothesis 6 stated that female gender would be a significant predictor of internalizing behaviors, as measured by the Anxiety, Depression, and Somatization subscales on the BASC, than males. This hypothesis was only supported on the teacher ratings of Somatization. Other parent and teacher ratings of internalizing behaviors did not support this hypothesis. 


\section{Table 21}

Overall Summary of Regression Results

Dependent Variable $\quad$ Significant Predictors from ADDES Parent Ratings

Significant Predictors from ADDES Teacher Ratings and Gender

BASC Parent

Anxiety

BASC Teacher

Anxiety

BASC Parent

Depression

BASC Teacher

Depression

BASC Parent

Somatization

BASC Teacher

Somatization

BASC Parent

Aggression

BASC Teacher

Aggression

BASC Parent

Hyperactivity

BASC Teacher

Hyperactivity

BASC Parent

Conduct Problems

BASC Teacher

Conduct Problems
ADDES Home Inattention

ADDES Home Inattention

ADDES Home Hyperactivity

ADDES School Hyperactivity

ADDES School Inattention

Females

ADDES Home Hyperactivity

ADDES School Hyperactivity Males

ADDES School Hyperactivity Males

Males

ADDES Home Inattention

ADDES Home Hyperactivity

ADDES Home Hyperactivity

ADDES School Hyperactivity Males

ADDES Home Hyperactivity Males
ADDES School Hyperactivity Males 


\section{CHAPTER 5}

\section{DISCUSSION}

\section{$\underline{\text { Introduction }}$}

This chapter presents a review of the purpose of the study, interpretation and discussion of the results, a summary of how these results compare to the current research literature in this area, and a discussion of implications and limitations of the research. Finally, suggestions for future research are discussed. This study was conducted to increase understanding of the associations between $\mathrm{AD} / \mathrm{HD}$, gender, and comorbidity. $\mathrm{AD} / \mathrm{HD}$ research literature has only recently begun to address comorbidity issues, particularly with respect to gender (Costin, Vance, Barnett, O'Shea, \& Luk, 2002). Without recognition of the impact of comorbid symptomatology with $\mathrm{AD} / \mathrm{HD}$, there are repercussions in terms of high morbidity, greater rates of disability, and a poor long-term prognosis for affected individuals (Faraone and Biederman, 1994). Consequently, expanding knowledge regarding $\mathrm{AD} / \mathrm{HD}$ symptomatology, gender, and comorbidity will improve identification, treatment, and overall long-term emotional and behavioral functioning of affected individuals.

\section{Internalizing Symptoms}

In the study, relationships were examined on three measures of internalizing symptoms: anxiety, depression, and somatization. The coexistence of anxiety disorder and $\mathrm{AD} / \mathrm{HD}$ has been extensively reported in the research literature (Biederman, et. al., 
1991; Jensen, et al., 1993; Perrin \& Last, 1996; Russo \& Biedal, 1994). The current results showed consistent findings across raters. Ratings showed that home inattention was a significant predictor of parent anxiety and school inattention was a significant predictor of teacher rated anxiety. Relationships were not found between home inattention and teacher anxiety or school inattention and parent anxiety. In addition, relationships were found between home inattention and parent rated depression and home and school rated hyperactivity and depression. Relationships were not found between measures of inattention or hyperactivity in the home and school environment on any parent or teacher measures of somatization.

Although the relationship between depression and inattention were only found on parent ratings and not on teacher ratings, the bulk of these results are consistent with previous research that demonstrates a relationship between anxiety, depression, and inattentive behaviors (Biederman, Newcorn, et al., 1991; Newcorn, et al., 2001; Pliszka, 1992). Likewise, the results found were consistent with research by Livingston, Dykman, \& Ackerman (1990), who also found a relationship between depression and inattention problems in children.

Associations found between inattention and anxiety were inconsistent with March, et al. (2000), who reported no differences between AD/HD children with and without coexisting anxiety disorder on ratings of inattentiveness. Other than in the area of somatization, the results are also inconsistent with those found from other researchers, who have not shown greater internalizing symptomatology with the inattentive subtype (Eiraldi, et al., 1997; Morgan, et al., 1996). 


\section{Externalizing Behaviors}

Relationships were also examined on three measures of externalizing symptoms: aggression, hyperactivity, and conduct problems. Many researchers have shown that externalizing behaviors commonly co-occur, as demonstrated in the current study (Abikoff, et al., 1993; Goldstein, 1996; Kashani, et al., 1979; Reid, et al., 2000; Schachar, et al., 1986; Stevens, et al., 1998). Higher ratings of hyperactivity in the home environment were predictive of all three externalizing behaviors as rated by parents, including measures of aggression, hyperactivity, and conduct problems, but only teacher ratings of hyperactivity. In addition, hyperactivity in the school environment was predictive of all teacher ratings of aggression, hyperactivity, and conduct problems, and only aggression as rated by parents. In sum, overall support for concomitant occurrence of externalizing behaviors was shown.

This presence of comorbid externalizing behaviors is indicative of more severe $\mathrm{AD} / \mathrm{HD}$ presentations and overall dysfunction, and is often predictive of negative longterm outcomes (August, et al., 1996; Burns \& Walsh, 2002; Gresham, et al., 1998;

Kuhne, et al., 1997; Newcorn, et al., 2001). This evidence thus supports the need to implement early and effective treatment strategies to prevent more severe disruptive behaviors later in life (Burns \& Walsh, 2002; Gresham, MacMillan, Bocian, Ward, \& Forness, 1998; Waschbusch, 2002).

\section{$\underline{\text { Gender }}$}

The current findings support research that shows no significant gender differences between ratings of inattention and hyperactivity with internalizing symptoms in the home and school settings, other than in the area of teacher ratings of somatization. This is 
consistent with research that demonstrates no significant differences in comorbidity rates of $\mathrm{AD} / \mathrm{HD}$ and internalizing behaviors between males and females (Arcia \& Conners, 1998; Berry, et al., 1985; Biederman, et al., 1994; Biederman, et al., 1999; Bird, et al., 1993; Faraone, et al., 1991; Hartung, et al., 2002; Horn, et al., 1989; Sharp, et al., 1999). Contrarily, some researchers have found lower rates of depression in females as compared to males (Biederman, et al, 2002), whereas others contend that $\mathrm{AD} / \mathrm{HD}$ in girls is characterized by a greater prevalence of comorbid internalizing behavior disorders, such as anxiety and depression, (APA, 1994; Allgood-Merten, et al., 1990; Berry, et al., 1985; Biederman, Newcorn, et al., 1991; Ge, et al., 1995; Gershon, 2002; Kato, Nichols, Kerivan, \& Huffman, 2001; Katz, Goldstein, \& Geckle, 1998; Leadbeater, et al., 1999; Lewinsohn, et al., 1993; Nolen-Hoeksema, \& Girgus, 1994; Pinn, 2003; Reeves, Werry, Elkind, \& Zametkin, 1987; Rucklidge \& Tannock, 2001; Weiss, et al., 2003).

Although some studies have found no differences on measures of externalizing problems with males and females (Berry, et al., 1985; Biederman, et al., 1999; Breen \& Altepeter, 1990; Brown, Madan-Swain, \& Baldwin, 1991; Castellanos, et al., 2000; Horn, Wagner, \& Ialongo, 1989; James \& Taylor, 1990; Kashani, Chapel, Ellis, \& Shekim, 1979; Sharp, et al., 1999; Silverthorn, Frick, Kuper, \& Ott, 1996), the majority indicate that boys display more externalizing behaviors, such as aggression, hyperactivity, and conduct problems, than girls (Arcia and Conners, 1998; Arnold, 1996; Barkley, 1998; Bauermeister, 1992; Befera \& Barkley, 1985; Berry, et al., 1985; Biederman, Newcorn, et al., 1991; Bird, et al., 1993; Carlson, Tamm, \& Gaub, 1997; deHaas \& Young, 1984; Eme, 1992; Gaub \& Carlson, 1997b; Gershon, 2002; Hartung, et al., 2002; Heptinstall \& Taylor, 1996; Hinshaw, 2002; Leadbeater, Kupermine, Blatt, \& Hertzog, 1999; 
Lewinsohn, et al., 1993; Lumley, et al., 2002; McDermott, 1996; Newcorn, et al., 2001; Waschbusch, 2002; Zahn-Waxler, 1993). The current results support the bulk of the research and demonstrated that on all parent and teacher ratings of externalizing behaviors, males showed significantly higher scores than females.

Some researcher have found that girls were more likely to exhibit comorbid conduct problems (Biederman, et al., 1999; Pelham, et al., 1989; Rucklidge \& Tannock, 2001) whereas others have found that co-occurring disruptive behavior problems are more common in males than females (Gaub \& Carlson, 1997b), particularly in classroom settings (deHaas, 1986). Boys may be referred at a higher rate because of the disruptive consequences of the coexisting behavior problems (Goldstein, 1996; Kashani, et al., 1979) as evidenced by the fact that girls with $\mathrm{AD} / \mathrm{HD}$ are referred less frequently for aggression than are boys with $\mathrm{AD} / \mathrm{HD}$ (Kashani, et al., 1979). These researchers found that $\mathrm{AD} / \mathrm{HD}$ boys engaged in more rule-breaking, disruptive, and externalizing behaviors in the classroom than did girls (Abikoff, et al., 2002). Because comorbidity with disruptive behaviors such as this is associated with behavioral deviance and aggression, particularly in males (Ackerman, Dykman, \& Oglesby, 1983; Battle and Lacey, 1972), and because these problems drive clinical referral, the lower rates of these disorders in girls may lead to the underrecognition of $\mathrm{AD} / \mathrm{HD}$ in girls.

Differences in teacher and parent ratings were evident on several variables.

Several researchers suggest more noticeable sex differences for teacher ratings, in that teachers have a tendency to rate males higher on $\mathrm{AD} / \mathrm{HD}$ behaviors (Breen \& Altepeter, 1990; McGee \& Feehan, 1991; McGee, et al., 1987; Szatmari, Offord, et al., 1989). Accordingly, it has been purported that parent and teacher ratings commonly differ on 
some of the core symptoms and comorbid conditions, and teachers rate $\mathrm{AD} / \mathrm{HD}$ males as significantly more impaired than $\mathrm{AD} / \mathrm{HD}$ females in comparison to parent ratings (Gershon, 2002). Such differences in ratings may indicate a "halo effect," whereby teachers overly attend to coexisting externalizing problems when rating $\mathrm{AD} / \mathrm{HD}$ symptom severity and downplay inattentive behaviors (Abikoff, et al., 1993; Reid, et al., 2000;

Schachar, et al., 1986; Stevens, et al., 1998). According to Barkley (1998), the level of agreement on symptoms between teachers and parents is often relatively low and may represent differences other than the presence of core symptoms.

\section{Limitations}

There are several limitations to the current study. The participants in this study were primarily referred from schools and parents, which may not allow comparisons to the general population. According to many researchers, children from these two types of samples may differ in important ways, including referral bias issues and/or symptom severity (Carlson, Tamm, \& Gaub, 1997; Gershon, 2002). Likewise, according to Carlson, Tamm, and Gaub (1998), assessing behavior disorders using clinic populations may be problematic to the extent that referral bias makes such populations unrepresentative of the general population of disordered children. Gershon (2002) concluded that referral source moderated the gender differences found in their metaanalysis, in that clinically referred samples were more likely to exhibit more severe presentation than community samples. In addition, comorbid children are more likely to be found in referred samples than in nonreferred samples, a phenomenon known as Berkson's bias. Thus, sample type (referred vs. nonreferred) may moderate differences between different groups (Waschbusch, 2002). 
Another limitation in this study was the use of rating scale data. Rating scales are subjective in nature and prone to several biases, such as halo effects, which may in turn limit the findings. In addition, the present study did not obtain information on $\mathrm{AD} / \mathrm{HD}$ symptoms as defined by DSM-IV directly. Although the factors scores on the rating scale were similar with DSM symptom criteria, the actual DSM symptoms were not assessed.

\section{Future Recommendations}

Particularly with regard to females and issues related to referral bias, studies are needed to establish criteria specific for $\mathrm{AD} / \mathrm{HD}$ in girls with the goal of accurate diagnosis, early identification, and development of effective treatments. Future research should compare males and females with overlapping comorbid disorders with different treatment approaches. Currently, most of the data on both medical and non-medical interventions are predominantly based on males. In addition, gender differences need to be more fully addressed in longitudinal and treatment studies.

Results from the current study utilized both parent and teacher ratings of $\mathrm{AD} / \mathrm{HD}$ and comorbid symptoms. In the future, differences in parent and teacher ratings should be explored further in order to increase the acceptable use of information gained from these instruments in clinical and research settings. In addition, data from studies such as this could be used to conduct research regarding convergent and divergent validity of varying instruments, such as the ADDES-2 and the BASC.

Furthermore, investigations of $\mathrm{AD} / \mathrm{HD}$ need to be extended to include samples that are representative of varying ethnicities and cultural backgrounds. In addition, subsequent studies should include more detailed examinations of genetic and environmental variables. Such investigations would be advantageous in terms of diagnosis and treatment of populations who have been underrepresented in past research. Further investigation of the developmental course of $\mathrm{AD} / \mathrm{HD}$ is also needed through 
longitudinal studies of males and females with $\mathrm{AD} / \mathrm{HD}$ from ethnically diversified backgrounds.

Another important issue to examine in subsequent research would be the development and implementation of training to parents, teachers, school counselors, mental health professionals, and physicians on recognizing $\mathrm{AD} / \mathrm{HD}$ symptoms in both males and females and the differential manifestation of the disorder by gender. In addition, revisions of current screening forms should be explored in order to emphasize gender-related symptoms based on more extensive research. An emphasis upon comorbid mood and conduct symptoms and behavior is suggested. Use of instruments, such as those employed in the current study, should also be considered in order to gain additional information about the presentation of the disorder.

\section{Summary}

Prior research has documented elevated rates of comorbid internalizing and externalizing psychopathology in children with AD/HD (Jensen, et al., 1993). Comorbid internalizing and externalizing problems affect severity, adaptive skills, treatment, and prognosis of AD/HD persons (Biederman, 1998; Biederman, et al., 1996, 1997; Brown, 2000; MTA, 1999; Pliszka, et al., 1999). The present study is supportive of previous research suggesting differences in the expression of internalizing and externalizing symptomatology for males and females, specifically in the area of a positive association between symptoms of anxiety and inattention, a positive association between symptoms of depression and inattention as rated by parents, co-occurrence of externalizing behaviors, and greater incidence of externalizing behaviors in males.

Although not hypothesized, this study also provides evidence regarding a relationship between hyperactivity and depression as rated by parents. Contrary to prior research, the majority of the results did not support a positive association between female gender and internalizing symptoms. 
The present study provides further evidence that the identification and treatment of $\mathrm{AD} / \mathrm{HD}$ should be modified to include considerations of gender and comorbid symptoms, which, in turn, may reduce the overall presentation and severity of the disorder. A more thorough evaluation of males and females for $\mathrm{AD} / \mathrm{HD}$ should take a broader look at their emotional, behavioral, social, and academic functioning so that a comprehensive treatment plan addressing all areas of important difficulty can be developed and implemented. In addition, when parents, educators, mental health professionals, and physicians become better informed about the manifestations of $\mathrm{AD} / \mathrm{HD}$ in males and females, the tendency for persons to go undiagnosed and untreated is also minimized. This is particularly true with females since they are at increased risk of being undetected and untreated (Cantwell, 1996). 


\section{REFERENCES}

Abikoff, Courtney, Pelham, \& Koplewicz (1993). Teachers ratings of disruptive behaviors. Journal of Abnormal Child Psychology, 21(5), 519-533.

Abikoff, H. B., Jensen, P. S., Arnold, L. L., Hoza, B., Hechtman, L., Pollack, S., et al. (2002). Observed classroom behavior of children with ADHD: Relationship to gender and comorbidity. Journal of Abnormal Child Psychology, 30(4), 349-359.

Abikoff, H., \& Klein, R. G. (1992). Attention-deficit hyperactivity and conduct disorder comorbidity and implications for treatment. Journal of Consulting and Clinical Psychology, 60(6), 881-892.

Achenbach, T.M. (1995). Diagnosis, assessment and comorbidity in psychosocial treatment research. Journal of Abnormal Child Psychology, 23(1), 45-65.

Ackerman, P. T., Dykman, R. A., \& Oglesby, D. M. (1983). Sex and group differences in reading and attention disordered children with and without hyperkinesis. Journal of Learning Disabilities, 16(7), 407-415.

Allgood-Merten, B., Lewinsohn, P.M., \& Hops, H. (1990). Sex differences and adolescent depression. Journal of Abnormal Psychology, 99(1), 55-63.

American Academy of Child and Adolescent Psychiatry (1997). Practice parameter for the assessment and treatment of children, adolescents, and adults with attentiondeficit/hyperactivity disorder. Journal of the American Academy of Child and Adolescent Psychiatry, 36(10S), 85S-121S.

American Academy of Child and Adolescent Psychiatry (2002). Practice parameter for the use of stimulant mediations in the treatment of children, adolescents, and 
adults. Journal of the American Academy of Child and Adolescent Psychiatry, $4 l(2 \mathrm{~S}), 26 \mathrm{~S}-49 \mathrm{~S}$.

American Academy of Pediatrics. (2000). Clinical practice guideline: Diagnosis and evaluation of the child with attention-deficit/hyperactivity disorder. Pediatrics, $105(5), 1158-1170$.

American Psychiatric Association (1967). Diagnostic and Statistical Manual of Mental Disorders ( $2^{\text {nd }}$ ed.). Washington, DC: Author.

American Psychiatric Association (1980). Diagnostic and Statistical Manual of Mental Disorders (3rd ed.). Washington, DC: Author.

American Psychiatric Association (1987). Diagnostic and Statistical Manual of Mental Disorders-Revised (3rd ed., rev.). Washington, DC: Author.

American Psychiatric Association (1994). Diagnostic and Statistical Manual of Mental Disorders (4th ed.). Washington, DC: Author.

American Psychiatric Association (2000). Diagnostic and Statistical Manual of Mental Disorders (4th ed., text rev.). Washington, DC: Author.

Anderson. S.L. \& Teicher, M.H. (2000). Sex differences in dopamine. Neuroscience and Biobehavioral Reviews, 24(1), 137-141.

Arcia, E., \& Conners, C. K. (1998). Gender differences in ADHD? Journal of Developmental and Behavioral Pediatrics, 19(2), 77-83.

Arnold, L. E. (1996). Sex differences in ADHD: Conference summary. Journal of Abnormal Child Psychology, 24(5), 555-569.

August, G. J., Braswell, L., \& Thuras, P. (1998). Diagnostic stability of ADHD in a community sample of school-aged children screened for disruptive behavior. Journal of Abnormal Child Psychology, 26(5), 345-356.

August, G. J., Realmuto, G. M., MacDonald, A. W., III, Nugent, S. M., \& Crosby, R. (1996). Prevalence of ADHD and comorbid disorders among elementary school 
children screened for disruptive behavior. Journal of Abnormal Child Psychology, 24(5), 571-595.

Bagwell, Newcomb, \& Bukowski (1998). Preadolescent friendship. Child Development, $69,104-153$.

Barkley R.A. (1989). Hyperactive girls and boys: Stimulant drug effects on mother-child interactions. Journal of Child Psychology and Psychiatry and Allied Disciplines, $30(3), 379-390$.

Barkley, R. A. (1998). Attention-Deficit Hyperactivity Disorder: A handbook for Diagnosis and Treatment ( $2^{\text {nd }} e d$.). New York, NY: The Guilford Press. Barkley, R.A. (2002). International Consensus Statement on AD/HD. Clinical Child and Family Psychology Review, 5(2), 89-111.

Barkley, R. A., DuPaul, G. J., \& McMurray, M. B. (1990). Comprehensive evaluation of attention deficit disorder with and without hyperactivity as defined by research criteria. Journal of Consulting and Clinical Psychology, 58(6), 775-789.

Battle, E.S. \& Lacey, B. (1972). A context for hyperactivity in children over time. Child Development, 43, 757-773.

Bauermeister, J. J. (1992). Factor analysis of teacher ratings of attention-deficit hyperactivity and oppositional defiant symptoms in children aged four through thirteen years. Journal of Clinical Child Psychology, 21(1), 27-34.

Bauermeister, J. J., Canino, G., \& Bird, H. (1994). Epidemiology of disruptive behavior disorders. Child and Adolescent Psychiatric Clinics of North America, 3(2), 177 194.

Befera, M.S. \& Barkley, R.A. (1985). Hyperactive and normal girls and boys. Motherchild interaction, parent psychiatric status, and child psychopathology. Journal of Child Psychology and Psychiatry and Allied Disciplines, 26(3), 439-452. 
Berry, C. A., Shaywitz, S. E., \& Shaywitz, B. A. (1985). Girls with attention deficit disorder: A silent minority? A report on behavioral and cognitive characteristics. Pediatrics, 76(5), 801-809.

Biederman, J., Faraone, S.V., Keenan, K., Benjamin, J., Krifcher, B., Moore, C., et al. (1992). Further evidence for family-genetic risk factors in attention deficit hyperactivity disorder: Patterns of comorbidity in probands and relatives of psychiatrically and pediatrically referred samples. Archives of General Psychiatry, 49, 728-738.

Biederman, J., Faraone, S.V., Keenan, K., \& Tsuang, M.T. (1991). Evidence of a familial association between attention deficit disorder and major affective disorders. Archives of General Psychiatry, 48, 633-642.

Biederman, J., Faraone, S. V., Mick, E., Williamson, S., Wilens, T. E., Spencer, T. J., et al. (1999). Clinical correlates of ADHD in females: Findings from a large group of girls ascertained from pediatric and psychiatric referral sources. Journal of the American Academy of Child and Adolescent Psychiatry, 38(8), 966-975.

Biederman, J., Faraone, S., Milberger, S., Guite, J. Mick, E., Chen, L., et al. (1996). A prospective 4-year follow-up study of attention-deficit hyperactivity and related disorders. Archives of General Psychiatry, 53(5), 437-446.

Biederman, J., Faraone, S. V., Spencer, T.J., Wilens, T., Norman, D., Lapey, K. A., et al. (1993). Patterns of psychiatric comorbidity, cognition, and psychosocial functioning in adults with attention deficit hyperactivity disorder. The American Journal of Psychiatry, 150, 1792-1798.

Biederman, J., Faraone, S. V., Spencer, T., Wilens, T., Mick, E., \& Lapey, K. A. (1994). Gender differences in a sample of adults with attention deficit hyperactivity disorder. Psychiatry Research, 53(1), 13-29. 
Biederman, J., Mick, E., Faraone, S.V. (1998). Depression in attention deficit hyperactivity disorder (ADHD) children: "True" depression or demoralization? Journal of Affective Disorders, 47, 113-122.

Biederman, J., Mick, E., Faraone, S. V., Braaten, E., Doyle, A., Spencer, T., et al. (2002). Influence of gender on attention deficit hyperactivity disorder in children referred to a psychiatric clinic. The American Journal of Psychiatry, 159(1), 36-42.

Biederman, J., Munir, K., \& Knee, D. (1987). Conduct and oppositional disorder in clinically referred children with attention deficit disorder: A controlled family study. Journal of the American Academy of Child and Adolescent Psychiatry, $26(5), 724-727$.

Biederman, J., Newcorn, J., \& Sprich, S. (1991). Comorbidity of attention deficit hyperactivity disorder with conduct, depressive, anxiety, and other disorders. The American Journal of Psychiatry, 148(5), 564-577.

Biederman, J., Wilens, T., Mick, E., Milberger, S.D., Spencer, T.J., \& Faraone, S.V. (1995). Psychoactive substance use disorders in adults with attention deficit hyperactivity disorder (ADHD): Effects of ADHD and psychiatric comorbidity. The American Journal of Psychiatry, 152(11), 1652-1658.

Bird, H.R., Gould, M.S., \& Stagheeza, B.M. (1993). Patterns of diagnostic comorbidity in a community sample of children aged 9 through 16 years. Journal of the American Academy of Child and Adolescent Psychiatry, 32(2), 361-368.

Blachman, D. R., \& Hinshaw, S. P. (2002). Patterns of friendship among girls with and without attention-deficit/hyperactivity disorder. Journal of Abnormal Child Psychology, 30(6), 625-640.

Breen, M.J. (1989).Cognitive and behavioral differences in ADHD boys and girls. Journal of Child Psychology and Psychiatry and Allied Disciplines, 30(5), 711716. 
Breen, M.J. \& Altepeter, T.S. (1990). Situational variability in boys and girls identified as ADHD. Journal of Clinical Psychology 46(4), 486-490.

Breen, M.J. \& Barkley, R.A. (1988). Child psychopathology and parenting stress in girls and boys having attention deficit disorder with hyperactivity. Journal of Pediatric Psychology, 13(2), $265-280$.

Brown, M. B. (2000). Diagnosis and treatment of children and adolescents with attentiondeficit/hyperactivity disorder. Journal of Counseling and Development, 78(2), 195-203.

Brown, R.T., Madan-Swain, A., \& Baldwin, K. (1991). Gender differences in a clinicreferred sample of attention-deficit-disordered children. Child Psychiatry and Human Development, 22(2), 15-28.

Burns, G.L. \& Walsh, J.A. (2002). The influence of ADHD-hyperactivity/impulsivity symptoms on the development of oppositional defiant disorder symptoms in a 2year longitudinal study. Journal of Abnormal Child Psychology, 30(3), 245-256.

Bussing, R., Zima, B. T., Gary, F. A., \& Wilson-Garvan, C. (2003). Barriers to detection, help-seeking, and service use for children with ADHD symptoms. The Journal of Behavioral Health Services and Research, 30(2), 176-189.

Cantwell, D. (1996). Attention Deficit Disorder: A Review of the past 10 years. Journal of the American Academy of Child and Adolescent Psychiatry, 35(8), 978-987.

Carlson, C. L., Tamm, L., \& Gaub, M. (1997). Gender differences in children with adhd, odd, and co-occurring adhd/odd identified in a school population. Journal of the American Academy of Child and Adolescent Psychiatric, 36(12), 1706-1714.

Caron, C. \& Rutter, M. (1991). Comorbidity in child psychopathology: Concepts, issues and research strategies. Journal of Child Psychology and Psychiatry, 32, 10631080.

Carter, C. O. (1969). Genetics of common disorders. British Medical Bulletin, 25, 5257. 
Castellanos, F. X., Marvasti, F. F., Ducharme, J. L., Walter, J. M., Israel, M. E., Krain, A., et al. (2000). Executive function oculomotor tasks in girls with ADHD. Journal of the American Academy of Child and Adolescent Psychiatry, 39(5), 644-650.

Chhabildas, N., Pennington, B. F., \& Willcutt, E. G. (2001). A comparison of the neuropsychological profiles of the DSM-IV subtypes of adhd. Journal of Abnormal Child Psychology, 29(6), 529-540.

Cohen (1989). Sex Differences in Childhood. Child Psychiatry and Human Development, 20(), 113-121.

Cohen, P., Cohen, J., Kasen, S., Velez, Harmark, \& Johnson (1993). An epidemiological study of disorders in late childhood and adolescence: I. Age- and gender-specific prevalence. Journal of Child Psychology and Psychiatry and Allied Disciplines, $34,851-867$.

Collett, B.R., Ohan, J.L., \& Myers, K.M. (2003). Ten-Year review of rating scales. V: Scales assessing Attention-Deficit/Hyperactivity Disorder. Journal of the American Academy of Child \& Adolescent Psychiatry, 42(9),1015-1037.

Connor, D. F., Edwards, G., Fletcher, K. E., Baird, J., Barkley, R. A., \& Steingard, R. J. (2003). Correlates of comorbid psychopathology in children with ADHD. Journal of the American Academy of Child and Adolescent Psychiatry, 42(2), 193-200.

Conners, C. K., March, J. S., Frances, A., Wells, K. C., \& Ross, R. (2001). Treatment of Attention-Deficit/Hyperactivity Disorder: Expert consensus guidelines. Journal of Attention Disorders, 4(S1), S7-S13.

Costin, J., Vance, A., Barnett, R., O'Shea, M., \& Luk, E.S. (2002). Attention deficit hyperactivity disorder and comorbid anxiety: Practitioner problems in treatment planning. Child and Adolescent Mental Health, 7(1), 16-24.

Cutting, L. E., Koth, C. W., Mahone, E. M., \& Denckla, M. B. (2003). Evidence for unexpected weaknesses in learning in children with attention-deficit/hyperactivity 
disorder without reading disabilities. Journal of Learning Disabilities, 36(3), 259269.

Dalsgaard, S., Mortensen, P. B., Frydenberg, M., \& Thomsen, P. H. (2002). Conduct problems, gender and adult psychiatric outcome of children with attention-deficit hyperactivity disorder. The British Journal of Psychiatry, 181, 416-421.

DeFries, J. (1989). Gender ratios in children with reading disability and their affected relatives: A commentary. Journal of Learning Disabilities, 22, 544-545. deHaas (1986). Attention styles and peer relationships of hyperactive and normal boys and girls. Journal of Abnormal Child Psychology, 14(3), 457 - 467.

deHaas \& Young (1984). Attention styles. Journal of Abnormal Child Psychology, 12, $531-546$.

Disney, E. R., Elkins, I. J., McGue, M., \& Iacono, W. G. (1999). Effects of adhd, conduct disorder, and gender on substance use and abuse in adolescence. The American Journal of Psychiatry, 156(10), 1515-1521.

Edwards, M. C., Schultz, E. G., \& Long, N. (1995). The role of the family in the assessment of attention deficit hyperactivity disorder. Clinical Psychology Review, 15, 375-394.

Eiraldi, R.B., Power, T.J., 7 Nezu, C.M. (1997). Patterns of comorbidity associated with subtypes of attention-deficit/hyperactivity disorder among 6- to 12-year-old children. Journal of the American Academy of Child and Adolescent Psychiatry, $36(4), 503-514$.

Elia, J., Ambrosini, P.J., \& Rapoport, J.L. (1999). Drug therapy: Treatment of attentiondeficit/hyperactivity disorder. New England Journal of Medicine, 340(10), 780788.

Eme, R.F. (1992). Selective female affliction in the developmental disorders of childhood: A literature review. Journal of Clinical Child Psychology, 21(4), 354364. 
Epstein, J. N., Conners, C. K., Erhardt, D., Arnold, L. E., Hechtman, L., Hinshaw, S. P., et al. (2000). Familial Aggregation of ADHD characteristics. Journal of Abnormal Child Psychology, 28(6), 585-594.

Ernst, M., Liebenauer, L. L., Jons, P.H., \& Zametkin, A. J. (1994). Cognitive and behavioral characteristics of adhd adolescents by gender. Presented at the $41^{\text {st }}$ Annual Meeting of the American Academy of Child and Adolescent Psychiatry, New York, NY, Oct 25-30.

Ernst, M., Liebenauer, L. L., King, A. C., Fitzgerald, G. A., Cohen, R. M., \& Zametkin, A. J. (1994). Reduced brain metabolism in hyperactive girls. Journal of the American Academy of Child and Adolescent Psychiatry, 33(6), 858-868.

Faraone, S.V. \& Biederman, J. (1994). Is attention deficit hyperactivity disorder familial? Harvard Review of Psychiatry, 1, 271-287.

Faraone, S. V., Biederman, J., Chen, W. J., Milberger, S., Warburton, R., \& Tsuang, M. T. (1994). Genetic heterogeneity in attention-deficit hyperactivity disorder (ADHD): Gender, Psychiatric Comorbidity, and Maternal ADHD, Journal of Abnormal Psychology, 104, 334-345.

Faraone, S.V., Biederman, J., Jetton, J.G., \& Tsuang, M.T. (1997). Attention deficit disorder and conduct disorder: Longitudinal evidence for a familial subtype. Journal of the American Academy of Child and Adolescent Psychiatry, 27(2), 291-300.

Faraone, S. V., Biederman, J., Keenan, K., \& Tsuang, M. T. (1991). Separation of DSMIII attention deficit disorder and conduct disorder: Evidence from a family-genetic study of American child psychiatric patients. Psychological Medicine, 21, 109121.

Faraone, S. V., Biederman, J., Lehman, B.K., Spencer, T., Norman, D., Seidman, L.J., Kraus I., Perrin, J., Chen, W.J., \& Tsuang, M.T. (1993). Intellectual performance 
and school failure in children with attention deficit hyperactivity disorder and in their siblings. Journal of Abnormal Psychology, 102(4), 616-623.

Faraone, S.V., Biederman, J., Milberger, S. (1994). An exploratory study of ADHD among second-degree relatives of ADHD children. Biological Psychiatry, 35, 398-402.

Faraone, S., Biederman, J., \& Monuteaux, B. A. (2002). Further evidence for the diagnostic continuity between child and adolescent ADHD. Journal of Attention Disorders, 6(1), 5-13.

Faraone, S.V., Biederman, J., \& Monuteaux, M.C. (2000). Attention-deficit disorder and conduct disorder in girls: Evidence for a familial subtype. Biological Psychiatry, 48(1), 21-29.

Faraone, S. V., Biederman, J., Spencer, T., Wilens, T., Seidman, L. J., Mick, E., \& Doyle, A.E. (2000). Attention-deficit/hyperactivity disorder in adults: An overview. Biological Psychiatry, 48, 9-20.

Fischer, M., Barkley, R.A., Smallish, L., \& Fletcher, K. (2002). Young adult follow-up of hyperactive children: Self-reported psychiatric disorders, comorbidity, and the role of childhood conduct problems and teen CD. Journal of Abnormal Child Psychology, 30(5), 463-475.

Fuchs, T., Birbaumer, N., Lutzenberger, W., Gruzelier, J.H., \& Kaiser, J. (2003). Neurofeedback treatment for attention-deficit / hyperactivity disorder in children: A comparison with methyphenidate. Applied Psychophysiology and Biofeedback, $28(1), 1-12$.

Gabel, S., Schmitz, S., \& Fulker, D.W. (1996). Comorbidity in hyperactive children: Issues related to selection bias, gender, severity, and internalizing symptoms. Child Psychiatry and Human Development, 27(1), 15-28.

Gaub, M., \& Carlson, C. L. (1997a). Behavioral characteristics of DSM-IV subtypes in a school-based population. Journal of Abnormal Child Psychology, 25(2), 103-111. 
Gaub, M., \& Carlson, C. L. (1997b). Gender differences in ADHD: A meta-analysis and critical review. Journal of the American Academy of Child and Adolescent Psychiatry, 36(8), 1036-1045.

Ge, X., Conger, R. D., Lorenz, F. O., Shanahan, M., \& Elder, G. H., Jr. (1995). Mutual influences in parent and adolescent psychological distress. Developmental Psychology, 31, 406-419.

Gershon, J. (2002). A meta-analytic review of gender differences in ADHD. Journal of Attention Disorders, 5(3), 143-154.

Goldstein (1987). Cognitive development in low attentive, hyperactive, and aggressive 6through 11-year-old children. Journal of the American Academy of Child and Adolescent Psychiatry, 26(2), 214-218.

Goldstein, S. (1996). Managing attention and learning disorders in late adolescence and adulthood. New York: Wiley.

Gomez, R., Harvey, J., Quick, C., Scharer, I., \& Harris, G. (1999). DSM-IV AD/HD: Confirmatory factor models, prevalence, and gender and age differences based on parent and teacher ratings of Australian primary school children. Journal of Child Psychology and Psychiatry and Allied Disciplines, 40(2), 263-274.

Goodman, R. \& Stevenson, J. (1989). A twin study of hyperactivity, II: The aetiological role of genes, family relationships, and prenatal adversity. Journal of Child Psychology and Psychiatry, 30, $691-709$.

Gjone, H., Stevenson, J., \& Sundet, J.M. (1996). Genetic influence on parent-reported attention-related problems in a norwegian general population twin sample. Journal of the American Academy of Child and Adolescent Psychiatry, 35(5), 588-596.

Greene, R. W., Biederman, J., Faraone, S. V., Monuteaux, M. C., Mick, E., DuPre, E. P., et al. (2001). Social impairment in girls with adhd: Patterns, gender comparisons, 
and correlates. Journal of the American Academy of Child and Adolescent Psychiatric, 40(6), 704-710.

Greene, R. W., Biederman, J., Faraone, S. V., Sienna, M., \& Garcia-Jetton, J. (1997). Adolescent outcome of boys with attention-deficit/hyperactivity disorder and social disability: Results from a 4-year longitudinal follow-up study. Journal of Consulting and Clinical Psychology, 65(5), 758-767.

Gresham F.M., MacMillan, D.L., Bocian, K.M., Ward, S.L., \& Forness, S.R. (1998). Comorbidity of hyperactivity-impulsivity-inattention and conduct problems: Risk factors in social, affective, and academic domains. Journal of Abnormal Child Psychology, 26(5), 393-406.

Gualtiere, T. \& Hicks, R. (1985). An immunoreactive theory of selective male affliction. Behaviroal and Brain Sciences, 8, 427-431.

Hart, E.L., Lahey, B.B., Loeber, R., Applegate, B., \& Frick, P.J. (1995). Developmental changes in attention-deficit hyperactivity disorder in boys: A four-year longitudinal study. Journal of Abnormal Child Psychology, 23, 729-750.

Hartung, C.M., Willcutt, E.G., Lahey, B.B., Pelham, W.E., Loney, J., Stein, M.A., \& Kennan, K. (2002). Sex differences in young children who meet criteria for attention deficit hy6peractivity disorder. Journal of Clinical Child \& Adolescent Psychology, 3l(4), 453-464.

Hazell, P. (1997). The overlap of attention deficit hyperactivity disorder with other common mental disorders. Journal of Paediatrics for Child Health, 33(2), 131137.

Heptinstahl \& Taylor (1996). Sex differences and their significance. In C. Sanberg Hyperactivity Disorders of Child hood (p. 329-345) Cambridge, England: Cambridge University Press.

Hinshaw, S. P. (2002). Preadolescent girls with attention-deficit/hyperactivity disorder: I. Background characteristics, comorbidity, cognitive and social functioning, and 
parenting practices. Journal of Consulting and Clinical Psychology, 70(5), 10861098.

Hinshaw, S. P., Carte, E. T., Sami, N., Treuting, J. J., \& Zupan, B. A. (2002).

Preadolescent girls with attention-deficit/hyperactivity disorder: II.

Neuropsychological performance in relation to subtypes and individual

classification. Journal of Consulting and Clinical Psychology, 70(5), 1099-1111.

Hinshaw, S.P. \& Melnick, S.M. (1995). Peer relationships in boys with attention deficit hyperactivity disorder with and without comorbid aggression. Developmental Psychopathology, 7, 627-647.

Hops, H., Sherman, L., \& Biglan, A. (1990). Maternal depression, marital discord, and children's

behavior: A developmental perspective. In G. R. Patterson (Ed.), Depression and aggression in family interaction (pp. 185-208). Hillsdale, NJ: Lawrence Erlbaum Associates.

Horn, W.F., Wagner, A.E., \& Ialongo, N. (1989). Sex differences in school-aged children with pervasive attention deficit hyperactivity disorder. Journal of Abnormal Child Psychology, 17(1), 109-123.

Hudziak, J. J., Heath, A. C., Madden, P. F., Reich, W., Bucholz, K. K., Slutske, W., et al. (1998). Latent class and factor analysis of DSM-IV ADHD: A twin study of female adolescents. Journal of the American Academy of Child and Adolescent Psychiatry, 37(8), 848-857.

Huselid, R. F., \& Cooper, M. L. (1994). Gender roles as mediators of sex differences in expressions of pathology. Journal of Abnormal Psychologyl, 103(4), 595-603.

James, A. \& Taylor, E. (1990). Sex differences in the hyperkinetic syndrome of childhood. Journal of Child Psychology and Psychiatry and Allied Disciplines, 31(3), $437-446$. 
Jensen, P. S. (2003). Comorbidity and child psychopathology: Recommendations for the next decade. Journal of Abnormal Child Psychology, 31(3), 293-300.

Jensen, P. S., Hinshaw, S. P., Kraemer, H. C., Lenora, N., Newcorn, J. H., Abikoff, H. B., et al. (2001). Adhd comorbidity findings from the MTA study: Comparing comorbid subgroups. Journal of the American Academy of Child and Adolescent Psychiatric, 40(2), 147-158.

Jensen, P. S., Martin, D., \& Cantwell, D. P. (1997). Comorbidity in adhd: Implications for research, practice, and DSM-V. Journal of the American Academy of Child and Adolescent Psychiatric, 36(8), 1065-1079.

Jensen, P.S., Shervette, R.E., Xenakis, S.N. \& Richters, J. (1993). Anxiety and depressive disorders in attention deficit disorder with hyperactivity: New findings. The American Journal of Psychiatry, 150, 1203-1209.

Kamphaus, R. W. \& Frick, P. J. (1996). Clinical assessment of child and adolescent personality and behavior. Boston: Allyn \& Bacon.

Kamphaus, R. W., Petoskey, M. D., \& Rowe, E. W. (2000). Current trends in psychological testing of children. Professional Psychology, 31(2), 155-164.

Kashani, J., Chapel, J. L., Ellis, J., \& Shekim, W. O. (1979). Hyperactive girls. Journal of Operational Psychiatry, 10(2), 145-148.

Kashani, J. H., Deuser, W., \& Reid, J. C. (1991). Aggression and anxiety: A new look at an old notion. Journal of the American Academy of Child and Adolescent Psychiatry, 30, 218-223.

Kato, P. M., Nichols, M. L., Kerivan, A. S., \& Huffman, L. C. (2001). Identifying characteristics of older and younger females with attention-deficit hyperactivity disorder. Developmental and Behavioral Pediatrics, 22(5), 306-315.

Katz, L. J., Goldstein, G., \& Geckle, M. (1998). Neuropsychological and personality differences between men and women with ADHD. Journal of Attention Disorders, 2(4), 239-247. 
Kazdin, A.E. (1995). Child, parent and family dysfunction as predictors of outcome in cognitive behavioral treatment of antisocial children. Behaviour, Research and Therapy, 33, 271-281.

Kazdin, A. E. \& Weisz, J. R. (1998). Identifying and developing empirically supported child and adolescent treatment. Journal of Consulting and Clinical Psychology, $66,19-36$.

Klein, R. G. \& Abikoff, H. (1997). Behavior therapy and methylphenidate in the treatment of children with ADHD. Journal of Attention Disorders, 2(2), 89-114.

Kollins, S. H., Barkley, R. A., \& DuPaul, G. J. (2001). Use and management of medications for children diagnosed with attention deficit hyperactivity disorder (ADHD). Focus on Exceptional Children, 33(5), 1-24.

Kovacs, M. \& Devlin, B. (1998). Internalizing disorders in childhood. Journal of Child Psychology and Psychiatry, 39(1), 47-63.

Kube, D. A., Petersen, M. C., \& Palmer, F. B. (2002). Attention deficit hyperactivity disorder: Comorbidity and medication use. Clinical Pediatrics, 4l(7), 461-469.

Kuhne, M., Schachar, R., \& Tannock, R. (1997). Impact of comorbid oppositional or conduct problems on attention-deficit hyperactivity disorder. Journal of the American Academy of Child and Adolescent Psychiatry, 36(12), 1715-1725.

Lahey, B.B., Applegate, B., McBurnett, K., Biederman, J., Greenhill, L., et al. (1994). DSM-IV field trials for attention deficit/hyperactivity disorder in children and adolescents. The American Journal of Psychiatry, 151, 1673-1685.

Latimer, W. W., Stone, A. L., Voight, A., Winters, K. C., \& August, G. J. (2002). Gender differences in psychiatric comorbidity among adolescents with substance use disorders. Experimental and Clinical Psychopharmacology, 10(3), 310-315.

Leadbeater, B. J., Kupermine, G. P., Blatt, S. J., \& Hertzog, C. (1999). A Multivariate Model of Gender Differences in Adolescents' Internalizing and Externalizing Problems. Developmental Psychology, 35(5), 1268-1282. 
Lewinsohn, P.M., Hops, H., Roberts, R.E., Seely, J.R., \& Andrews, J.A. (1993).

Adolescent psychopharmacology: I. Prevalence and incidence of depression and other DSM-III-R disorders in high school students. Journal of Abnormal Psychology, 102(1), 133-144.

Livingston, R.L., Dykman, R. A., Ackerman, P. T. (1990). The frequency and significance of additional self-reported psychiatric diagnoses in children with attention deficit disorder. Journal of Abnormal Child Psychology, 18, 465-476.

Loeber \& Keenan (1994). Interaction between conduct disorder and its comorbid conditions: Effects of age and gender. Clinical Psychology Review, 14(6), 497523.

Lopez, R.E. (1965). Hyperactivity in twins. Canadian Psychiatric Association Journal, $10,421-426$.

Lumley, V. A., McNeil, C. B., Herschell, A. D., \& Bahl, A. B. (2002). An examination of gender differences among young children with disruptive behavior disorders. Child Study Journal, 32(2), 89-100.

MacDonald, V. M. \& Achenbach, T. M. (1999). Attention problems vs. conduct problems as 6-year predictors of signs of disturbance in a national sample. Journal of the American Academy of Child and Adolescent Psychiatry, 38(10), 1254-1261.

Mannuzza, S., Klein, R. G., Bessler, A., Malloy, P., \& Lapadula, M. (1993). Adult outcome of hyperactive boys: Educational achievement, occupational rank, and psychiatric status. Archives of General Psychiatry, 50, 565-576.

Mannuzza, S., Klein, R. G., Bessler, A., Malloy, P., \& Lapadula, M. (1998). Adult psychiatric status of hyperactive boys grown up. American Journal of Psychiatry, $155,493-498$.

Mannuzza, S., \& Gittelman, R. (1984). The adolescent outcome of hyperactive girls. Psychiatry Research, 13, 19-29. 
March, J.S., Swanson, J.M., Arnold, L.E., Hoza, B., Conners, C.K., Hinshaw, S.P., Hechtman, L., Kraemer, H.C., Greenhill, L.L., Abikoff, H.B., Elliottt, L.G., Jensen, P.S., Newcorn, J.H., Vitielo, B., Severe, j., Wells, K.C., \& Pelham, W.E. (2000). Anxiety as a predictor and outcome variable in the multimodal treatment study of children with ADHD (MTA). Journal of Abnormal Child Psychology, $28(6), 527-541$.

Markowitz, J. S., Straughn, A. B., \& Patrick, K. S. (2003). Advances in the pharmacotherapy of attention-deficit-hyperactivity disorder: Focus on methylphenidate formulations. Pharmacotherapy, 23(10), 1281-1299.

McCarney, S.B. (1989a). The Attention Deficit Disorders Evaluation Scale, Home Version, Technical Manual. Columbia, MO: Hawthorne Educational Service. McCarney, S.B. (1989b). The Attention Deficit Disorders Evaluation Scale, School Version, Technical Manual. Columbia, MO: Hawthorne Educational Service. McCarney, S.B. (1995a). The Attention Deficit Disorders Evaluation Scale, Home Version, Technical Manual, 2nd ed. Columbia, MO: Hawthorne Educational Service.

McCarney, S.B. (1995b). The Attention Deficit Disorders Evaluation Scale, School Version, Technical Manual, 2nd ed. Columbia, MO: Hawthorne Educational Service.

McInnes, A., Humphries, T., Hogg-Johnson, S., \& Tannock, R. (2003). Listening comprehension and working memory are impaired in attention-deficit hyperactivity disorder irrespective of language impairment. Journal of Abnormal Child Psychology, 31, $427-445$.

McDermott, P.A. (1996). A nationwide study of developmental and gender prevalence for psychopathology in childhood and adolescence. Journal of Abnormal Child Psychology, 24(1), 53-67. 
McGee, R., \& Feehan, M. (1991). Are girls with problems of attention underrrecognized? Journal of psychopathology and behavioral assessment, 13(3), 187-198.

McGee, R., Williams, S., \& Feehan, M. (1992). Attention deficit disorder and age of onset of problem behaviors. Journal of Abnormal Child Psychology, 20(5), 487 502.

McGee, R., Williams, S., \& Silva, P.A. (1987). Comparison of girls and boys with teacher-identified problems of attention. Journal of the American Academy of Child and Adolescent Psychiatry, 28(5), 773-776.

Melnick, S. M., \& Hinshaw, S. P. (2000). Emotion regulation and parenting in ad/hd and comparison boys: Linkages with social behaviors and peer preference. Journal of Abnormal Child Psychology, 28(1), 73-86.

Mikami, A. Y., \& Hinshaw, S. P. (2003). Buffers of peer rejection among girls with and without ADHD: The role of popularity with adults and goal-directed solitary play. Journal of Abnormal Child Psychology, 31(4), 381-397.

Milberger, S., Biederman, J., Faraone, S.V., Murphy, J., \& Tsuang, M.T. (1995). Attention deficit hyperactivity disorder and comorbid disorders: Issues of overlapping symptoms. American Journal of Psychiatry, 152, 1793-1799.

Milich, R., Lynam, D., \& Balentine, A. C. (2001). ADHD combined type and ADHD predominantly inattentive type are distinct and unrelated disorders. Clinical Psychology: Science and Practice, 8(4), 463-488.

Molina, B. S. \& Pelham, W. E. (2003). Childhood predictors of adolescent substance use in a longitudinal study of children with ADHD. Journal of Abnormal Psychology, 112(3), 497-507.

Monastra, V.J., Lubar, J.F., \& Linden, M. (2001). The development of a quantitative electroencephalographic scanning process for attention deficit-hyperactivity disorder: Reliability and validity studies. Neuropsychology, 15(1), 136- 144. 
Morgan, A.E., Hynd, G.W., Riccio, C.A., \& Hall, J. (1996). Validity of DSM-IV ADHD predominantly inattentive and combined types: Relationship to previous DSM diagnoses/subtype differences. Journal of the American Academy of Child and Adolescent Psychiatry, 35(3), 325-333.

Morrison, J. \& Stewart, M. (1973). The psychiatric status of the legal families of adopted hyperactive children. Archives of General Psychiatry, 28, 888-891.

The MTA Cooperative Group. (1999). Moderators and mediators of treatment response for children with attention-deficit/hyperactivity disorder: The multimodal treatment study of children with attention-deficit/hyperactivity disorder. Archives of General Psychiatry, 56(12), 1088-1096.

Nadeau, Littman, \& Quinn (1999). Understanding Girls with ADHD. Silver Spring MD: Advantage Books.

Nadeau, K.G. \& Quinn (2001). Gender differences in the diagnosis of ADHD. ADDvance, 5, 17-21.

National Institutes of Health (2000). National Institutes of Health consensus development conference statement: Diagnosis and treatment of attention-deficit/hyperactivity disorder (ADHD). Journal of the American Academy of Child and Adolescent Psychiatry, 39(2), 182-193.

Neuman, R.J., Todd, R.D., Heath, A.C., Reich, W., Hudziak, J.J., Bucholz, K.K., Madden, P.A., Begleiter, H., Porjesz, B. Kuperman, S., Hesselbrock, V. \& Reich, T. (1999). Evaluation of ADHD typology in three contrasting samples: A latent class approach. Journal of the American Academy of Child and Adolescent Psychiatry, 38(1), 25-33.

Newcorn, J. H., Halperin, J. M., Jensen, P. S., Abikoff, H. B., Arnold, L. E., Cantwell, D. P., et al. (2001). Symptom profiles in children with adhd: Effects of comorbidity and gender. Journal of the American Academy of Child and Adolescent Psychiatric, 40(2), 137-146. 
Nolan, E., Volpe, R. J., Gadow, K. D., \& Sprafkin, J. (1999). Developmental, gender, and comorbidity difference in clinically referred children with adhd. Journal of Emotional and Behavioral Disorders, 7(1), 11-25.

Nolen-Hoeksema, S. \& Girgus, J.S. (1994). The emergence of gender differences in depression during adolescence. Psychological Bulletin, 115(3), 424-443.

Olfson, M., Gameroff, M. J., Marcus, S. C., Jensen, P. S. (2003). National trends in the treatment of attention deficit hyperactivity disorder. American Journal of Psychiatry, 160(6), 1071-1077.

Ostrander, R., Weinfurt, K. P., Yarnold, P. R., \& August, G. J. (1998). Diagnosing attention deficit disorders with the behavioral assessment system for children and the child behavior checklist: Test and construct validity analyses using optimal discriminant classification trees. Journal of Consulting and Clinical Psychology, $66(4), 660-672$.

Pauls, D.L. (1991). Genetic factors in the expression of attention-deficit/hyperactivity disorder. Journal of Child \& Adolescent Psychopharmacology, 1(5), 353-360.

Pelham, W. E., Walker, J. L., Sturges, J., \& Hoza, J. (1989). Comparative effects of methylphenidate on ADD girls and ADD boys. Journal of the American Academy of Child and Adolescent Psychiatry, 28(5), 773-776.

Perrin, S. \& Last, C. G. (1996). Relationship between ADHD and anxiety in boys: Results from a family study. Journal of the American Academy of Child and Adolescent Psychiatry, 35(8), 988-996.

Petersen, A.C., Sarigiani, P.A., and Kennedy, R.E. (1991). Adolescent depression: Why more girls? Journal of Youth and Adolescence, 20(2), 247-271.

Pillow, D. R., Pelham, W. E., Hoza, B., Molina, B.S., \& Stultz, C.H. (1998). Confirmatory factor analyses examining attention deficit hyperactivity disorder symptoms and other childhood disruptive behaviors. Journal of Abnormal Child Psychology, 26(4), 293-309. 
Pineda, D., Ardila, A., \& Roselli, M. (1999). Neuropsychological and behavioral assessment of adhd in seven- to twelve-year-old children: A discriminant analysis. Journal of Learning Disabilities, 32(2), 159-175.

Pinn, V. W. (2003). Sex and gender factors in medical studies: Implications for health and clinical practice. The Journal of the American Medical Association, 289(4), $397-400$.

Pliszka, S.R. (1992). Comorbidity of attention-deficit hyperactivity disorder and overanxious disorder. Journal of the American Academy of Child and Adolescent Psychiatry, 31(2), 197-203.

Reeves, J. C., Werry, J. S., Elkind, G. S., \& Zametkin, (1987).Attention deficit, conduct, oppositional, and anxiety disorders in children: II. Clinical characteristics. Journal of the American Academy of Child and Adolescent Psychiatry, 26(2), 144-155.

Reid, R., Riccio, C. A., Kessler, R. H., DuPaul, G. J., Power, T. J., Anastopoulos, A. D., et al. (2000). Gender and ethnic differences in adhd as assessed by behavior ratings. Journal of Emotional and Behavioral Disorders, 8(1), 38-48.

Rhee, S.H., Waldman, I.D., Hay, D.A., \& Levy, F. (1999). Sex difference in genetic and environmental influences on DSM-III-R attention-deficit/hyperactivity disorder. Journal of Abnormal Psychology, 108(1), 24-41.

Rey, J.M., Walter, G., Plapp, J.M., \& Denshire, E. (2000). Family environment in attention deficit hyperactivity, oppositional defiant and conduct disorders. Australian and New Zealand Journal of Psychiatry, 34, 453-457.

Reynolds, C. R. \& Kamphaus, R. W. (1992). Behavior Assessment System for Children, Circle Pines, NM: American Guidance Services.

Robison, L. M., Skaer, T. L., Sclar, D. A., \& Galin, R. S. (2002). Is attention deficit hyperactivity disorder increasing among girls in the US?: Trends in Diagnosis and the prescribing of stimulants. CNS Drugs, 16(2), 129-137. 
Root, R. W., II, \& Resnick, R. J. (2003). An update on the diagnosis and treatment of attention-deficit/hyperactivity disorder in children. Professional Psychology: Research and Practice, 34(1), 34-41.

Rucklidge, J. J., \& Tannock, R. (2001). Psychiatric, psychosocial, and cognitive functioning of female adolescents with adhd. Journal of the American Academy of Child and Adolescent Psychiatry, 40(5), 530-540.

Russo, M. F., \& Beidel, D. C. (1994). Comorbidity of childhood anxiety and externalizing disorders: Prevalence, associated characteristics, and validation issues. Clinical Psychology Review, 14, 199-221.

Scahill, L., \& Schwab-Stone, M. (2000). Epidemiology of ADHD in school-age children. Child and Adolescent Psychiatric Clinics of North America, 9(3), 541-555.

Scahill, L., Schwab-Stone, M., Merikangas, K. R., Leckman, J. F., Zhang, H., \& Kasl, S. (1999). Psychosocial and clinical correlates of adhd in a community sample of school-age children. Journal of the American Academy of Child and Adolescent Psychiatric, 38(8), 976-984.

Scaramella, L. V., Conger, R. D., \& Simons, R. L. (1999). Parental protective influences and gender-specific increases in adolescent internalizing and externalizing problems. Journal of Research on Adolescence, 9(2), 111-141.

Schachar, Sandberg, \& Rutter (1986). Agreement between teachers ratings. Journal of Abnormal Child Psychology, 14, 331-345.

Seidman, L. J., Biederman, J., Faraone, S. V., Weber, W., Mennen, D., \& Jones, J. (1997). A pilot study of neuropsychological function in girls with ADHD. Journal of the American Academy of Child and Adolescent Psychiatry, 36(3), 366-373.

Sharp, W. S., Walter, J. M., Marsh, W. L., Ritchie, G. F., Hamburger, S. D., \& Castellanos, F. X. (1999). ADHD in girls: Clinical comparability of a research sample. Journal of the American Academy of Child and Adolescent Psychiatry, $38(1), 40-47$. 
Shaywitz, S. E., \& Shaywitz, B. A. (1991). Introduction to the special series on attention deficit disorder. Journal of Learning Disabilities, 24(2), 68-72.

Sherman, D.K., McGue, M.K., \& Iacono, W.G. (1997). Twin Concordance for attention deficit hyperactivity disorder: A comparison of teachers' and mothers' reports. American Journal of Psychiatry, 154 (4), 532 - 535.

Sherman, D.K., Iacono, W.G., \& McGue, M.K. (1997). Attention-deficit hyperactivity disorder dimensions: A twin study of inattention and impulsivity-hyperactivity. Journal of the American Academy of Child and Adolescent Psychiatry, 36(6), 745-753.

Silverthorn, P., Frick, P.J., Kuper, K., \& Ott, J. (1996). Attention deficit hyperactivity disorder and sex: A test of two etiological models to explain the male predominance. Journal of Clinical Child Psychology, 25(1), 52-59.

Solden, S. (1995). Women with attention deficit disorder. Grass Valley, CA: Underwood Books.

Stevens, J., Quittner, A. L., \& Abikoff, H. (1998). Factors influencing elementary school teachers' ratings of ADHD and ODD behaviors. Journal of Clinical Child Psychology, 27(4), 406-414.

Surgeon General's Report (2001). Report of the surgeon general's conference on children's mental health.: An action agenda. Department of Health and Human Services.

Swenson, A. R., Birnbaum, H. G., Secnik, K., Marynchenko, M., Greenberg, P., \& Claxton, A. (2003). Attention-deficit/hyperactivity disorder: Increased costs for patients and their families. Journal of the American Academy of Child and Adolescent Psychiatry, 42(12), 1415-1423.

Szatmari, P. (1992). The epidemiology of attention-deficit hyperactivity disorder. Child and Adolescent Psychiatric Clinics of North America, 1, 361-371.

Szatmari, P., Boyle, M., \& Offord, D.R. (1989). ADDH and CD: Degree of diagnostic 
overlap and differences among correlates. Journal of the American Academy of Child and Adolescent Psychiatry, 28(6), 865-872.

Szatmari, P., Offord, D.R., \& Boyle, M. (1989). Correlates, associated impairments, and patterns of service utilization of children with attention deficit disorder: Findings from the Ontario Child Health Study., Journal of Child Psychology and Psychiatry, 30, 205-217.

Taylor, E. W. \& Keltner, N. L. (2002). Messy purse girls: Adult females and adhd. Perspectives in Psychiatric Care, 38(2), 69-72.

Taylor, E., Heptinstall, E., Sonuga-Barke, E.J., Sandberg, S. (1998). Sex differences in the prevalence of hyperactivity. Presented at Royal College of Psychiatrists, Annual Scientific Meeting, London, January.

Treuting, J. J., \& Hinshaw, S. P. (2001). Depression and self-esteem in boys with attention-deficit/hyperactivity disorder: Associations with comorbid aggression and explanatory attributional mechanisms. Journal of Abnormal Child Psychology, 29(1), 23-39.

Vance, A. L. \& Luk, E. S. (1998). Attention deficit hyperactivity disorder and anxiety: Is there an association with neurodevelopmental deficits? Australian and New Zealand Journal of Psychology, 32, 650-657.

Waschbusch, D. A. (2002). A meta-analytic examination of comorbid hyperactiveimpulsive-attention problems and conduct problems. Psychological Bulletin, $128(1), 118-150$.

Weiss, M. \& Murray, C. (2003). Assessment and management of attention-deficit hyperactivity disorder in adults. Canadian Medical Association Journal, 168, 715-722.

Weiss, M., Worling, D., \& Wasdell, M. (2003). A chart review study of the inattentive and combined types of AD/HD. Journal of Attention disorders, 7(1), 1-9. 
Werry, J. S., Elkind, G.S., \& Reeves, J.C. (1987). Attention deficit, conduct, oppositional, and anxiety disorders in children: III. Laboratory differences. Journal of Abnormal Child Psychology, 15(3), 409-428.

Wolraich, M.L. (2003). The use of psychotropic medications in children: An American view. Journal of Child Psychology and Psychiatry, 44(2), 159-168.

Wolraich, M. L., Lambert, E. W., Baumgaertel, A., Garcia-Tornel, S., Feurer, I. D., Bickman, L., et al. (2003). Teachers' screening for attention deficit/hyperactivity disorder: Comparing multinational samples on teacher ratings of ADHD. Journal of Abnormal Child Psychology, 31(4), 445-455.

Woodward, L., Taylor, E., \& Dowdney, L. (1997). Child and family factors influencing the clinical referral of children with hyperactivity: A research note. Journal of Child Psychology and Psychiatry, 39, 161-169.

Zahn-Waxler, C. (1993). Warriors and Worriers, Gender and psychopathology. Development and Psychopathology, 5, 79-90. 


\section{APPENDIX A}

From: Leitsch, Patricia (Norma I King)

To: annalp@insightbb.com; Kirby, Kathleen M

Date: $\quad 5 / 13 / 20051: 22: 41 \mathrm{PM}$

Subject: $\quad$ IRB STudy \#279.05 - Gender Manifestations of

Attention-Deficit/Hyperactivity Disorder

\section{University of Louisville}

Institutional Review Board

MedCenter One, STE 200

501 E Broadway

Louisville, KY 40202-1798

Kathleen M. Kirby, PhD

(Anna L. Peterson)

\section{RE: 279.05 - Gender Manifestations of Attention-Deficit/Hyperactivity Disorder}

\section{Dear Doctor Kirby:}

\section{EXEMPT}

The above study has been received by the Human Subjects Protection Program Office. It has been determined by the chair of the Institutional Review Board that the study is exempt according to 45 CFR 46.101(b) 2 since this is research involving the collection or study of existing data, documents, records, pathological specimens, or diagnostic specimens, if these sources are publicly available or if the information is recorded by the investigator in such a manner that subjects cannot be identified, directly or through identifiers linked to the subjects. The study is exempt only if information that could identify subjects is not recorded.

This study was also approved through 45 CFR 46.116 (D), which means that it has been granted a waiver of informed consent because it meets the following criteria:

$\S \quad$ The research involves no more than minimal risk to the subjects.

$\S \quad$ The waiver or alteration will not adversely affect the rights and welfare of the subjects.

$\S \quad$ The research could not practicably be carried out without the waiver or alteration. $\S \quad$ Whenever appropriate, the subjects will be provided with the additional pertinent information after participation. 
The purpose of this study is to examine gender differences in $\mathrm{AD} / \mathrm{HD}$ and determine the relationship between the diagnosis of $\mathrm{AD} / \mathrm{HD}$ and rates of comorbid internalizing and externalizing behaviors in males and females with and without AD/HD.

Since this study has been found to be exempt, no additional reporting, such as submission of Progress Reports for continuation reviews, is needed. Best wishes for a successful study. Please send all inquires and electronic revised/requested items to our office email address at hsppofc@louisville.edu.

Sincerely,

Patricia K. Leitsch, Ph.D., Chair,

Behavioral/Social/Educational Institutional Review Board

Correspondence prepared by:

Norma I. King

Program Assistant Senior

UofL Human Subjects Protection Program

MedCenter One, Suite 200

501 East Broadway

(502) $852-5188$ 


\section{Anna L. Peterson}

11902 Berry Hill Rd.

Louisville, KY 40243

annalp@insightbb.com

\section{EDUCATION}

Ph. D. Candidate, Educational and Counseling Psychology

University of Louisville

December 2005

G.P.A. 3.98

Licensed Professional Clinical Counselor

November 2001

M. Ed., Educational and Counseling Psychology

University of Louisville

December 1992

G.P.A. 4.0

B.A., Psychology

University of Louisville

December 1990

\section{OTHER EDUCATIONAL EXPERIENCES}

Child-Parent-Relationship (C-P-R) Training: A Ten Session Filial Therapy Model Sue Bratton, Kentucky Association for Play Therapy, Louisville, KY

March 2005

Working With Latinas/os from Culture-Specific Perspectives

Patricia Arredondo, Kentucky Psychological Association Training, Louisville, KY November 2004 
ADHD in Children and Adolescents: Nature, Diagnosis, and Management Russell A. Barkley, Learning Disabilities Association of Kentucky, Inc., Louisville, KY August 2004

Psychoanalytic Therapy

Paul Adams, Psychoanalytic Institute, Louisville KY

October 2000

Pain Management

Jim Thompson, The Pain Institute, Louisville KY

October 2001

Psychopharmacology, 11 hours

Solutions Training, Nashville IN

September 1998

AIDS/HIV, 2 hours

Bellewood Children's Home, Louisville KY

January 1998

Clinical Hypnosis, 32 hours

Erikson Foundation, Phoenix AZ

December 1997

Solution-Focused Therapy, 12 hours

Solutions Training, Nashville IN

October 1997

Gang Awareness, 2 hours

Rick Flaherty, Bellewood Children's Home, Louisville KY

June 1997

Art As Therapy, 2 hours

Brenda Wallover, Bellewood Children's Home, Louisville KY

May 1997

Brief Therapy and Chemical Dependency, 6 hours

Terence Gorski, Solutions Training, Nashville IN

April 1997

Therapeutic Conversation As Collaborative Inquiry, 12 hours Michael White, Family and Children's Agency, Louisville KY July 1994 
Family Therapy Training/Supervision, 62 hours

Family and Children's Agency, Louisville KY

February 1993 - April 1993

Safe Physical Management

Bellewood Children's Home, Louisville KY

$1991-1998$

\section{PROFESSIONAL EXPERIENCE}

Doctoral Intern, June 2004 - present

Seven Counties Services, Inc., Specialized Child and Family Services, Louisville, KY Family Connections, Transitions, and Western Day Treatment

- Provided outpatient individual, family, and group therapeutic services for children and adolescents with severe emotional disabilities and their families in a community mental health setting

- Provided outpatient individual, couple, family, and group therapy services to victims and perpetrators of spouse abuse, sexual abuse, and child abuse and their families in a community mental health setting

- Provided intensive individual, family, and group therapy services to children with severe emotional disabilities and their families in a school setting

- Completed comprehensive psychological evaluations for children, adolescents, and adults to assess intellectual, academic, emotional, adaptive, and behavioral functioning

Practicum Student/Field Placement, January 2002 - February 2003

Learning Improvement Center, University of Louisville, Louisville KY

- Completed comprehensive psychoeducational batteries for adults and children to assess intellectual, academic, emotional, adaptive, and behavioral functioning

Practicum Student, August 2001 - May 2002

Archdiocese of Louisville, Louisville KY

- Provided counseling and assessment services for elementary school children and their families in a school setting

- Provided outpatient therapy services for children, adolescents, adults, and families

Clinical Supervisor/Therapist, October 1992 - January 1999

Bellewood Children's Home, Anchorage KY

- Provided intensive counseling services for individuals, couples, families, and groups on an inpatient and outpatient basis

- Supervised the daily operation of a family reunification program for adolescents and families 
Practicum Student, January 1992 - December 1992

Seven Counties' Center for Consulting Services East, Louisville KY

- Enhanced therapy skills and professional knowledge through employment at a community mental health center which provided counseling services to children, adults, and families

Program Counselor, October 1991 - October 1992

Bellewood Children's Home, Anchorage KY

- Provided supervision and case management for emotionally and behaviorally disturbed adolescents in a residential treatment center

\section{PROFESSIONAL ORGANIZATIONS}

Doctoral Student Organization, Treasurer

American Psychological Association

American Counseling Association

Kentucky Counseling Association

\section{HONORS AND AWARDS}

Certificate of Merit Award for Outstanding Achievement in Psychology

Psi Chi Psychology Honor Society

Dean's List

\section{RESEARCH EXPERIENCE}

Independent Research

University of Louisville

Fall 1999 - present

- Reviewed, analyzed, and synthesized literature in the areas of attentiondeficit/hyperactivity disorder, eating disorders, multisystemic therapy, conduct disorder, and chemical dependency

Research Seminar Participant

University of Louisville

August 1999 - May 2001

- Reviewed literature, formulated research hypotheses, and developed research design for a study focusing on the relationship between suggestibility and the placebo effect as it relates to the treatment of depression

Research Assistant

University of Louisville

September 1989 - May 1990 
- Conducted experimental trials and collected data for a study in the area of vision and perception

\section{PRESENTATIONS}

Body Image and the Prevention of Eating Disorders

University of Louisville

Spring 2002

Multisystemic Therapy: A Viable Alternative to Incarcerating Troubled Youth University of Louisville

Spring 2001

Eating Disorders: Prevention and Treatment

University of Louisville

Spring 1999

A Predictive Model of Placebo Response

Ohio Valley Education Research Partnership

May 2000

Effective Therapeutic Intervention with Troubled Youth

Bellewood Children's Home

November 1992 - September 1997

Anger Management

Bellewood Children's Home

September 1994 - April 1997

Parent Training Workshop

Bellewood Children's Home

September 1995 - May 1996

Drug/Alcohol Prevention and Treatment

Bellewood Children's Home

September 1994 - April 1997 